\title{
WestVirginiaUniversity
}

THE RESEARCH REPOSITORY @ WVU

Graduate Theses, Dissertations, and Problem Reports

2016

\section{The impact of rural contexts on citizenship education}

\author{
Eric D. Moffa
}

Follow this and additional works at: https://researchrepository.wvu.edu/etd

\section{Recommended Citation}

Moffa, Eric D., "The impact of rural contexts on citizenship education" (2016). Graduate Theses,

Dissertations, and Problem Reports. 6240.

https://researchrepository.wvu.edu/etd/6240

This Dissertation is protected by copyright and/or related rights. It has been brought to you by the The Research Repository @ WVU with permission from the rights-holder(s). You are free to use this Dissertation in any way that is permitted by the copyright and related rights legislation that applies to your use. For other uses you must obtain permission from the rights-holder(s) directly, unless additional rights are indicated by a Creative Commons license in the record and/ or on the work itself. This Dissertation has been accepted for inclusion in WVU Graduate Theses, Dissertations, and Problem Reports collection by an authorized administrator of The Research Repository @ WVU.

For more information, please contact researchrepository@mail.wvu.edu. 


\title{
THE IMPACT OF RURAL CONTEXTS ON CITIZENSHIP EDUCATION
}

\author{
Eric D. Moffa \\ Dissertation submitted to the \\ College of Education and Human Services at West Virginia University \\ in partial fulfillment of the requirements for the degree of \\ Doctor of Education \\ in \\ Curriculum and Instruction
}
Robert A. Waterson, Ph.D., Chair
Mary E. Haas, Ed.D.
Sam F. Stack Jr., Ph.D.
Erin C. McHenry-Sorber, Ph.D.
G. H. Budd Sapp, Ed.D.

Department of Curriculum and Instruction/Literacy Studies

\author{
Morgantown, West Virginia \\ 2016
}

Keywords: citizenship education, civics, social studies, rural education, teacher perceptions, gatekeeping, social contexts, place-based learning

Copyright 2016 Eric Moffa 


\section{ABSTRACT \\ The Impact of Rural Contexts on Citizenship Education}

Eric D. Moffa

Social studies teachers are sensitive to local school and community values and, therefore, tactful when making decisions about their curriculum (Romanowski, 1996; Shaver, Davis, \& Helburn, 1980; Thornton, 1989), including its citizenship aims (Saada, 2013; Sondel, 2015; Vinson, 1998). For this reason, scholars call for better contextual understandings of teachers' curricularinstructional gatekeeping (Thornton, 1989; Vinson, 1998). Rural-specific examples of this phenomenon remain largely unexamined (Martin \& Chiodo, 2007; Pattison-Meek, 2012), though rural schools make up 32.9\% of all schools in the United States (Johnson, Showalter, Klein, \& Lester, 2014) and rural communities offer distinct socio-geographic and socio-cultural contexts (Brown \& Schafft, 2011). To address this research deficit, the current study sampled five government teachers in rural schools to examine their conceptualizations of citizenship education, perceptions of place, and the influences that affect their curricular-instructional gatekeeping. This study adopted a social constructionist perspective to explore the values and meanings participants placed on citizenship within their rural contexts. It utilized a grounded theory research design to sample government teachers from four "distant-rural" schools and collect data from three sources: interviews, classroom observations, and teaching artifacts. A constant comparison method of data analysis produced a theory to describe citizenship education in rural contexts. The theory consists of three themes that emerged from the data: (1) citizenship education as practical knowledge; (2) place-based learning for future (dis)placements; and (3) the gatekeeping triad. Descriptions of these themes and their relationships with one another illuminate the practices of citizenship education in rural areas and provide knowledge of the rural conditions that influence it. Findings suggest government teachers in rural areas need to become more critical of their treatment of place and citizenship to encourage place-conscious civic life. 


\title{
IN DEDICATION
}

\author{
To my wife Hope
}

You are a constant source of love, support, and inspiration. Without you, this dissertation would not have been possible. You encouraged me to pursue my doctorate. You supported me while I completed this research. No one knows my journey more intimately. You celebrated the highs with me and alleviated the lows. Most importantly, you believe in me like no one ever has before and it makes me a better man. Thank you. I love you.

\section{To my daughter Rosaline}

This journey started before you were born, but you showed up in time to help daddy finish. In the last month of writing, I cradled you in my arms while I typed. I hope this dissertation inspires you to discover the joys of learning and to pursue your dreams. I want you to live life passionately, learn deeply, love endlessly, and work to improve our world.

Daddy loves you. 


\section{ACKNOWLEDGEMENTS}

Thank you Dr. Robert Waterson for your advice and scholarly insights throughout my doctoral journey. From my first day on campus, you took serious my desires to become a scholar and offered me candid conversations about higher education and the research process. You were always selfless with your time. Thank you for involving me with the many programs and projects of the Center for Democracy and Citizenship Education. Also, I am thankful for the gracious hospitality Luann and you showed me at your home. I appreciate our long phone conversations where you offered your support and guidance. You are an excellent teacher, mentor, and friend... and a pretty darn good driver in snow storms!

Thank you to the other members who serve on my dissertation committee: Dr. Mary Haas, Dr. Sam Stack, Dr. Erin McHenry-Sorber, and Dr. Budd Sapp. I appreciate our conversations and your helpful comments on my research project. I truly value your expertise and patience. You are each wonderful teachers and scholars whom act as role models for me.

I'd like to thank the other faculty members in the College of Education and Human Services whom I've had as instructors. They have each enhanced my development as a scholar. Also, thank you to my C\&I classmates who offered words of support and encouragement throughout our time together. I wish you all the best of luck in completing your degrees and excelling in your careers.

Last but not least, I'd like to thank my family and friends. My mom and dad are the original source of my development as a scholar. They provided me with a safe, loving environment and nurtured my interests to read and to learn. More importantly, they taught me the power of love and laughter. Along with the rest of my family and friends, their support and prayers helped me to persevere. I am forever grateful. 


\section{TABLE OF CONTENTS}

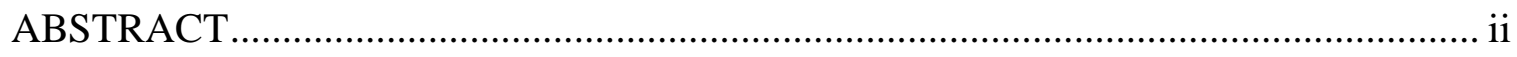

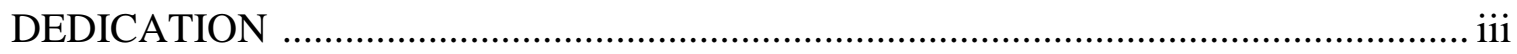

ACKNOWLEGEMENTS ...................................................................................... iv

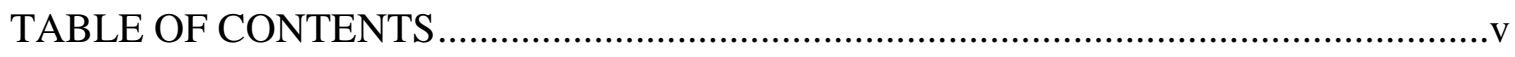

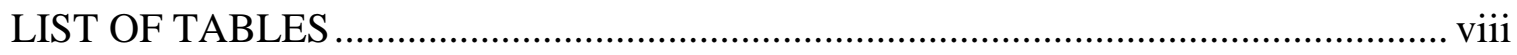

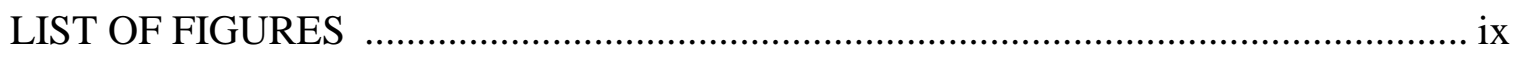

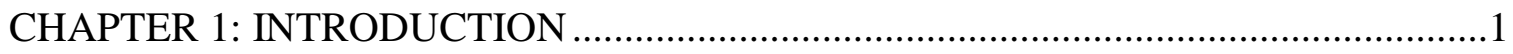

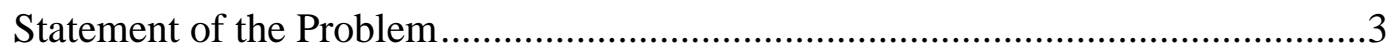

Statement of Purpose and Research Questions ...................................................

Study Rationale and Significance .....................................................................

Overview of Methodology ......................................................................10

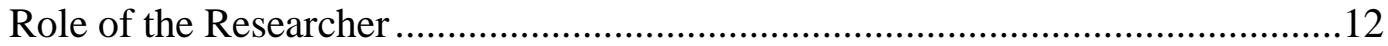

Researcher Positionality ..................................................................................13

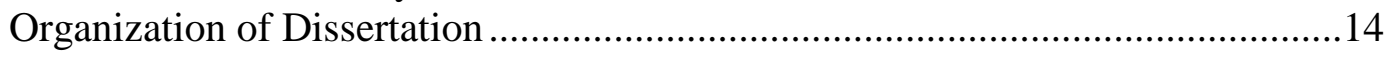

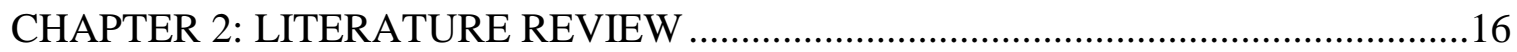

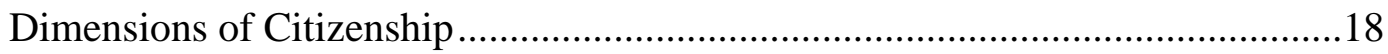

Theories of Citizenship Education ........................................................................22

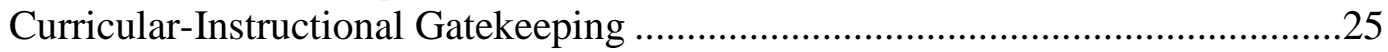

Teachers' Conceptualizations of Citizenship Education .......................................28

The Importance of Contexts............................................................................... 33

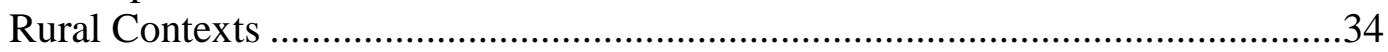

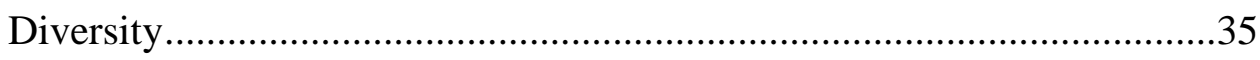

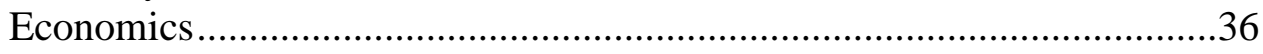

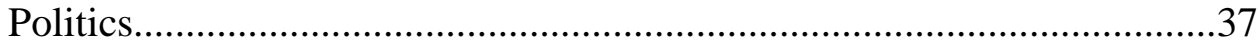

Social and Cultural Values........................................................................39

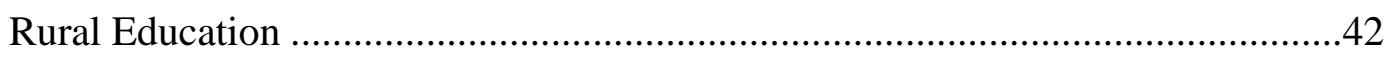

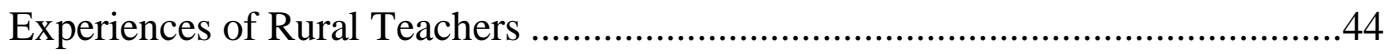

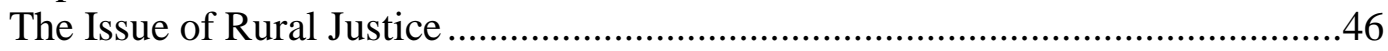

Citizenship Education in Rural Contexts ...........................................................47

Rationale for a Qualitative Study ....................................................................51

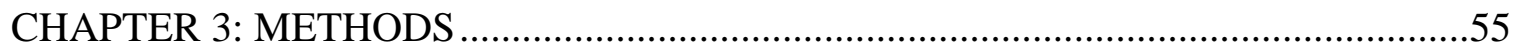

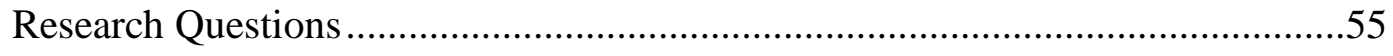




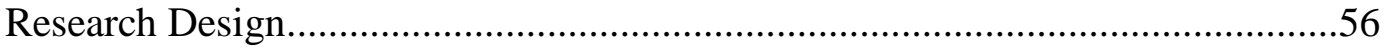

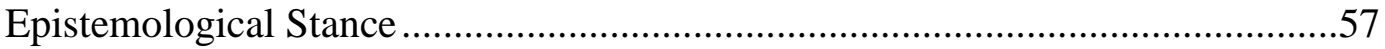

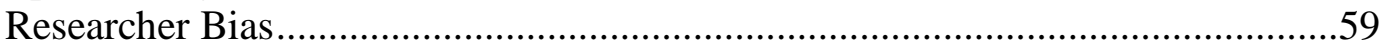

Participants and Sampling Procedures...............................................................61

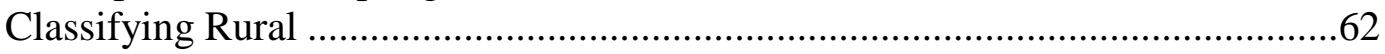

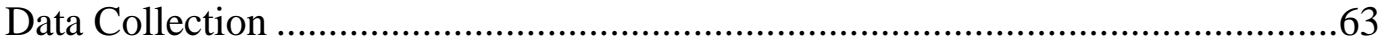

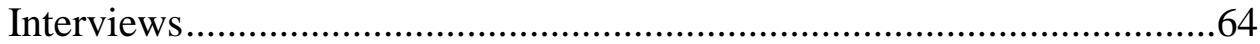

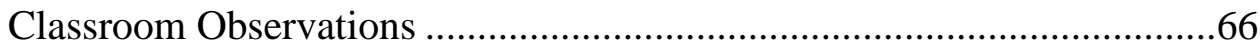

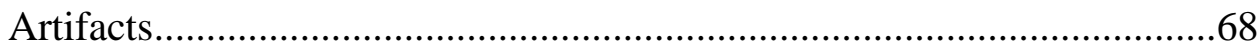

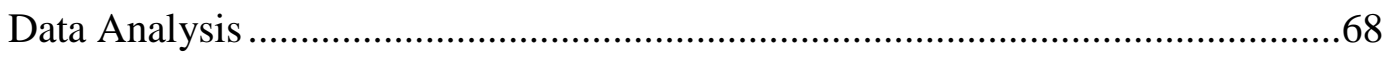

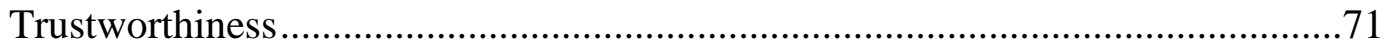

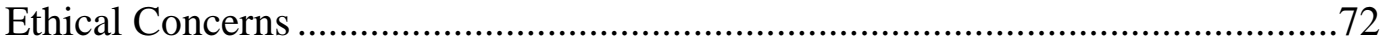

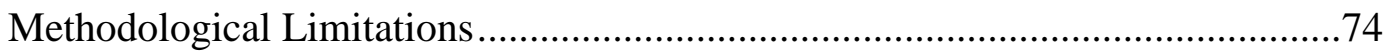

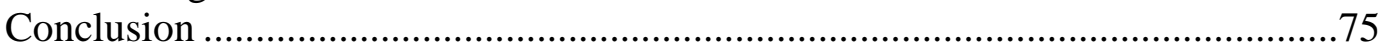

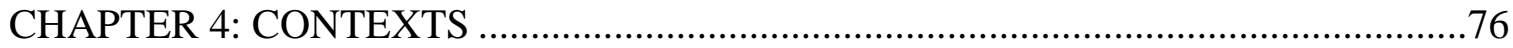

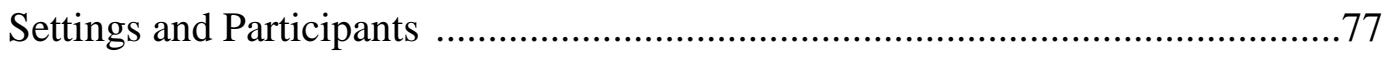

Smallwood High School .........................................................................79

Mr. Howard and Ms. Finch..........................................................8 80

Stuart County High School ................................................................8

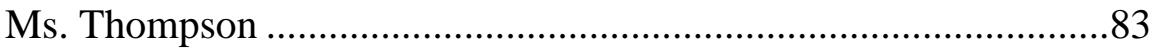

Central County High School …………………………………….......84

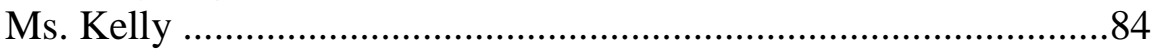

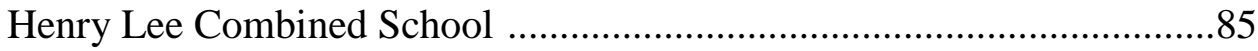

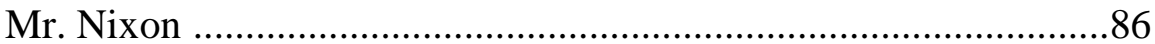

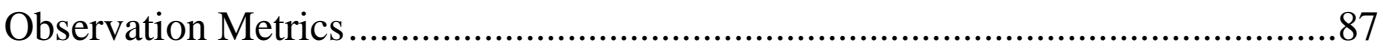

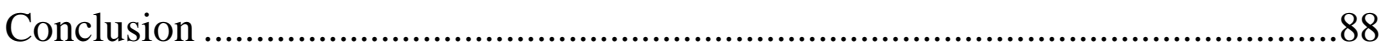

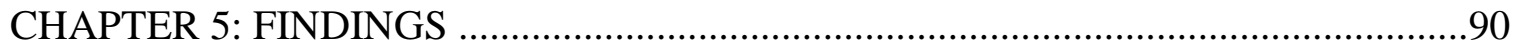

Theme 1: Citizenship Education as Practical Knowledge …………….................95

Theme 2: Place-based Learning for Future (Dis)placements ..............................104

Theme 3: The Gatekeeping Triad ...............................................................110

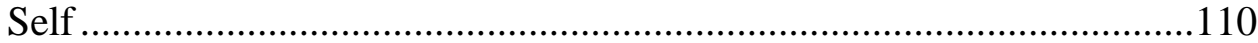

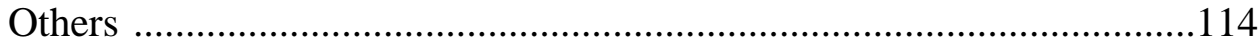

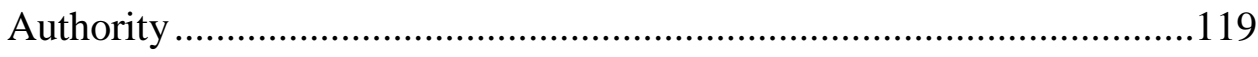

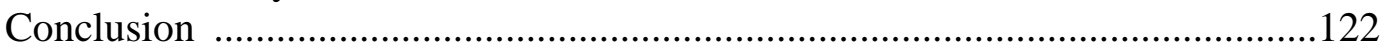

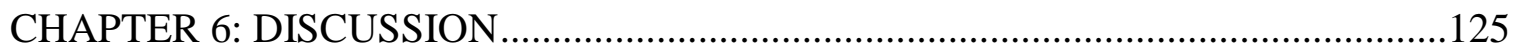

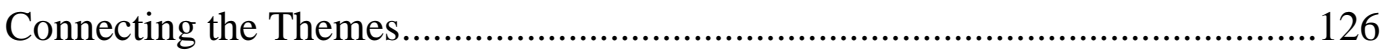

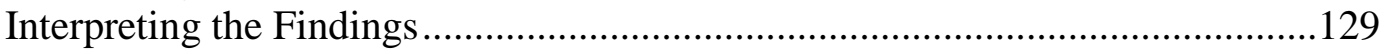

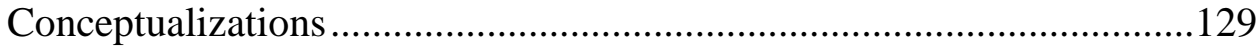

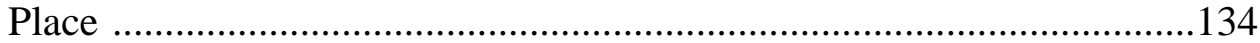

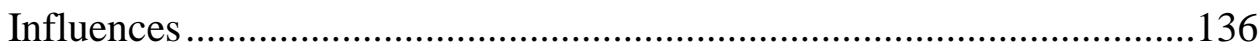




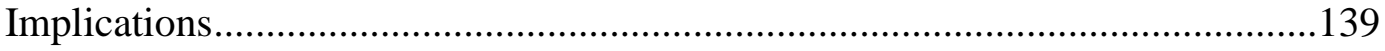

Limitations and Future Research ............................................................142

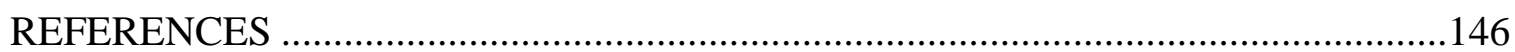

APPENDIX A: INTERVIEW PROTOCOL .................................................... 161

APPENDIX B: PARTICIPANT CONSENT LETTER ..............................................162

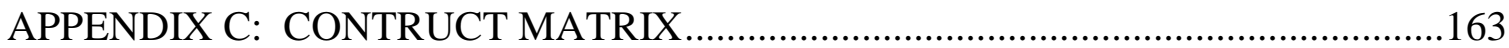




\section{LIST OF TABLES}

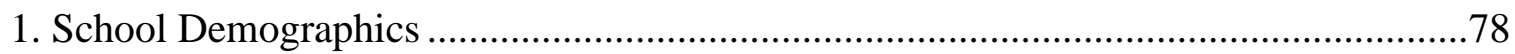

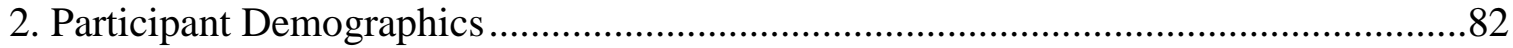

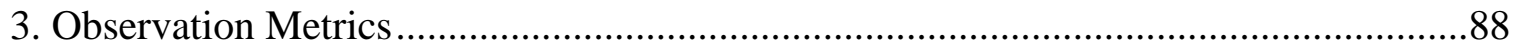

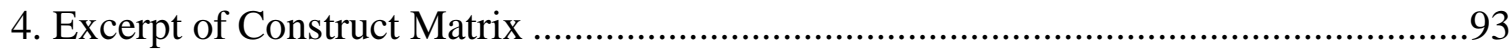




\section{LIST OF FIGURES}

1. Intersections within Rural Citizenship Education....................................................129 


\section{CHAPTER I}

\section{INTRODUCTION}

One of the central aims of social studies instruction is to prepare students for the "office of citizen" (National Council for Social Studies [NCSS], 2001, para. 1); however, teachers possess differing conceptions of citizenship that influence their curriculum and instructional decisions (Anderson, Avery, Pederson, Smith, \& Sullivan, 1997; Patterson, Doppen, \& Misco, 2012; Saada, 2013; Sondel, 2015; Vinson, 1998). Specifically, teachers bring a "frame of reference" to social studies education that includes their preconceptions of ideal citizenship (Thornton, 1989, p. 5), leading them to make decisions that endorse certain content knowledge and curricular purposes while devaluing others (Westheimer \& Kahne, 2004). Because of their decision-making power, Thornton $(1989,2005)$ calls social studies teachers curricularinstructional gatekeepers. Working under these assumptions, many researchers have examined social studies teachers' conceptualizations of citizenship education (Anderson et al., 1997; Patterson et al., 2012; Saada, 2013; Sondel, 2015; Vinson, 1998); yet, few studies examine the impact of distinct social contexts on teachers' conceptualizations and their subsequent curriculum (Vinson, 1998) - presenting incomplete knowledge on the determinants of citizenship curricula.

Failing to understand the impact of local contexts on curricular decisions hinders connections between the citizenship education theories emphasized in social studies teacher preparation programs and actual classrooms praxis (Thornton, 1989). Thornton (1989) calls the impact of the local social environment "the ecological character of gatekeeping" and says it "goes a long way toward explaining why periodic attempts at social studies reform, such as the implementation of a new curriculum in isolation from other factors, seldom succeed" (p. 9). 
Likewise, other research suggests gatekeeping in social studies education is influenced by local school and community values (Shaver, Davis, \& Helburn, 1980; Romanowski, 1996; Saada, 2013). However, very few inquiries about the citizenship aims of social studies seek understanding of this ecological character (Vinson, 1998; Sondel, 2015). Of the studies that exist, teachers report feeling pressured to conform to traditional approaches to citizenship instruction (Fry \& O’Brien, 2015; Sondel, 2015). As it stands, integration of theoretical work into the practices of social studies teachers remains inconsistent across the nation (Anderson et al., 1997; Patterson et al., 2012).

Deficits in the field of citizenship education impede fulfillment of the democratic purposes of education. Citizenship education offers possibilities to equip students with the knowledge, skills, and values to deal with complex local, national, and global issues (NCSS, 2001). Scholars must reengage with the ecological character of gatekeeping to gain contextspecific knowledge in citizenship education.

Rural settings present one distinct social context that is under-researched in social studies education (Burton, Brown, \& Johnson, 2013; Martin \& Chiodo, 2007; Pattison-Meek, 2012), though rural schools make up $32.9 \%$ of all schools in the United States and $20.4 \%$ of all students (Johnson, Showalter, Klein, \& Lester, 2014). Rural communities foster place-based identities, values, and customs, particularly in regard to civic life (Theobald, 1997) and attitudes toward schooling (Corbett, 2007). Theobald (1997) suggests the place-consciousness of rural areas has been devalued by society, but reclaiming it can benefit democracy as it can re-engender mutual commitment and responsibility to a community. Understanding rural citizenship education in its current practice is the first step toward improving democratic life in rural areas. Accordingly, this study identifies rural social studies teachers' conceptualizations of citizenship education, 
examines the impact of place on citizenship education, and reports contextual factors that influence rural teachers' decisions about the citizenship curriculum.

\section{Statement of the Problem}

Due to variations in social studies teachers' conceptualizations of citizenship, some students in the United States experience an education that inadequately prepares them for democratic life (Parker, 1994; Westheimer \& Kahne, 2004). Currently, the citizenship education literature contains a scarcity of knowledge on rural contexts; therefore, rural students' preparation for democratic life is largely unknown. Outside of one national survey (Anderson et al, 1997), no research explicitly studies rural teachers' conceptualizations of citizenship, though a teacher's notion of citizenship is a key factor that "shapes teaching and learning in the classroom" (p. 356). If rural students are to become conscientious citizens, then social studies scholars must work to understand the nature of rural citizenship education.

All approaches to citizenship education are not equal (Abowitz \& Harnish, 2006; Parker, 1994; Westheimer \& Kahne, 2004). Abowitz and Harnish (2006) studied portrayals of citizenship in an array of educational texts and discovered that "citizenship as practiced in schools is predominantly taught as civic republican literacy (factual consumption of American history, geography, and government), combined with varying degrees of patriotic identity and the liberal virtue of tolerance for difference" (p. 680). Traditional notions of citizenship tend to dominate educational texts; yet, scholars recommend teachers should move beyond traditional notions and instruct for more critical conceptions that produce the skills and dispositions necessary for life in a pluralistic democracy (Abowitz \& Harnish, 2006; Castro, 2013; Parker, 1994; Westheimer \& Kahne, 2004). 
Westheimer and Kahne (2004) advocate for teachers to focus on participatory and justice-oriented approaches to citizenship because they epitomize democratic processes like joining in collective actions and criticizing structural injustices, respectively. The authors criticize more traditional personally responsible notions of citizenship because they only emphasize individual acts like obeying laws and volunteering in times of need - acts that are not exclusive to democracies. Other scholars concur with Westheimer and Kahne by disparaging the narrowness of traditional conceptions of citizenship for their failure to acknowledge more direct forms of participatory democracy (Parker, 1994), multicultural experiences (Banks, 2008; Castro, 2013; Parker, 1994), social justice issues (Abowitz \& Harnish, 2006; Fry \& O’Brien, 2015; Pattison-Meek, 2012), global perspectives (Gaudelli \& Heilman, 2009; Noddings, 2005), and critical discourses like transnationalism and feminism (Abowitz \& Harnish, 2006).

While scholarly support is abundant for teaching non-traditional conceptions of citizenship, research on teachers' conceptualizations of citizenship education offer convoluted findings. Two investigations report a majority of social studies teachers possess critical conceptions of citizenship (Anderson et al., 1997; Vinson, 1998), but recent investigations suggest social studies teachers (Patterson et al., 2012) and pre-service teachers (Castro, 2013; Fry \& O’Brien, 2015) tend to possess traditional views of citizenship. These divergent findings indicate a possible shift in the landscape of citizenship instruction toward more conventional aims. Moreover, research on curriculum materials (Abowitz \& Harnish, 2006) and social studies instructional strategies (Kahne, Rodriguez, Smith, \& Thiede, 2000; Torney-Purta, 2002) display the overwhelming pervasiveness of traditional conceptions of citizenship, indicating possible disconnections between teachers' conceptions and practice. 
In addition to these discrepancies, only a few studies account for the impact of local contexts on teachers' conceptualizations and gatekeeping processes. Saada (2013) reports that social studies teachers in a Michigan-based Islamic school were influenced by local and international sociopolitical contexts, leading teachers to feel moral tensions between teaching for Islamic and democratic identities. Sondel (2015) discovered that the neoliberal social climate of charter schools adversely impacted teachers' capacity and autonomy to teach justice-oriented citizenship curricula. This study witnessed the termination of one justice-oriented teacher because she was deemed no longer a "good fit" by school administrators (p. 303). Both studies (Saada, 2013; Sondel, 2015) suggest the presence of school and community factors that impact teachers' decisions concerning citizenship curricula. Apart from these studies, no other citizenship education research seeks to understand the influence of local contexts on teachers' conceptualizations or gatekeeping. New studies are needed to understand the connections between local contexts and teachers' decision making about citizenship education. Doing so contributes to a theoretical statement that explains this relationship and, therefore, informs the work of future educators.

The context of rural schooling provides a drastically different context than urban or suburban schooling (Burton et al., 2013). Common rural characteristics, such as remoteness, smallness of size, limited resources, poverty, and marginalization (see Bouck, 2004; Herzog \& Pittman, 1995) likely impact teachers' conceptualizations of citizenship and approaches to teaching it, though these relationships are not yet understood. Likewise, the dominance of social conservatism (Brown \& Schafft, 2011), individualism (Dudley, 1996), and "intradependence" (Theobald, 1997, p. 7) in rural areas suggest the existence of place-specific knowledge and sentiments; yet, these too remain unexamined by educational scholars and, therefore, risk being 
misunderstood by teacher educators and practitioners. In the field of social studies, rural education is under-researched (Burton et al., 2013; Martin \& Chiodo, 2007; Pattison-Meek, 2012) and little is known about the impact of "place" on the citizenship aims of the rural social studies curricula.

The unique characteristics of rural communities present a compelling need for improving citizenship education for rural students. Rural marginalization, geographical remoteness, and misunderstood urban-rural interconnectivity foster the need to prepare knowledgeable and skillful students who can participate in the interplay of local and non-local political life. Azano (2011) suggests rural students should be asked to apply a critical lens when learning about place. In doing so, "students would be encouraged to address any limitations of living in their particular community so that, if they chose, they might be empowered to change those limiting aspects of the community or to become more resourceful in the face of such obstacles" (Azano, 2011, p. 9). Similarly, Theobald (1997) suggests rural students must be taught "a sense of political efficacy and ... community enculturation into the ethic of shouldering a responsible measure of civic virtue" (p. 133).

Currently, the small amount of knowledge on rural teachers' perspectives of citizenship education comes from one national survey that suggests a traditional citizenship notion (i.e. assimilation) was more common among teachers in small towns than in urban or suburban school districts (Anderson et al., 1997). Assimilation is a perspective that tends to devalue multiculturalism and political tensions in favor of political cohesion and unified values (Abowitz \& Harnish, 2006). Though offering some divergent view on rurality, the study suggests assimilation was not common among teachers in rural farming areas (Anderson et al., 1997). This peculiarity may be explained, in part, by the fact that rural areas are not homogenous across 
different regions in ethnicity or economic endeavors (Brown \& Schafft, 2011). One could speculate that agrarian lifestyles may produce specific values and desires that impact conceptions of citizenship differently, but as of now, this remains unconfirmed.

Prior research points to rural characteristics that engender the need for the current study. Studies shows conservative ideologies are present in rural areas more than urban locales (Gimpel \& Karnes, 2006; Brown \& Schaft, 2011). Since conservatives tend to support traditional social values and civic ideals, conflict may arise between rural conservatism and more critical or progressive conceptions of citizenship. For example, Rapoport (2010) warns that "small town mindsets" and "local mindsets" work as microcosms that pressure social studies teachers against teaching concepts of citizenship deemed unpatriotic (p. 186). To untangle this point, traditional orientations of citizenship emphasize patriotism and a strong commitment to the existing political community; yet, many citizenship scholars advocate for the treatment of patriotism as a contested concept that encourages critiques of governmental policies in order to improve society (Abowitz \& Harnish, 2006; Kahne \& Middaugh, 2006; Rapoport, 2010).

While this presents a possible ideological conflict over the curriculum between social studies teachers and community-members in rural locales, other research suggests teachers are sensitive to the values of the community and not likely to teach students to challenge established community values (Romanowski, 1996; Shaver et al., 1980) - even when theorists suggest doing so as a way to prepare students for democracy (Abowitz \& Harnish, 2006; Westheimer \& Kahne, 2004). Traditionally, social studies teachers perceive their role as citizenship educators in fitting the transmission model of education where "formal schooling functions in part to transmit and preserve society's values" (Shaver et al, 1980, p. 12). Research concurs that the transmission model is most prevalent in citizenship education materials (Abowitz \& Harnish, 2006). 
It is reasonable to suspect that the close-knit social life, smallness of size, and remote locations of rural communities may increase the difficultly of teaching notions of citizenship that challenge students to become social critics. Past research suggests teachers' sensitivity to school and community values leads them to be diplomatic and tactful in their approach to controversial issues in the curriculum (Romanowski, 1996; Shaver et al., 1980), feel tensions due to the pull between local and non-local sociopolitical forces (Saada, 2013), or abandon certain citizenship aims because of fear of administrative reprisal (Fry \& O’Brien, 2015; Sondel, 2015).

The current problem is that little knowledge exists about rural teachers' conceptions of citizenship, their gatekeeping of the curriculum, or how place intersects with rural citizenship education. This study helps to reveal teachers' perceptions of rural-specific factors on citizenship education and uncovers teachers' negotiation of gatekeeping in rural environments. Failure to study this phenomenon leaves a void in knowledge on the practices of citizenship education that results in unfulfilled democratic potential in rural areas and allows for the continued misunderstanding of rural places.

\section{Statement of Purpose and Research Questions}

This study contributes context-specific knowledge to the field of citizenship education that is necessary to ensure the best citizenship curricula and teaching practices are enacted in rural classrooms. This study provides organic understandings of the phenomena by utilizing the voices and lived experiences of rural teachers. Rural teachers, as gatekeepers of the curriculum, are in the best position to provide their authentic conceptualizations of citizenship and practicebased, place-based knowledge on navigating school and community factors.

Uncovering knowledge on rural citizenship education opens potential pathways to connect theory and practice. Teacher educators, and ultimately prospective teachers, will be 
informed with accurate accounts of rural teaching. If teacher educators can better prepare prospective teachers for the realities of rural citizenship education, then prospective teachers will be better prepared to foster democratic skills and dispositions in their future students. Ideally, rural communities will be bolstered by the development of citizens who have the knowledge, skills, and dispositions to think critically and work democratically on local and non-local problems.

To fulfill the purposes of this study, the following questions guide this investigation:

1. How do government teachers in rural schools conceptualize citizenship education?

2. How do teachers' perceptions of place impact citizenship education in rural contexts?

3. How is curricular-instructional gatekeeping in citizenship education impacted by rural contexts?

\section{Study Rationale and Significance}

This examination contributes deeper understandings on rural educational contexts by exploring government teachers' perspectives on citizenship curriculum determinants. Findings produce new knowledge about how teachers negotiate various, and sometime competing (see Evans, 2004), sociopolitical forces within their local contexts that impact the aims of the social studies curriculum. Consequently, this study reveals the level of professional autonomy government teachers have in rural schools to pursue their desired citizenship aims. Findings contribute significantly to the present miniscule knowledge of rural-specific social studies instruction (Burton et al., 2013; Martin \& Chiodo, 2007; Pattison-Meek, 2012). 
This study's qualitative research design offers the ability to depict the particular characteristics of school and community environments. Descriptive data of this type informs teacher educators of practice-based knowledge so they can better prepare social studies teachers to navigate the rural realities. This knowledge helps to fulfill calls to make future rural teachers school and community ready, in addition to classroom ready (White \& Kline, 2012). Ultimately, this knowledge leads to teachers who are more place-conscious in their gatekeeping and, therefore, more competent citizenship educators. This knowledge increases the likelihood that theoretical work on citizenship education will become part of rural teachers' enacted curriculum. This study also contributes more generally to accurate depictions of rural life. Teachers often hold inaccurate presumptions about rural students, such as expecting ideological sameness (Pattison-Meek, 2012; Washington \& Humphries, 2011). Studying the impact of rural contexts on citizenship education contributes essential knowledge to overcome inaccurate presumptions and better serve an underserved group of America's youth (see Bouck, 2004). Also, findings deepen knowledge in the field of curriculum theory by reporting on the effects of sociopolitical factors on the social studies curriculum. As a citizenship education study, findings contribute knowledge to disciplines outside the field of education, particularly rural sociology, political science, social psychology, and other disciplines that focus on political socialization. Most importantly, the findings of this study can be applied by practitioners to empower rural people for democratic life. Utilizing community-driven knowledge illuminates connections between place and gatekeeping and, therefore, pathways to enhance citizenship in ways that are relevant and responsive to rural communities.

\section{Overview of Methodology}


Since this study explored teaching in rural environments, a relatively unknown context for citizenship instruction, a grounded theory design was employed (Corbin \& Strauss, 1990, 2014). The purpose of a grounded theory is to "uncover relevant conditions... [and] determine how the actors under investigation actively respond to those conditions, and to the consequences of their actions" (Corbin \& Strauss, 1990, p. 419). A grounded theory design enabled thick descriptions of rural conditions unique to the research settings. Examining teachers' conceptualizations of citizenship and their navigations of rural-specific conditions enabled a fuller and deeper analysis of citizenship education in this context. Adopting a grounded theory design encouraged new perspectives to emerge directly from the data instead of imposing prescriptive theoretical categories. Inductive data analysis contributed to the development of a descriptive theoretical statement on the phenomenon.

This study utilized a sample of five government teachers in rural high schools. Data were drawn from three sources: interviews, classroom observations, and artifacts. Individual semistructured interviews uncovered each teacher's conceptualization of citizenship education and their perception of the forces that contribute to their decision-making about the citizenship curriculum. All data underwent the constant comparison analysis technique to reveal themes relevant to answering the research questions (Corbin \& Strauss, 2014; Miles, Huberman, \& Saldaña, 2013).

Four of the five participants' classrooms were periodically observed over the course of three months, allowing the researcher to witness an average of eight different lessons per teacher. One participant was not observed because she was not teaching government during the semester in which the study occurred. Observations enabled the researcher to document teachers' curricular-instructional decisions and witness the participants fulfilling teacher roles within the 
contexts of their schools, including their formal and informal interactions with students. Observations of classroom praxis across four participants within similar rural settings supported robust data collection to gauge the consistency of teachers' citizenship conceptualizations and the relationship between their stated aims and their enacted curricula.

Informal interviews occurred after each observation. These interviews sought to understand how teachers' citizenship goals were implemented in the observed lessons. Postobservation interviews enabled deeper scrutiny of teachers' conceptualizations and curriculum decision-making and increased the credibility of the researcher's interpretation of data. Additionally, teaching artifacts were collected during classroom observations as evidence of curriculum decisions and were used to corroborate connections between conceptualizations and practices. Finally, a culminating interview occurred after all classroom observations were complete. This interview encouraged participants to check the researcher's emergent findings and explore various themes from the data at a deeper level.

\section{Role of the Researcher}

During the research process, the researcher's main role was one of participant observer. Specifically, during interviews, the researcher's intimacy and interaction with participants enabled a co-construction of knowledge (see Kvale \& Brinkmann, 2009). Kvale and Brinkmann (2009) recommend using this closeness as a means to uncover knowledge that is "neither inside a person nor outside the world, but exists in the relationship between persons and world" (p. 53). This interview approach aligns with the social constructionist framework of the study. During classroom observations, the researcher acted as a passive or "moderate" participant. This meant that the researcher was present in the research setting, but did not actively participate, or only occasionally interacted, with people in it (DeWalt, DeWalt, \& Wayland, 1998, p. 262). 
Immersion into the research environment in this capacity allowed the researcher to observe the social conditions of the phenomenon in a way that "enhances the quality" and "interpretation of the data" (p. 264).

\section{Researcher Positionality}

In qualitative investigations, the researcher acts as a "human instrument" (Merriam, 2002, p. 5). This means the researcher, with his or her unique identities and biases, has potential to impact the research process (Bourke, 2014). Scholars advise researchers to identify their positionality, or identities in relation to the setting and participants under investigation, to make transparent any preconceptions (Bourke, 2014). As a social studies teacher in an Appalachian public high school, the researcher of this study has experienced teaching citizenship in a small town context. While this classroom experience, in part, provides the impetus for the study, it also produces the researcher's personal conception of citizenship education, experiences navigating local school and community influences on the curriculum, and a closeness to rural culture. The researcher acknowledges that these experiences produce some "insider" knowledge, but also acknowledges that the rurality of a mid-size Appalachian town is relative to one's perspective on rural. The researcher assumes that conceptions of rurality differ due to their unique life experiences of participants and that rurality is diverse and particularistic across rural areas.

To moderate researcher predispositions when moving into rural environments and assessing a familiar phenomenon, an interview protocol was constructed prior to contact with participants (see Appendix A). This document acted as a guide to ensure that interview questions encouraged the discovery of unique participant perspectives and contextual factors. The protocol was rooted in knowledge from existing research on citizenship education and rural schooling. Questions were adapted from two past studies, Castro (2013) and Saada (2013), and themes that 
emerged from the aggregated literature review. The researcher purposely suspended judgements during the interview process to ensure participants' perspectives were untainted by the reactions of the researcher.

Unavoidably in qualitative research, the researcher's own identities and experiences shade some parts of the data collection, analysis, and reporting. Scholars suggest this is not necessarily a negative occurrence that must be controlled. Kvale and Brinkmann (2009) advance the notion that interviewers' subjectivity and background knowledge enable them to know where to look and what questions to ask. Noting the inherent involvement of the researcher in qualitative methodologies, Miles et al. (2013) suggest the researcher must possess "good familiarity with the phenomenon and setting under study," be "nonjudgmental with participants in the setting," and have "a heightened sense of empathetic engagement, balanced with a heightened sense of objective awareness" (p. 42). The researcher adopted these guidelines for use in the current study.

\section{Organization of Dissertation}

The current chapter introduced the problem, purpose, and significance of the study. It presented the research questions, provided a brief overview of the methodology, and discussed the role of the researcher and the researchers' positionality.

Chapter two provides a review of relevant literature in the areas of citizenship education, curricular-instructional gatekeeping, and rural contexts. This review helps to situate the study within these relevant fields of knowledge and offers support for the research questions and methodological approach. Westheimer and Kahne's (2004) theoretical categories of citizenship education are described to orientate readers to the controversies of citizenship education and provide a framework for later data analysis. Critiques of past research methods are offered and 
remaining research gaps are identified. A framework for understanding rural places as both socio-geographic and socio-cultural locales is presented (Brown \& Schafft, 2011), as is a rationale for a qualitative study.

Chapter three provides an in-depth description of the study's methodology. First, the researchers' social constructionist epistemological stance is presented. Next, the study's grounded theory design is described with support offered from literature on qualitative research methods. Participant sampling methods are defined, including how rural is classified in the study to ensure the sample appropriately represented the desired population. The chapter describes the data collection and data analysis methods, and issues of trustworthiness, ethics, and methodological limitations are discussed.

Chapter four provides the context of the study. Each rural school and community is introduced using geographical and demographical data. Also, biographical information is provided for each of the five participants. Observation metrics, including their frequency and duration, are reported.

Chapter five relates the findings of the study through three interconnected themes. These themes are described and supported by evidence from the data. They produce an emergent descriptive theory about the impact of rural contexts on citizenship education.

Chapter six, the final chapter, offers a discussion of the findings in light of previous research and discusses the implications of the results. A figure of the emergent theory is presented to visually express the intersection of various components in rural citizenship education. The limitations of the study are examined and suggestions are made for future research. 


\section{CHAPTER II}

\section{LITERATURE REVIEW}

Preparation for citizenship has long been considered the main purpose for social studies education (Engle, 1960/1996; National Council for the Social Studies, 1994; Saxe, 1992), but the aims of such an education are often contentious (Abowitz \& Harnish, 2006; Barr, Barth, \& Shermis, 1978; Evans, 2004; Parker, 1994; Ross, 2001; Westheimer \& Kahne, 2004). Debates stem from individuals who possess opposing views on the roles and responsibilities of citizens. Research shows teachers are among those that hold disparate views on citizenship and that their views impact the curriculum (Anderson et al., 1997; Patterson et al., 2012; Sondel, 2015; Vinson, 1998). Opposing views on citizenship education can most easily be understood by separating them into two broadly defined groups: traditionalists and progressives (Parker, 1994). Traditionalists want to prepare youth with the fundamental values of their political community, scholarly knowledge of government institutions, and skills for participation in customary governmental processes, such as voting and campaigning (Parker, 1994). Progressives desire that students be given opportunities for practical reasoning, decision making, and more direct forms of participation in democracy (Parker, 1994). In recent years, the field of citizenship education has become complicated due to the impact of new discourses on multiculturalism (Banks, 2008), globalization (Rapoport, 2009), and transnationalism (Abowitz \& Harnish, 2006). The diverse and often competing aims of citizenship education make teaching social studies a controversial act - one that requires forethought and professional discernment on behalf of teachers.

The National Council for the Social Studies [NCSS] (1994) states, "The primary purpose of social studies is to help young people make informed and reasoned decisions for the public good as citizens of a culturally diverse, democratic society in an interdependent world" (p. 3). 
Not only does this statement indicate the democratic goals of social studies education, but also offers support for progressive notions of citizenship through use of the phrases, "reasoned decisions" and "culturally diverse." However, examinations of social studies teachers' (Patterson et al., 2012; Sondel, 2015) and pre-service teachers' citizenship conceptualizations (Castro, 2013; Fry \& O'Brien, 2015) reveal that these democratic aims are not shared by all teachers as a majority support more traditional notions of citizenship. Thornton $(1989,2005)$ postulates that the breakdown between the democratic aims of social studies and classroom practices can be understood by researching the teacher's role as curricular-instructional gatekeeper. Though multiple studies examine teachers' conceptualizations of citizenship, few account for the social context of schooling on the decision-making process. Specifically, no studies exist that purposefully investigate the impact of rural communities on teachers' decisions about the citizenship curriculum. The failure to fully understand the convergence of rural-specific contexts and gatekeeping results in failures to improve connections between theory and practice; and presents a deficit to understanding contextual influences on the social studies curriculum.

This study helps to fulfill multiple calls for additional research from both social studies and rural education scholars. Thornton $(1989,2005)$ calls for better understanding of curricularinstructional gatekeeping to improve connections between social studies theory and practice. Others suggest that more extensive research is needed on the ways contexts place constraints on teachers and the curriculum (Westheimer \& Kahne, 2004; Vinson, 1998). Similarly, Martin and Chiodo (2007) and Pattison-Meek (2012) encourage researchers to explore connections between rural communities and citizenship education. To deepen "the understanding of education in rural areas," Burton et al. (2013) call for investigations into rural-specific social studies as it lags behind other disciplines (e.g. special education, science, technology, and math) (p. 10). Lastly, 
White and Kline (2012) appeal to teacher educators to help prospective rural teachers understand "the links between the classroom, the school, and the wider rural community and their place across these three different contexts" (p. 40). This current study helps prospective rural teachers by providing knowledge of school and community influences to foster place-conscious gatekeeping of the curriculum.

To establish support for research on rural citizenship instruction, this chapter reviews the relevant literature on citizenship education, curricular-instructional gatekeeping, and rural contexts. Specifically, it helps familiarize readers with the politically-charged nature of citizenship education; it explains the concept of curricular-instructional gatekeeping; it reports prior investigations on social studies teachers' conceptualizations; and it provides the theoretical framework that was utilized in data analysis. Additionally, this chapter defines rural as a unique construct and explores prior scholarship on the convergence of rurality and citizenship education. An evaluation of previous research methodologies and findings highlight unresolved problems in the field.

\section{Dimensions of Citizenship}

The fourteenth amendment of the United States Constitution defines citizenship as a legal concept, stating "All persons born or naturalized in the United States, and subject to the jurisdiction thereof, are citizens of the United States and of the State wherein they reside." Yet, social studies scholars, such as Parker and Jarolimek (1984), define a citizen as "an informed person; skilled in the processes of a free society; who is committed to democratic values and is able; and feels obliged; to participate in social; political; and economic processes" (p. 6). Juxtaposing these definitions reveals that citizenship does not have one firm conceptualization, but instead represents multiple dimensions of civic life. 
Within civic education discourses, citizenship is regularly presented as the knowledge, thoughts, and commitments of citizens that transfer into actions to sustain a representative government (aka the "practice of citizenship") (Conover \& Searing, 2000), but the specific knowledge and desired actions remain unsettled (Abowitz \& Harnish, 2006; Westheimer \& Kahne, 2004). Different conceptions of citizenship are based on individuals' ideas about the rights, duties, and distinctions of citizens in a given political community. This section examines the construct of citizenship through three dimensions. This enables citizenship to be seen as a varied and contentious aim in social studies education.

Citizenship is often represented in three dimensions: citizenship-as legal-status, citizenship-as-activity, and citizenship-as-identity (Kymlicka \& Norma, 1994; Leydet, 2011). Kymlicka and Norman (1994) identify citizenship-as-legal-status as a conceptualization that encompasses the civil, political, and social rights of someone as a member of a political community ( $\mathrm{p}$ 353). This dimension is represented by the fourteenth amendment seen above. It encompasses discourses on legal protections and civil rights for minorities, immigrants, and other specialized groups; however, this dimension fails to reveal more duty- or dispositionfocused definitions of the term. For example, recognizing citizenship as a legal status does not expose the methods of political participation individuals have within their community, the distribution of political power among different groups, and the nature of social responsibility each citizen has toward others or toward the government. To encompass these traits, citizenship must also be thought of as an activity.

Citizenship-as-activity highlights the extent and quality of citizenship as a function of one's participation in the political community (Kymlicka \& Norman, 1994). Most scholars promote this conceptualization as a means to discuss the relationship between civic knowledge 
and citizenship actions. The duties embedded within the citizenship-as-activity dimension vary depending on one's orientation towards democracy. Straightforwardly, it can be understood by divisions between traditionalist and progressive notions (Parker, 1994). Traditionalists desire civic republican ideals that focus on possessing the requisite knowledge to vote for representatives and display patriotism, while progressives desire classic liberal ideals that focus on equalitarian deliberations and collective actions. Regardless of one's orientation to democracy, Kymlicka and Norman (1994) and Parker (1997) are critical that focusing on rights (as-legal-status) and duties (as-activity) may ignore the impact that identity can play when talking about citizenship as a member of a political community. For this reason, the last dimension, citizenship-as-identity, is seen as the most complex (Leydet, 2011).

Citizenship-as-identity is traditionally interwoven with national sovereignty and allegiance to certain moral commitments (Williams, 2003); yet, it elicits questions about the tensions between holding a common citizenship identity within a political community versus holding a differentiated citizenship identity that embraces cultural plurality (Kymlicka \& Norman, 1994). A differentiated citizenship identity counters traditional ideas of cultural conformity and assimilation. Thinking about identity in this manner broadens the construct to embrace multicultural and global or transnational citizenship theories. Banks (2008) suggests citizenship be viewed as transformative "to develop reflective cultural, national, regional, and global identifications and to acquire the knowledge and skills needed to promote social justice in communities, nations, and the world" (p. 137). Similarly, Williams (2003) proposes moving toward the idea of citizenship-as-shared-fate, a conceptualization that emphasizes the agency to remake our identity connections with others instead of relying "on the historic convergence of boundaries (territorial, cultural/national/linguistic, institutional, and moral)” (p. 209). Williams's 
(2003) shared-fate identity alludes to a new conception of citizenship for a global, multicultural sociopolitical life. Similarly, Avery's (2004) conception of future-oriented citizenship demands the consideration of global perspectives to ensure success in dealing with human rights and environmental issues; and Butts's (1980) advocates for civic learning that recognizes global interdependence and teaches about international human rights.

Global citizenship, as a new identity construct, seeks for individuals to extend their social responsibility and care for people beyond one's national boundaries (McIntosh, 2005). Global citizenship, defined in this manner, makes nation-bound identities insufficient because they do not account for the idea of identifying with people outside one's own political community. To encompass global citizenship discourses, a psychological element of citizenship must be adopted - one that emphasizes mutual human concern over national identity. Yet, global citizenship remains an unsettled construct, with both democratic and non-democratic notions present in education (Gaudelli \& Heilman, 2009). Gaudelli and Heilman (2009) theorize that neoliberal, disciplinary, and human relations conceptions of global citizenship are not democratically congruent, whereas cosmopolitanism, environmentalism, and critical justice are democratically congruent conceptions of global citizenship.

As seen here, dimensions of citizenship creates space for negotiating traditional, progressive, and more critical conceptions of the construct (Kymlicka \& Norman, 1994); and present the ways citizenship is both conceptualized and put into action in society as a legal status, a duty, or an identity with (or beyond) one's political community. The political-charged volatility within each dimension is not exclusive. Someone can hold in their mind more than one dimension at a time. These dimensions provide a foundation for understanding the citizenship aims of the social studies curriculum. Teachers, as gatekeepers of the curriculum, transmit the 
ideas and language of citizenship to students. Since education may emphasize citizenship in a variety of ways, researchers often ask: How do teachers' conceptualize citizenship? How do conceptions of citizenship affect curricular-instructional gatekeeping? And what factors influence teachers' conceptions of citizenship and their curriculum decision making?

\section{Theories of Citizenship Education}

Social studies teachers either purposefully or unintentionally advance specific knowledge, skills, and dispositions for citizenship. Yet, as seen above, citizenship embodies a multitude of dimensions and little agreement exists on the knowledge and skills students need for competent civic involvement, or what identities and values teacher should emphasize.

Recognizing these variations, educational researchers have constructed multiple theories to assess social studies teachers' citizenship aims. Martorella (1996) provides a framework that categorize teachers' citizenship education aims under five themes: reflective inquiry, informed social criticism, personal development, citizenship transmission, and social science. A similar framework is posited by Anderson et al. (1997), offering four themes: critical thinking, legalism, cultural pluralism, and assimilation. Both frameworks present differentiated aims for citizenship education that stem from either traditional perspectives (personal development, citizenship transmission, assimilation, and legalism) or more progressive perspectives (reflective inquiry, informed social criticism, critical thinking, and cultural pluralism).

The job of the social scientist is to create measurement systems that "maximize between category differences while minimiz(ing) within category variability" (Brown \& Schafft, 2011, p. 21). Understandably, other scholars have formulated citizenship education typologies into more abstract themes. Three frameworks have emerged as seminal in citizenship education. As previously mentioned, Parker (1994) presents the dichotomy of traditionalist and progressive 
perspectives on citizenship. Also, Parker (1994) offers a critique of this dichotomy and recommends for teachers to adopt more "advanced" notions of citizenship that include multicultural understandings (p. 13). Abowitz and Harnish (2006) review educational texts and categorize citizenship discourses into three groups: liberal, civic republican, and critical notions. Similarly, Westheimer and Kahne (2004) present a three-type framework (personal responsibility, participatory, and justice oriented) that they use to assess the aims of civic education programs and others have used to identify teacher's conceptualizations (Patterson et al., 2012; Sondel, 2015) and pre-service teachers' orientations (Fry \& O’Brien, 2015).

An exhaustive comparison of citizenship education typologies is unnecessary for the goals of this study, but it is noteworthy to point out each framework deals similarly with citizenship by grouping related ideals and labeling them to reveal the divisions in orientations to citizenship. Conceptual divisions in each framework could be placed on the spectrum from more traditional, unified understandings of citizenship to more progressive, pluralistic notions. Traditional conceptions of citizenship incorporate the political philosophies of both civic republicanism and some aspects of classic liberalism. They tend to emphasize disciplinary knowledge, character development, and commitment to common political values, such as freedom and justice. Progressive citizenship notions do not necessarily reject traditional notions, but instead extend upon liberal notions to include more direct participation in democracy. Hence, progressives tend to focus on critical thinking, collective actions, and equality within a culturally pluralistic society. Also, multiple citizenship frameworks offer more critical orientations to citizenship that advocate for criticizing the social order, fighting for social justice, and creating space for marginalized groups (Abowitz \& Harnish, 2006; Parker, 1994; Westheimer \& Kahne, 
2004), though newer, critical discourses are not yet widely present in curriculum materials (Abowitz \& Harnish, 2006).

For this study, Westheimer and Kahne's (2004) framework was adopted to make sense of rural teachers' citizenship conceptualizations. This framework was chosen because of its philosophical divisions between democratic actions and actions not exclusive to democracy. It clusters conceptions of citizenship into three distinct categories: personally responsible, participatory, and justice oriented. Westheimer and Kahne (2004) state the following criteria to which their categories adhere:

1. They aligned well with prominent theoretical perspectives...

2. They highlight important differences in the ways that educators conceive of democratic educational aims; that is, they frame distinctions that have significant implications for the politics of education for democracy; and

3. They articulate ideas and ideals that resonate with practitioners (teachers, administrators, and curriculum designers) (p. 240).

Personally responsible approaches to citizenship emphasize acting responsibly, paying taxes, obeying laws, and volunteering in times of crisis. It represents conservative notions of civic duties due to its focus on good character and individual acts. Participatory approaches to citizenship emphasize becoming active members of community organizations, being knowledgeable about how government agencies work, and knowing strategies to accomplish collective tasks. Participatory-minded citizens take leadership within established systems and community structures. Justice oriented approaches to citizenship focus on critically assessing societal structures to see beyond surface causes of inequalities. Justice oriented citizens seek out 
and address areas of discrimination and inequality. They are committed to questioning, debating, and changing established systems that reproduce patterns of injustice over time.

Westheimer and Kahne (2004) criticize personally responsible approaches to citizenship education for failing to prepare students for the realities of democratic life. They suggest participatory and justice oriented aims are more compatible for democratic citizenship. In their critique of personally responsible citizenship, the authors propose that teachers who emphasize honesty, hard work, and obedience to laws, as well as character development and individual civic acts, obfuscate the need for collective action when addressing societal problems. Moreover, stressing personally responsible notions of citizenship fails to prepare students with the knowledge, skills, and dispositions to analyze the causes of social problems and fight for systemic changes. The authors theorize that there is nothing inherently democratic about personally responsible citizenship as it would be equally valued in "a totalitarian regime" since it prioritizes obedience and patriotism (Westheimer \& Kahne, 2004, p.244). Westheimer and Kahne (2004) raise concerns that a 1999 study by the National Association of Secretaries of State found $94 \%$ of young people believe their most important citizenship duty is to help people - not democratic engagement in politics. Recent scholarship using this framework discovered personally responsible notions are most the common type of citizenship orientations among social studies teachers in one Midwestern state (Patterson et al, 2012) and elementary social studies pre-teachers across 20 states (Fry \& O’Brien, 2015).

\section{Curricular-Instructional Gatekeeping}

Curricular-instructional gatekeeping positions teachers, with their unique knowledge and conceptions of citizenship, as the critical lynchpin in determining the enacted curriculum for their students. Curricular-instructional gatekeeping is described by Thornton (1989) as "a 
decision-making process governed by the elements of the teacher's frame of reference" (p. 5). In defining "frame of reference" and connecting it to gatekeeping, Thornton looks to Beard (1934) who said:

Every human being brought up in society inevitably has in mind a frame of social knowledge, ideas, and ideals... and too this frame or pattern, his thought and action will be more or less consciously referred... Since all things known cannot be placed before children in the school room, there must and will be, inevitably, a selection, and the selection will be made with reference to some frame of knowledge and values, more or less consciously established in the mind of the selector. (p. 182)

This suggests teachers' frames of reference drive their gatekeeping about the aims, content, and methods of instruction. Though many school districts adopt official curriculum guides aligned with state standards and materials (textbooks, tests, etc.), the official curriculum is interpreted through each teacher's frame of reference and decisions are made about how and what to emphasize in their classrooms (Archbald \& Porter, 1994). Essentially, gatekeeping is synonymous with this decision-making process, stemming from teachers' frames of reference, that results in the enacted curriculum.

Since preparation for citizenship is the most commonly accepted purpose of the social studies (see NCSS, 2001), examining teachers' conceptualizations of citizenship enable researchers to assess the frames of reference teachers use for gatekeeping. Thornton (1989) suggests that teachers do not always consciously weigh alternatives and examine their assumptions; and other scholars report that teachers' tacit conceptualizations nonetheless drive decision making about the curricula (Cornett, 1990; Evans, 1990; Fickel, 2000). Examining 
teachers' implicit conceptualizations of citizenship reveals the underpinnings of the enacted curricula that would otherwise go unnoticed in curriculum studies.

Complementing teachers' conceptualizations, research depicts a myriad of other contextual factors that influence teachers' gatekeeping of the curriculum. Factors include: teachers' belief systems (Parajes, 1992), personal histories (Fickel, 2000), college coursework (Cornett, 1990), school culture (Sondel, 2015), state standards (Romanowski, 1996), and community beliefs (Shaver et al., 1980; Romanowski, 1996). Only a handful of studies exist that report the relationships between these factors or examine in-depth the interplay of conditions that result in certain curriculum decisions. This is despite Thornton's (1989) suggestion that "gatekeeping is part of an interactive system of beliefs and contextual factors that must be understood as a whole" (p. 10).

The few studies that recognize the discernible influence of school and community pressures on teachers' gatekeeping provide some foundational knowledge on the impact of social conditions upon gatekeeping (see Romanowski, 1996; Shaver et al., 1980; Saada, 2013; Sondel, 2015). Romanowski's (1996) analyzed the factors that shape the teaching of United States history and found that close scrutiny by local forces (school and community) have a subtle, but present impact on teachers' approach to certain topics in their classes. Aware of the influence of Christian ethics in his community, one participant in the study shared the insight that "within the context of this community, I think that they want [pause] American history taught within the framework of some kind of moral values." (p. 296). Romanowski (1996) interprets the study's findings, stating that "Instructional decisions require that teachers engage in a dialogue between their particular subject matter, their own belief systems, and the climate and beliefs of the local community and society" (p. 297). These results are compatible with theories that suggest 
teachers are diplomatic when teaching controversial issues because of the influence of community values (Shaver et al., 1980). Moreover, some support is garnered for Garcia's (1991) notion that "what is taught and what is learned in any classroom is tremendously influenced by the community's beliefs and values" (p. 45).

While Romanowski's study reports the influence of contextual factors on gatekeeping in history courses, the literature remains thin in regard to the relationship between teachers' conceptualizations, community values, and gatekeeping in citizenship education. Researchers speculate that teacher's citizenship conceptualizations and community desires may not always coincide (Rapoport, 2009), particularly since the aims of citizenship education are politically contentious (Evans, 2004). The next section reviews prior research on teachers' conceptualizations of citizenship education and further illuminates the bidirectional relationship between society and schooling.

\section{Teachers' Conceptualizations of Citizenship Education}

Prior research shows that social studies teachers tend to utilize a combination of instructional approaches, but possess one deep, singular conception of social education (Brubaker, 1977) or conceptualization of citizenship (Patterson et al., 2012). Examining teachers' conceptions produce knowledge on the aims of schooling from the ground level where gatekeeping occurs (Thornton, 2005). This section examines the existing literature on social studies teachers' conceptualizations of citizenship education (e.g. Anderson et al., 1997; Castro, 2013; Fry \& O’Brien, 2015; Patterson et al., 2012; Saada, 2013; Sondel, 2015; Vinson, 1998).

Studies were chosen to illuminate the various methodological approaches, findings, and knowledge gaps in the field. 
In one study, 220 social studies teachers from across the nation were surveyed about their beliefs on the purposes, content selection, and methods of citizenship education (Vinson, 1998). Using Martorella's (1996) alternative citizenship education framework, Vinson (1998) found that teachers reported the following purposes for their citizenship instruction: reflective inquiry (23.6\%), informed social criticism (24.5\%), personal development (15\%), citizenship transmission $(9.5 \%)$ and social science $(3.6 \%)$. These findings suggest the existence of what Vinson called an "anti-conservative backlash" among social studies teachers because teachers appeared to reject traditional citizenship aims in face of the growing right-wing movement towards cultural literacy and rote learning (p.74). Yet, these findings are thrown into question by contradictory results in several different studies.

Surveying students, as opposed to teachers, Torney-Purta (2002) found that $90 \%$ of US students report textbooks and worksheets as the most common form of civic instruction teaching methods that correlate more with citizenship transmission and social science traditions (Abowitz \& Harnish, 2006). Additionally, in another study researchers observed classrooms to assess citizenship education practices and found only $12 \%$ of classrooms engaged students in higher order thinking for a substantial part of the lesson; $7.4 \%$ of classrooms focused on deep disciplined inquiry; 7.4\% gave students substantial experiences in democracy as a way of life; and only $1.5 \%$ provided opportunities for students to consider the complexities of life in a diverse society (Kahne et al., 2000). The findings of these two studies suggest traditionalist perspectives of citizenship dominate American classrooms which stands at odds with Vinson's conclusions about the presence of an anti-conservativism backlash. This discrepancy implies a disconnection between teachers' self-reported beliefs and actual classroom practices - something in need of further investigation. 
Methodological limitations may have skewed Vinson's (1998) findings. The study sampled high school social studies teachers that held membership in NCSS. Membership in NCSS may unduly influence participants' beliefs on citizenship toward more progressive notions of citizenship (NCSS, 1994). Members receive opportunities for professional development and periodicals that emphasize critical inquiry and multiculturalism. If teachers from outside NCSS had a chance to be included in the sample, results may have varied. Noteworthy, NCSS membership is not proportional across states. It is possible that understandings of citizenship were not represented equitably within the study's sample. Recognizing the limitations of the study, Vinson (1998) calls for future researchers to examine "the role played by context" and its relationship to instructional approaches (p. 75).

The results of at least one earlier study concur with Vinson's (1998) findings. Anderson et al. (1997) used a national survey and found that a majority of teachers held progressive or critical perspectives on citizenship; yet, this study also assessed only NCSS members. Using different conceptual categories based on their own scaffolded research design, Anderson et al. (1997) found nationally that NCSS member teachers held four perspectives on citizenship education: critical thinking (47\%), cultural pluralism (26\%), legalism (13\%), and assimilation (8\%). Legalism and assimilation are both identified as conservative perspectives while critical thinking and cultural pluralism are identified as liberal perspectives. Significant to this study, correlations existed between different citizenship perspectives and teachers' religions, regions, and political ideologies. For example, teachers in small towns were twice as likely to teach for assimilation as urban or suburban teachers, suggesting conservative citizenship perspectives are more likely in non-metro areas of America. 
The fact that Vinson (1998) and Anderson et al. (1997) carried out their research prior to the $21^{\text {st }}$ century must be considered in light of recent changes to America's political climate - a known influence on the social studies curriculum (Evans, 2004). Twenty-first century political events altered the culture of schooling in America. Apple (2002) suggests the terrorist attacks of 2001 established a culture of enforced nationalism, making it harder to criticize governmental policies. In a meta-analysis of qualitative studies, Au (2007) found a prevailing occurrence of curricula narrowing due to emphasis on standardized testing in the wake of the 2001 No Child Left Behind Act. Also, the effects of today's American political culture are unknown. AntiMuslim rhetoric has been on the rise in the wake of terrorist-related mass shootings in both France and the United States (Beinart, 2015) and a new comprehensive federal educational law was enacted in December of 2015 that many predict will decentralize educational decision making (Turner, 2015).

In another study, Patterson et al. (2012) counters the claims that non-conservative conceptions and practices are the dominant approaches to citizenship education. The research team surveyed 155 social studies teachers in one Midwestern state. Using the framework provided by Westheimer and Kahne (2004), they discovered $62.8 \%$ of social studies teachers were categorized as personally responsible citizenship teachers. One-fourth $(25.2 \%)$ were categorized as participatory and only $3.8 \%$ were labeled as justice-oriented. These results show the dominance of conservative perspectives on citizenship education. However, two considerations must be stated. First, the results of the study by Patterson et al. (2012) represent only perspectives within one limited context. Second, researchers noticed a disconnection between what teachers say and what they do. Teachers articulated "university speak" about citizenship aims while the nuances of their responses suggested a different kind of citizenship 
than what scholars advocate (Patterson et al., 2012, p. 204). Future studies should uncover these nuances to better understand teachers' conceptualizations.

Some studies utilize qualitative methods to illuminate teachers' conceptualizations. Saada (2013) reports the experiences of social studies teachers dealing with competing citizenship identities and aims. The researcher conducted in-depth interviews with four social studies teachers in two Islamic schools about their perspectives on citizenship education and the dilemmas they face teaching for unity and diversity. Teachers reported a difficulty balancing education for Islamic and American identities. They felt contested between teaching the moral absolutism of Islam and moral pluralism of democracy. Tensions existed due to students' national and transnational identities. Findings suggest teachers' decisions about citizenship education are influenced by local and international sociopolitical factors. Further studies could reveal the extent that this is true for other contexts in America, such as rural communities, and how teachers negotiate such tensions.

Examining teacher preparation, Castro (2013) conducted a study on 15 pre-service teachers' views of ideal citizenship at one Midwestern university. Using semi-structured interviews and a card-sorting activity, the researcher found participants possessed conservativevalues-based or awareness-based definitions of citizenship, both orientations towards citizenship that lack social justice components. The researcher calls for teacher educators to work on fostering critical and multicultural awareness among pre-service teachers. This study raises questions for future researchers about the continuity between pre-service and in-service teaching, as well as the effectiveness of justice-oriented college coursework.

A recent study reports a majority of elementary pre-service teachers possess simplistic notions of good citizenship (Fry \& O’Brien, 2015). The researchers surveyed 846 pre-service 
elementary teachers across 20 states asking them to answer the open-ended question: "What is a good citizen?" (p. 411). They discovered the most common responses fit Westheimer and Kahne's (2004) personally responsible orientation to citizenship. Participants reported a good citizen should help others $(n=606,71.6 \%)$, follow rules/laws $(n=380,44.9 \%)$, and respect others $(n=242,28.6 \%)$. Only 49 participants $(5.8 \%)$ reported "standing up to injustice", only 34 (4\%) mentioned some aspect of thinking critically, and only 27 (3.2\%) addressed the causes of social issues (p. 416-417). A second phase of data collection included interview with 21 participants. Fourteen of the 21 teachers reported minimal support for and even resistance to a justice-oriented approach to citizenship. As to why a justice orientation is not more prevalent, the researchers theorize that teachers lack the necessary content knowledge to criticize social structures and an unwillingness to challenge school authority.

Likewise, another recent study suggests that the dominance of neoliberalism in the authority structure and culture of charter schools led to discrediting any citizenship orientations other than personally responsible (Sondel, 2015). One participant who fought against the culture of neoliberalism by attempting to teach justice-oriented citizenship approaches was terminated because she was no longer considered a "good fit" by administrators (p. 303). Both studies (Fry \& O’Brien, 2015; Sondel, 2015) display the potential for social contexts, particularly school culture and administrative authority, to influence gatekeeping on citizenship education.

\section{The Importance of Context}

Knowledge of social contexts is considered to be a critical component of effective teaching (Darling-Hammond, 2006). Teaching does not occur in a bubble detached from the outside world. Dewey (as cited in Thornton, 1989) denounced "an education that is conducted blindly under the control of customs and traditions that have not been examined or in response to 
immediate social pressures" (p. 4). Dewey’s focus on immediacy suggests support for the continual analysis and examination of social pressures on classroom practices. Yet, as shown above, few studies fully immerse into specific contexts to gauge their influence on the curriculum (Vinson, 1998) - and this is particularly true of rural contexts (Pattison-Meek, 2012).

The methodological limitations of past studies highlights a pressing need for new studies. Anderson et al. (1997) paid heed to contextual factors (i.e. region, size of town, political beliefs) in their survey research by denoting these factors' relationships to various conceptualizations of citizenship education; yet, the factors where pre-defined (not open to participant input) and the qualitative impact of factors remained uninvestigated. Elsewhere, studies delved deeper into social contexts (Fry \& O’Brien, 2015; Saada, 2013; Sondel, 2015); yet, produce knowledge only specific to a small subsection citizenship educators (e.g. Islamic schools, charter schools) or preservice teachers. It appears, as a whole, scholars have failed Dewey's call for analysis of immediate social pressures on classroom practices. The impact of contexts on citizenship education remains unknown in many distinct locales where teachers live and work, like rural communities; therefore, little is known about how teachers' gatekeeping is affected by these pressures and by perceptions of place. As mentioned above, this produces an impediment to connecting theory and practice (Thornton, 1989).

\section{Rural Contexts}

Use of the term rural is somewhat ambiguous across social science research (Brown \& Schafft, 2011). Brown and Schafft (2011) state that disagreements about the term are "between scholars who consider rural to be a type of socio-geographical locality and those who see rural as a social construct" (p. 4). As a socio-geographical locale rural is often defined by physical space, population size, and geographic characteristics; whereas, as a social construct rural is placed 
within the realm of the imagination (Halfacree, 2004), being seen as "a socially constructed state of mind" (Brown \& Schafft, 2011, p. 5). In this latter perspective, researchers look to the social, moral, and cultural values people use to think of themselves as rural (Cloke \& Milbourne, 1992).

Following cues from Brown and Schafft (2011), the current study treats "the two perspectives as complementary rather than competitive" (p. 5). For example, to provide a uniform standard from which to sample rural teachers requires geographical criteria based on population size and proximity to urbanized areas; however, once the researcher stepped into the research environment, rural was largely analyzed through a sociocultural lens, examining participants' values and their place-consciousness. This enabled rural to be understood "not only demographically and geographically, but culturally as well" (Donehower, Hogg, \& Shell, 2011, p. 10). The following subsections review literature to familiarize the reader with characteristics of rural places, helping to clarify common misconceptions.

\section{Diversity}

Despite public misconceptions, very little homogeneity exists between rural communities. DeYoung (1987) suggest this complexity is why some rural researchers advocate against overgeneralizing rurality and instead examine the more particularistic circumstances of rural communities. Inter-community diversity is seen by the various class and ethnic makeup of rural areas in the United States. Examples of rural ethnic diversity across regions in the United States, include white Appalachians, African-Americans in the Southeast, Hispanics in the Southwest, American Natives in the high plains regions, and Alaskan natives. Some rural areas are undergoing growth from immigrant populations (Brown \& Schafft, 2011). It is worth noting that rural areas see periodic net increases of in-migration from urban areas versus out-migration (Brown \& Schafft, 2011), but overtime out-migration to urban areas has outpaced in-migration. 
In 2010 , United States' rural population was $19.3 \%$, compared to $21 \%$ in 2000 and $24.8 \%$ in 1990 (U. S. Census Bureau, 1995, 2015). Out-migration from rural areas to urban areas, particularly of young adults, is often driven by social and economic deficits in rural communities (Brown \& Schafft, 2011); and has been a concern for rural sustainability (Carr \& Kefalas, 2009).

\section{Economics}

Economic life and class differences in rural communities also present a type of intercommunity diversity. As a whole, rural areas (17\%) have higher rates of poverty when compared to metro areas (14.6\%) (Kusmin, 2012) and traditional rural jobs in extractive and manufacturing sectors are declining (Brown \& Schafft, 2011). Yet, it is incorrect to assume that all rural areas experience similar economic plights at any given time. In the recent recession, beginning December of 2007, the most low-density rural counties suffered less unemployment decline (1.3\%) than medium- or high-density rural counties (5-6\%) (Hertz, Kusmin, Marre, \& Parker, 2014). Also, rural areas with the highest concentration of African Americans saw a more pronounced decline in employment (7.9\%) than rural counties that have no minority populations (4.1\%); and rural counties in the Great Plains regions fared better than other rural regions in the United States, in part because of their stable agricultural sector (Hertz et al., 2014).

The mobility of workers impacts socio-geographic understandings of rurality. As of 2007 , approximately $27 \%$ of rural workers held jobs in counties that differed from where they lived (Brown, 2008). When rural employment is scarce, commuting to work outside of one's rural community becomes commonplace (Mitchell, 2005). Some scholars suggest commuting from rural residences to urban places of employment may be a source of population retention and growth in rural areas (Partridge, Ali, \& Olfert, 2010). Cognizance of the bidirectional 
relationship and increasingly blurring lines between rural and urban communities is essential in $21^{\text {st }}$ century investigations of rurality (Lichter \& Brown, 2014).

\section{Politics}

The political beliefs and behaviors of rural communities have been explored by sociologists and political scientists (Brown \& Schafft, 2011; Gimpel \& Karnes, 2006; McKee, 2008; Walsh, 2012). Brown \& Schafft (2011) suggest that rural people are more socially conservative due to their decisive support for socially conservative candidates in many parts of the United States. Illuminating this, one study discovered that rural areas, both Northern and Southern, are increasingly voting for Republican candidates in elections (McKee, 2008). McKee (2008) suggests the closing of a Northern-Southern sectional cleavage in politics has "opened up a chasm between rural and urban voters" (p. 106). Mann (2006) proposes that a culture war exists between urban and rural people, with rural "homelanders" wanting to re-instill traditional values in America's national culture (p. 278). Though the nation is becoming more urbanistic and culturally diverse, Mann (2006) believes rural voters are a strong political force for traditional values in the $21^{\text {st }}$ century.

The geographic polarization of American politics may stem from people self-selecting where to live on the basis of economic and social criteria that are highly correlated with their political views (Bishop, 2008). Coinciding with this occurrence, the Republican Party's political platform has shifted since the early 1980s towards ideals that align well with rural places protestant religious values, gun rights, and desires for a smaller federal government (Starr, 2014). Yet, it is important to recognize that some rural counties still hold higher rates of Democratic Party membership, such as blue-dog (socially conservative) democrats in Appalachian counties and enclaves of ethnic minorities. Also, rural political diversity can be seen by voting margins 
between Democratic and Republican candidates in rural counties. In many locales, the losing Democratic candidate still carries a substantial amount of support, representing more diverse intra-community political ideologies than often assumed by outsiders (Bishop, 2015).

Rural people tend to vote at higher rates per capita than urban voters. However, from 2008 to 2012 , rural voting dropped by $18.3 \%$, more than double the national decline of $9 \%$ during the same time with much of the decline coming from Obama supporters (Bishop \& Gallardo, 2012). This drastic decline in voter turnout may represent increased feelings of disenfranchisement or marginalization by rural people or specific rural populations, but remains undiagnosed by researchers.

Rural community political marginalization is, however, a common theme in the literature. Scholars have critiqued society's political and economic structures as being devastating to rural ways of being (Theobald, 1997). Urban-located governments have failed to cater to the needs and desires of rural people (Walsh, 2012). Secretary of Agriculture, Tom Vilsack, acknowledged political marginalization when he said rural people are "becoming less and less relevant" in national politics (U. S. Department of Agriculture, 2012). Vilsack's words were prompted by the reoccurring farm bill's failure to pass in the House - a bill in place since 1933. Rural people report the belief that political elites located in urban areas misunderstand and misrepresent them (Walsh, 2012).

Studying rural communities in Wisconsin, Walsh (2012) found rural citizens believe their community deprivation is due to the decision making of urban political elites who disregard and disrespect rural residents and rural lifestyles. In the study, rural people tended to possess antigovernment or limited government sentiments and maintained a belief in an American work ethic. Walsh (2012) speculates that anti-government views may be at odds with rural people's 
economic self-interests. For example, poor rural citizens are unlikely to support increases in taxes on the wealthy because they perceive this government action as antithetical to supporting the American work ethic (Walsh, 2012). Place-consciousness led to a rural political climate of low efficacy and distrust of governments.

\section{Social and Cultural Values}

Brown and Schafft (2011) suggest the sociocultural distinctions of rural communities may be the least reliable measurement of rurality, though they concede some distinctions between urban and rural values are supported through empirical analysis, such as social conservatism. While questions are raised about the cultural distinctions of rurality (Brown \& Schafft, 2011; Woods, 2009), many researchers work under the assumption that rural people live in spaces that produce place-consciousness, place-based identities, and socially constructed understandings of rurality (see Azano, 2011; Gilbert \& Yerrick, 2001; Halfacree, 2006; Schafft \& Youngblood Jackson, 2010). This section explores this vein of research to expose rurality as a sociocultural construct and provide background knowledge on how rural values and placeconsciousness may impact citizenship curricula.

First, the concept of community is often tied to rural places (Brown \& Schafft, 2011; Theobald, 1997). Wilkinson (1991) defined community as "a natural disposition among people who interact with one another on various matters that compromise a common life" (p. 17). As part of a community, people share a sense of belonging and commitment to a shared culture, including values, norms, and meanings; and "as a result, community has moral authority" (Brown \& Schafft, 2011, p. 35). Yet, not all communities behave with the same degree of identity, moral authority, and collective organization (Brown \& Schafft, 2011). Community may act as an ideal, more than a reality (Brown \& Schafft, 2011). Yet, as a mentally construed ideal, 
social constructionist theory suggest it can behave as a determinant to the ways people act in their environment (Berger \& Luckmann, 1966).

Wilkinson's (1991) definition of community recognizes that small, remote populations in rural areas likely foster "natural dispositions" towards their common life. In small localized networks, familiarity is part of most social interactions. Relationships develop temporally, intertwining individuals and families over multiple generations. Churches and schools act as institutions that foster a common life, offering a shared space for rural citizens that enable the formation of a collective identity and connection to place. However, social identity theory suggest that the formation of group identities may also foster an "us" versus "them" attitude towards outsiders (Hogg, 2006), a potentially anti-democratic force.

Rural community is linked to place-consciousness, a recognition of the interdependence of people with one another and with the land (Theobald, 1997). This milieu of interdependence, between the cultural, social, and natural, constructs particular beliefs and sentiments about rural life (Brown \& Schafft, 2011). Yet, rural place-consciousness is often subordinated by urban commercial interests (Theobald, 1997; Walsh, 2012). Rural people are frequently stereotyped, ridiculed, and marginalized in mainstream American society (Theobald \& Wood, 2010). This type of rural marginalization can have an adverse impact on democracy. For example, research shows many rural citizens hold low levels of political efficacy (Lay, 2006) and, as stated above, distrust governments located in urban areas (Walsh, 2012). Theobald (1997) suggests denigration of rural areas, coupled with a rising societal emphasis on "the self," has devastated a sense of community in the United States and threatens democracy (p. 120).

Research shows rural residents have community-based orientations to life that differ than urban residents. Rural people possess a willingness to volunteer and feelings of civic duty at 
higher rates than in non-rural locales (Gimpel \& Karnes, 2006). Also, rural areas have higher per capita military enlistments than other locales (Kane, 2005). Related to education, research shows that students who do not aspire to college are much more likely to enlist in the military, as are students from a lower socioeconomic status (Kleykamp, 2006). These findings coincide with findings from rural education research where lowered educational aspirations are more common among rural, than non-rural students (Hektner, 1994). Citizenship educators in rural areas should think critically about the interactive system of beliefs and economics that stimulate students' post-secondary goals.

Individualism acts as another strong rural ideal (Dudley, 1996; Gimpel \& Karnes, 2006). Individualism is a belief in self-reliance and freedom of action - traits that benefit remote, agrarian lifestyles. However, some scholars warn against hyper-individualism in society as it leads to a decline in social engagement or a loss of concern for others (Hoyle \& Slater, 2001). Hyper-individualism should alarm proponents of democracy as it may represent a devaluing of public spaces and the power of the collective to initiate societal change. On the other hand, while rural individualism appears to subvert communitarianism, Dudley (1996) reconciled these ideals after observing a rural community in Minnesota in an ethnographic study. The researcher concluded that "individualism... is not antithetical to community, but often constitutive of it" (p. 56); meaning rural communities are built around their shared belief in individualism. This raises concerns about the impact of the individualist community perspective on teachers' decisions about citizenship curricula, particularly their emphasis on collective actions and social responsibility - something Theobald (1997) raises concerns about as well.

Some scholars theorize that hard divisions between rural and urban are problematic in research because social space is changing rapidly with rural-urban boundaries blurring (Lichter 
\& Brown, 2011); yet, Lichter and Brown (2011) concede that "rural areas and small towns often remain misunderstood and are too frequently ignored, overlooked, or reduced to stereotypes in the public and scholarly discourse" (p. 566). This suggests a power discrepancy that favors urban over rural places. The bidirectional and uneven relationship between urban and rural is an aspect of citizenship education that needs to be better understood to foster political equality across locales of varying density and development.

\section{Rural Education}

Rural schools make up 32.9\% of all United States public schools (Johnson, Showalter, Klein, \& Lester, 2014). Because of the unique contexts of rural communities, schools embedded in such areas face different challenges than their urban and suburban counterparts. Herzog and Pittman (1995) detail common rural educational challenges, citing poverty, remoteness, lack of economic diversity, and lack of access to high quality teachers. These challenges tend to marginalize rural students by denying them educational opportunities more readily available to non-rural students. While recent data show urban districts contain higher levels of dropout rates than rural districts, both fall behind their suburban counterparts (National Center for Education Statistics [NCES], 2007). Compounding problems, rural education receives substantially less attention from policymakers and researchers than non-rural education (Sherwood, 2001) and rural-specific educational problems remain largely misunderstood and ignored by mainstream educational research circles (Burton et al, 2013). This dearth of attention on rural educational research further facilitates a lack of investments in rural communities.

Economic deficiencies and the resulting out-migration to urban area has been shown to adversely affect rural students and threatens community sustainability (Bouck, 2004; Theobald, 1997). For example, growing poverty and a sparse population create less funding for educational 
resources and fewer course offerings. In turn, rural students experience diminished educational opportunities (Bouck, 2004). Bouck (2004) presents an analysis on the effects of the rural contexts of education and confirms rural schools have less technology, fewer course offerings, and lower quality teaching. Other research shows that lower quality teaching often stems from teacher recruitment and retention issues (Burton et al., 2013). Also, the National Education Association (n.d.) reports rural schools receive less federal funding than other schools. Perhaps the most damaging effect of low funding and a declining population are decisions to implement school closures and consolidations (Purcel \& Shackelford, 2005). School closures remove community institutions that would otherwise act as shared public spaces and contributors to a collective identity. Closing small schools eliminates what is often the only public institution in rural towns, an institution that connects multiple generations. As it stands, the impact of rural education challenges (i.e. school closures, fewer course offerings, or teacher shortages) on citizenship preparedness is unknown.

In addition to the effects of systemic challenges, rural teachers may confront cultural clashes between educational aims and community expectations. Analyzing data from 918 high school students in the Midwest, Hektner (1994) found more rural than non-rural adolescents perceived a conflict between staying close to relatives and moving away from their communities. This conflict caused rural youths, particularly males, to lower their educational aspirations and feel anger about their futures. Corbett (2007) performed an ethnographic study of a rural coastal community in Nova Scotia and also found conflicts existed between local cultural codes and formal schooling. Rural students associated success in school and college attendance with separation from family. Woodrum (2004) suggests differences exist between middle class and working class rural students concerning their allegiance to place and community. The 
intersection of rural place and citizenship is unexamined, but differing perceptions of place may alter teachers' presumptions about the citizenship aims of their curriculum.

Other research specific to social studies education suggests that civic pluralism may be a difficult subject to broach in rural classrooms. It appears that rural insularity adversely affects discussions involving race and culture in social studies classes (Lee, 2006; Washington \& Humphries, 2011). Washington and Humphries (2011) describe the existence of overt racism in one rural classroom during student discussions of slavery and Lee (2006) found rural students displayed othering, or measuring global cultures based on United States culture, when participating in an international educational program. Though not generalizable to all rural environments or all rural students, these cases call attention to the disconnection some rural students have with people and cultures that differ from their own. These studies suggest the need for further examinations of rural social studies education to identify and understand the effects of insularity on citizenship education.

\section{Experiences of Rural Teachers}

Rural teaching is different than urban or suburban teaching (Burton et al., 2013). Utilizing a meta-analysis, one study examined how rural teachers were portrayed in published research articles over a 40 year span from 1970-2010 (Burton et al., 2013). The researchers found four distinct storylines present in the literature: (a) rural teachers are professionally isolated; (b) rural teachers are different from urban and/or suburban teachers; (c) rural teachers are often lacking in professional knowledge/teaching credentials; and (d) rural teachers are particularly resistant to change. The authors raise the point that the storylines may "speak to the pressing need for researchers to become reflective and critical of the ways in which their work implicitly and explicitly is a product of and helps to recreate these storylines" (p. 10). The 
current study hopes to authenticate rural teacher experiences by positioning their voices at the forefront of the evidence, revealing the realities and potential nuances of isolation, professional knowledge, and resistance to change.

Particularly relevant, Burton et al. (2013) found that rural teachers often identified with their community, including its insularity. Teachers unwilling to change were considered as "insiders" while teachers that promoted change were viewed as "outsiders" (Burton et al., 2013). Rural teacher bifurcations within schools can create tensions over curriculum and pedagogy decisions. Since prior research shows that multiple conceptualizations of citizenship education exist (Westheimer \& Kahne, 2004) and school culture influences teachers' decisions about the curriculum (Sondel, 2015), rural teacher schisms hold potential to impact classroom occurrences of gatekeeping for citizenship education.

Problematizing rural community-school relations, other research suggests the existence of bifurcations between rural teachers and community members during labor-related political disputes (McHenry-Sorber, 2014). A teacher strike in rural Pennsylvania led to the district's whole teacher corps being labeled as outsiders by community members (McHenry-Sorber, 2014). The teachers, even long-term residents, faced attacks, ridicule, and negative media attention because of their desire for higher benefits and pay. This study demonstrates that rural places are not ideologically homogeneous communities, but instead fragment along class lines and group identities. This is a crucial understanding for prospective rural teachers as they will likely navigate competing community ideologies influenced by class and group identities.

Lastly, smallness of scale heightens rural ideological divides. Smaller school and community size means teachers' personal lives become publicly known because of their increased visibility outside of school (Seifert \& Simone, 1980). Professional autonomy within 
the classroom may be jeopardized through increased interaction with parents and community members. Citizenship educators are particularly susceptible to challenges to autonomy due to their politically-charged and value-infused curricula. Learning from rural teachers about their navigation of curricula in light of community expectations becomes critical. If not considered by prospective rural teachers, future confrontations between competing rural ideologies may result in personal and professional problems for teachers.

\section{The Issue of Rural Justice}

Before examining the convergence of rural education and citizenship education in existing studies, the concept of rural justice should be examined as it relates to this study. Prior literature suggests rural areas in the United States are often more economically distressed than urban areas, contain diverse minority populations (including Appalachian whites), and are culturally marginalized and stereotyped by mainstream society; hence, the case can be made to address rural citizenship education as a social justice issue. Social justice is about ensuring equal access to liberties, rights, and opportunities, and taking care of the least advantaged members of society (Rawls, 1971). Rural poverty, remoteness, lack of equity in education, and negative perceptions place rural citizens at a disadvantage (Herzog \& Pittman, 1995). Additionally, rural citizens report feeling misrepresented or ignored in political and economic decision making (Walsh, 2012), depriving them of effective participation in government and signifying the need for politically equality.

While social justice is often framed by deficiencies of economic capital, Roberts and Greene (2013) recommend broadening social justice discourses to include spatial understandings. In this way, advocates can reframe rural justice by accepting the subjectivities and particularities of rural spaces, instead of using urban lenses to judge rural lives. Roberts and 
Greene (2013) want people to overcome geographical blindness when advocating for rural concerns.

To empower the silenced voices of rural people, this study adopts a justice-orientation. It seeks to learn the subjectivities and particularities of citizenship education from the experiences of rural teachers themselves with cognizance of forces that oppress or discredit rural people, such as the "demonization" of rural life and people in history textbooks (Howley, Howley, \& Eppley, 2013, p. 189). Applying the lens of rural justice is accomplished by elevating teachers' perceptions and the experience of working and living in specific rural communities. Understanding connections between place and the citizenship curriculum informs teacher educators so they can better prepare pre-service teachers to combat the realities of rural marginalization and foster appropriate citizenship knowledge, skills, and dispositions in their students, ultimately improving rural democratic life from within.

\section{Citizenship Education in Rural Contexts}

Theobald (1997) suggests "rural teachers are, or ought to be, the stewards of the intellectual life in their communities" (p. 114). Citizenship educators should be prepared with knowledge on how rural-specific characteristics can influence gatekeeping. Citizenship educators hold the capacity to empower rural students to address concerns germane to their communities, tapping into their place-consciousness, while simultaneously preparing them for broader involvement with political life. This broader consideration is due to the trend of young adults moving out of rural areas after high school (Brown \& Schafft, 2011). While rural community sustainability is threatened by the rural brain drain, or out-migration of high achieving young people (Carr \& Kefalas, 2009), citizenship education offers students the skills to think critically 
about their commitments to community and civic life and the relationship between rural and nonrural places.

This section reviews all of the literature that could be found on citizenship education in rural contexts. There have been very few studies of this phenomenon; therefore, very little ruralspecific knowledge on citizenship education exists. Most knowledge of the phenomenon comes through national surveys or testing data that designate "rural" or "small towns" as one of many categories (see Anderson et al., 1997; Easton, 1985) or from studies that use convenience sampling of rural schools (see Washington \& Humphries, 2011). There are no qualitative studies of teachers' conceptualizations of citizenship education in rural areas, though calls exist to understand contextual factors in this vein of research (Vinson, 1998; Pattison-Meek, 2012). Only one study purposely samples rural students to learn explicitly about their views of citizenship (see Martin \& Chiodo, 2007). This study intends to help fill the rural-deficit in citizenship education research.

National assessments on civic knowledge (Easton, 1985) and surveys on the purposes of social studies (Anderson et al., 1997) suggest traditionalist approaches to citizenship education are common practice in rural locales. Anderson et al. (1997) report small town teachers, though not teachers in rural farming areas, are more likely to teach citizenship as assimilation then compared to teachers in other locales. Assimilation is defined as a conservative approach to citizenship education that encourages a sense of patriotism, loyalty, and civic duty, as well as the transmission of dominant American social values (p. 348). Teachers who identified highly with the assimilation perspective were more likely to hold conservative political views, possess negative views of the national government, be resistant to multicultural education, and be members of the Republican Party. Though only $16 \%$ of small town teachers strongly identified 
with the assimilation approach, it was double the national total (8\%) and four times the rate of suburban teachers $(4 \%)$. Also of interest, $10 \%$ of urban teachers identified with assimilation (p.353).

Journell's study on governmentality (i.e. the way the state exercises control of the populace) in political education may illuminate this discrepancy. Journell (2011) found high school government teachers often reflect the citizenship expectations of the communities in which they are embedded. Some students experience citizenship pedagogies that are limited by the teachers' emphasis on students' anticipated adult roles instead of empowering students through broader ideas about democracy and citizenship. Since local sociopolitical factors influence teachers' views and practices of citizenship (Saada, 2013), it is likely rural teachers' perceptions of their communities' values influence their instruction for citizenship, though this speculation has yet to be verified by research.

In the only study that explicitly examines rural students' views, Martin and Chiodo (2007) found rural students believe good citizenship is grounded in community service, not political engagement. While the authors are optimistic that rural students' conceptualizations of citizenship were age appropriate ( $8^{\text {th }}$ and $11^{\text {th }}$ grade students), this study suggests rural teachers are teaching for personally responsible citizenship (Westheimer \& Kahne, 2004) and not more progressive or critical notions of citizenship. Citizenship education scholars are critical of emphasizing individual acts of service because they fail to teach group deliberations and criticisms of the social structures that produce inequities (Westheimer \& Kahne, 2004).

Easton (1985) aggregated data from national assessments of civic knowledge, suggesting that rural areas differ from one another across the United States. Easton reports that rural students receive inferior social studies instruction when compared to their non-rural counterparts, 
but studies of specific rural areas (often designated by state) show superior performance when compared with national rural averages. These findings suggest the heterogeneity of rural schools. The researcher did not diagnose specific teaching methods or teachers' conceptualizations from either high achieving or low achieving rural areas. The report focused on data from standardized tests; therefore, it provides no empirical knowledge on classroom practices and does not report on citizenship skills or dispositions. Findings rely on positivist research methodologies and traditionalist orientations to citizenship.

Two other quantitative studies suggest positive occurrences of citizenship education in rural contexts. Lay (2006) compared urban and rural youth, finding that close social networks in rural areas offered opportunities for political discussions and the development of political knowledge. Also, Lay (2006) states that African-Americans and poor students in rural areas displayed significantly greater political knowledge than their urban counterparts. Likewise, Conover and Searing (2000) report that $68 \%$ of rural students experience political discussions in school versus $24 \%$ in urban and 50\% in suburban classrooms. However, Pattison-Meek (2012) suggests their findings may obfuscate the reality of rural citizenship learning. Citing work by Hess and Ganzler (2007) and Richardson (2006), Pattison-Meek (2012) points out that students and researchers often mistake political discussions with classroom talk and confuse current events with controversial issues. Conflations such as these suggest rural citizenship education may be less optimistic than its surface appearance.

Raising additional concerns, researchers indicate that teachers' assumptions about rural students can adversely impact citizenship education. If teachers perceive rural students as homogeneous, it can present problems in cultivating political discussions (Pattison-Meek, 2012); and students' rural-specific knowledge and values may counter teachers' presumptions of what is 
controversial (Washington \& Humphries, 2011). To foster beneficial forms of rural citizenship instruction, Pattison-Meek (2012) recommends within-community differences and disagreements must be skillfully "activated" by rural teachers (p. 608). However, since quantitative studies narrowly treat the phenomenon, Pattison-Meek (2012) calls for more qualitative studies to illuminate rural occurrences of citizenship. Likewise, Avery (2007) acknowledges that rural communities are studied less than urban and suburban settings in regards to civic education and engagement, suggesting the need for more rural-specific studies.

\section{Rationale for a Qualitative Study}

The above literature points to several reasons to undertake a qualitative investigation of citizenship education in rural contexts. Many scholars suggest that school and community values influence teachers' decisions about the curriculum (Romanowski, 1996; Saada, 2013; Shaver et al., 1980; Sondel, 2015); yet, no research exists that examines the influence of rural contexts on gatekeeping. Qualitative methods enable researchers to focus on a "phenomenon embedded in its context" (Miles, Huberman, \& Saldaña, 2014, p. 11). They allow the researcher to examine the particular conditions of a setting and participant experiences within the setting (Glasser \& Strauss, 2009). Applied to the phenomenon of gatekeeping, this enables perceptions of school and community factors to be illuminated. Miles et al. (2014) write that "the influences of the local context are not stripped away but are taken into account. The possibility for understanding latent, underlying, or nonobvious issues is strong" (p. 11).

Past research shows that teachers are unaware of their own frames of reference and conceptualizations (Cornett, 1990; Evans, 1990; Fickel, 2000). Examining teachers' latent conceptualizations reveal underpinnings of the citizenship curricula that would otherwise go unnoticed in curriculum studies. Qualitative methods reveal context-specific conditions and 
participant's responses to those conditions (Glasser \& Strauss, 2009), hence, they provide the best possibility to understand relationships between conditions, conceptualizations, and the curriculum.

In addition to examining interrelated components within a setting, knowledge gaps in citizenship education offer support for this study. Contradictory findings exist between studies on conceptualizations of citizenship education (Anderson et al., 1997; Patterson et al., 2012; Vinson, 1998); and inconsistencies may exist between conceptualizations and classroom practices (Kahne et al., 2000; Torney-Purta, 2002). Furthermore, due to rural heterogeneity, some researchers question the effectiveness of large-scale surveys like the one undertaken by Anderson et al. (1997) because they "have little utility for addressing and solving most of the diffuse and particularistic community-based needs" (DeYoung, 1987, p. 142). Quantitative research methods often group rural areas based on a bureaucratically suitable criterion, such as population size; yet, rurality is complex and differs across regions and communities (Brown \& Schafft, 2011). Instead, qualitative research methods borrowed from anthropology offer the possibility to understand the nuances of rural life by providing "thick descriptions" of the environment (see Geertz, 1973, p. 214). This ensures rural communities are not misrepresented or misunderstood by scholars and policymakers. Qualitative studies can illuminate the ways teacher navigate pressures on their curriculum and expose the source of contradictions between theory and practice.

The nation's sociopolitical situation has changed in the wake of $21^{\text {st }}$ century events like terrorist attacks (Apple, 2002) and federal education legislation (Au, 2007). Evans (2004) suggests that the national and international political climate influence the social studies curriculum in material ways through changes in standards and textbook content. Saada (2013) 
demonstrates that sociopolitical factors affect teachers' perceptions, causing possible tensions between competing values and citizenship identities. New research is needed to gauge the extent that national and international factors permeate other local classrooms and influence gatekeeping, specifically in geographically remote areas.

Patterson et al. (2012) note that teachers use "university speak" when discussing the aims of citizenship (p. 204). If teachers know the language but do not execute their conceptions, qualitative studies can provide deeper insight into teachers' knowledge, motives, and actions in the classroom. Naturalistic data collection can reveal nuanced beliefs about citizenship education and the factors that teachers respond to when teaching within their lived contexts.

One of the most compelling reasons for the study of rural-specific context lies in the anticipated conceptual tensions between socially conservative rural communities and the unsettled aims of the social studies curriculum. While qualitative researchers should not bound their conceptual focus too tight prior to executing the study (aka putting the cart before the horse), Miles et al. (2014) suggest it is "self-defeating" if researchers do not use their background knowledge as a "conceptual strength" (p. 20). The authors suggest researchers "know some of the questions to ask, which incidents to attend to closely, and how (our) theoretical interests are embodied in the field (p. 20). Several prior studies suggest socially conservative communities influence gatekeeping (Garcia, 1991; Rapoport, 2009; Romanowski, 1996; Shaver et al., 1980); therefore, a qualitative research design is relevant for examining gatekeeping processes related to rural citizenship education.

Finally, the issue of rural justice supports the use of qualitative methods. Studying particular practices of rural social studies teachers validates their experiences and fosters improved understandings of rural places. This type of authentic knowledge can help others 
overcome geographic blindness that adversely affects rural populations. Consciousness of rural justice seeks to promote the relevancy of place, de-marginalize rural people, and think critically about civic life and community (see Theobald, 1997). Since prospective rural teachers should be made school and community ready (White \& Kline, 2012), qualitative studies of rural contexts produce requisite knowledge for just and purposeful teacher preparation.

The next chapter describes in-depth the research design and methods used to investigate citizenship education in rural contexts. It orientates the reader to the study's epistemological stance, and discusses issues of trustworthiness, research ethics, and the study's methodological limitations. 


\section{CHAPTER III}

\section{METHODS}

This chapter reports the study's qualitative research methods. Methods were chosen to best answer the research questions, thereby, producing knowledge to help fill the gap in rural citizenship education. This study followed a developing line of inquiries into teachers' conceptualizations of citizenship education (see Anderson et al., 1997; Fry \& O'Brien, 2015; Patterson et al., 2012; Saada, 2013; Sondel, 2015; Vinson, 1998), none of which examined citizenship education within rural settings. This rural deficit means the field of citizenship education knows little about the curricular goals or instructional practices that affect the learning of just over a fifth of United States students (Johnson, Showalter, Klein, \& Lester, 2014). This study was designed to address this deficit by examining rural teachers' conceptualizations of citizenship education, perceptions of place, and the influences on their curricular-instructional gatekeeping.

\section{Research Questions}

While noted in chapter one, restating the research questions here refocuses the reader's attention on the aims of the study. The following research questions guided the examination of rural citizenship education:

1. How do government teachers in rural schools conceptualize citizenship education?

2. How do teachers' perceptions of place impact citizenship education in rural contexts?

3. How is curricular-instructional gatekeeping in citizenship education impacted by rural contexts? 


\section{Research Design}

Since the influence of rural contexts on citizenship education is unknown, this study implemented a grounded theory research design. Grounded theory research is appropriate for unknown contexts because it can "uncover relevant conditions... [and] determine how the actors under investigation actively respond to those conditions, and to the consequences of their actions" (Corbin \& Strauss, 1990, p. 419). A grounded theory design requires attention be placed on the research environment and participants' experiences living and working in those environments. While not a strictly an ethnographic study, this study borrowed the type of naturalistic data collection common to ethnography, where data is collected to seek a "deeper immersion in others' worlds in order to grasp what they experience as meaningful and important" (Emerson, Fretz, \& Shaw, 2011, p. 3).

In this study, a grounded theory design enabled organic descriptions citizenship education in rural places and the contextual factors that influence the curriculum. Through immersion into the research setting, the researcher saw "firsthand and up close how people grapple with uncertainty and ambiguity, how meanings emerge through talk and collective action, how understandings and interpretations change over time, and how these changes shape subsequent actions" (Emerson et al., 2011, p. 5). Close contact with participants produced large quantities of data that offered the possibility for inductive data analysis. Inductive data analysis can be utilized with a particular data set to create a plausible theory about the phenomenon, building knowledge from the ground up. To build theory inductively, grounded research "uses a series of cumulative coding cycles and reflective analytic memoing to develop major categories for theory generation" (Miles et al., 2014, p. 8). In this way, perspectives on rural citizenship education emerged directly from participants' words and actions, which were embedded in their lived 
contexts, instead of imposing prescriptive theoretical categories that might misrepresent or misunderstand the phenomenon.

\section{Epistemological Stance}

Crotty (2003) suggests researchers should share their epistemological stance to describe their way of looking at the world and how they make sense of it. This study was rooted in social constructionism. Social constructionism is a sociological theory of knowledge where "everyday life presents itself as reality interpreted by men and subjectively meaningful to them as a coherent world" (Berger \& Luckmann, 1966, p. 20). In other words, social constructionism focuses on people's constructions of reality, the meanings they attach to the objective world, formed through interaction with others and the environment and "transmitted within an essentially social context" (Crotty, 2003, p. 42). Social constructionism suggests knowledge of the objective world can only be understood through people's socially-influenced assemblages of reality. Moreover, the variety of viewpoints and priorities of individuals within a given setting signify that multiple truths exist (Emerson, et al., 2011).

In this study, rural teachers' conceptualizations and gatekeeping processes situated teachers' interactions with people and places, and their ability to foster meanings, values, and knowledge in the teachers, as the sole constitution of human understanding about their world. Simply put, learning about the rural world occurred by learning people's mental constructions of it. The study's social constructionist lens recognized that knowledge was not absolute, but instead subjective and mutable, crafted temporally and spatially. The concept of citizenship education, as understood by teachers, was formed through the language people used and the meanings people attached to relevant objects, processes, and words, occurring within the rural 
cultural context. These meanings were context-bound, value-laden, unfixed, and subjective much like social life itself.

The key importance of adopting the social constructionist framework for this study was that it sought to examine teachers' conceptualizations and their perceptions of their rural community. These mental recognitions acted as participants' understandings of rural realities and directed their actions within their social contexts. This study did not attempt to identify the objective existence of the rural community (though it utilized geographical data to complement contextual knowledge), but instead came to understand how community was imagined through the social, moral, and cultural values that people used to think of themselves as rural (Cloke \& Milbourne, 1992). Through social constructionism, this realm of imagined life, made through interactions, constituted knowledge about rural places.

Social constructions of reality are complicated by power structures between people, groups, and institutions that interact to position certain knowledge as more valid than others (Apple, 1996). This is particularly true in ethnically and socially heterogeneous places where some groups possess unequal amounts of resources, unequal access to and control of information, and are supported by historically-entrenched power structures. Apple (1996) writes: Thus, whether we like it or not, differential power intrudes into the very heart of curriculum, teaching, and evaluation. What counts as knowledge, the ways in which it is organized, who is empowered to teach it, what counts as an appropriate display of having learned it, and - just as critically_-who is allowed to ask and answer all these questions, are part and parcel of how dominance and subordination are reproduced and altered in this society. (pp. 22-23) 
Rural communities are not immune to the effects of power structures and cultural hegemony, both internal and external, which may marginalize the community as a whole or minimize the importance of the life experiences of certain groups within the community. Rural places share an unequal, fluctuating relationship with urban places (Lichter \& Brown, 2014), are ethnically diverse across various regions (Brown \& Schafft, 2011) and, at times, are internally bifurcated by class and group identities (McHenry-Sorber, 2014).

A neo-Marxist critique of power in education suggests the curriculum found through national/state standards, standardized tests, and textbooks, represent the "politics of official knowledge" (Apple, 1996, p. 23); or, in other words, decisions about whose knowledge is legitimated and whose knowledge is marginalized. Despite this, teachers have the decisionmaking power as curricular-instructional gatekeepers over what knowledge is validated in their classroom (Thornton, 1989; 2005). Teachers' decisions are made with cognizance of other educational stakeholders' desires (Romanowski, 1996; Shaver et al., 1980), the sociopolitical culture (Saada, 2013), and the school authority structure (Sondel, 2015). For these reason, this study was concerned with rural teachers' perspectives and how they negotiated curricula, or made decisions about whose knowledge and values were included or excluded, and why worth was placed in that knowledge.

\section{Researcher Bias}

The design of this study facilitated close interactions between participants, the rural environment, and the researcher to help establish deep understandings of the phenomenon and explore its nuances. The questions driving this study dictated a focus on knowledge embedded in social contexts, instead of knowledge that stemmed from remote data collections. Knowledge in this study was dialogically produced between the parties involved during the qualitative research 
experience. Stepping into the research environment enabled the coalescence of perspectives and the ability for holistic understandings of the phenomenon to emerge. However, this closeness required the researcher to acknowledge potential bias that could influence participant behaviors and the researchers' interpretations.

The reader is reminded to see chapter one for a full disclosure of researcher positionality; however, potential methodological biases are discussed here. Qualitative studies demand close encounters with the population under study and may create an opportunity for the researcher to "go native" or desire to protect the population under scrutiny (Miles et al., 2014). An associated concern is that the researcher may miss outside influences on the phenomenon due to his or her immersion within the community. Also, the researcher's preconceived notions can produce misrepresentations of the data in the form of confirmation biases.

While it has already been stated that the researcher was well aware of his role as a "human instrument" (Merriam, 2002, p. 5), ethnographers offer additional advice to ensure field work reveals indigenous meanings. Emerson et al. (2011) suggest researchers "must learn to recognize and limit reliance upon preconceptions about members' lives and activities” (p. 16). A sensitive ethnographer privileges "insider" descriptions and categories over "outsider" views (p. 29).

Emerson et al. (2011) raise concerns that the presence of the researcher within the research setting produces reactive effects, or influences how people talk and behave while being observed (Emerson et al., 2011, p. 4). However, the authors state that "relationships between the field researcher and people in the setting do not so much disrupt or alter ongoing patterns of social interaction as they reveal the terms and bases on which people form social ties in the first place" (p. 4). Rather than attempting to control or eliminate reactive effects, the researcher 
should become sensitive and perceptive to how he or she is being seen and treated by others (Emerson, et al., 2011). In this study, the developing relationship between the researcher and participants was a point of focus due to its potential to reveal patterns of social interaction within rural communities.

\section{Participants and Sampling Procedures}

This study sampled five government teachers in rural schools. Five participants provided the convergence of multiple perspectives during data analysis and, therefore, strengthened the inductive theoretical statement. Participants were purposively selected to ensure they fit the community that best represents the phenomenon of rural citizenship education. In this study, participants fit the following three criteria:

1. They were high school teachers (grades 9-12).

2. They taught courses in civics and/or government.

3. They worked in schools designated as rural by the National Center for Educational Statistics [NCES] (2007).

These criteria ensured the sample of participants represented the desired population. While research suggests social studies teachers possess one dominant conception of citizenship education regardless of their specific areas of instruction (Brubaker, 1977; Patterson et al., 2012; Westheimer \& Kahne, 2004), the concept of citizenship was specifically included in the state standards for high school government courses in this study; therefore, only social studies teachers who instructed government courses were selected. This criterion ensured that citizenship was part of teachers' pre-established curricular aims and was likely addressed through their classroom instruction. Lastly, the designation of a bureaucratically-defined rural school ensured 
consistency in the sample of rural contexts. The next section describes in depth the rural sampling criterion.

Gaining access to the five participants was accomplished by identifying rural schools within close proximity to the researcher's location, contacting school and/or county administrators, and asking for recommendations of government teachers that may be interested in participation. Participants were contacted via email and/or phone and provided a cover letter describing the research study and detailing the IRB requirements (see Appendix B). Once a teacher agreed to participate and administrative approval was granted, the first interview was scheduled.

\section{Classifying Rural}

This study adopted the NCES (2007) urban-centric classification system to provide a consistent rural sample. The NCES urban-centric classification system denotes four major locales from which all of the nations' schools are identified: city, suburb, town, and rural. Each of the four major locales contains three subcategories based on population size and distance from urbanized areas, hence the "urban-centric" name. This study is concerned with the classification of rural schools, so the subcategories for city, suburb, and town will not be reviewed here. Each possible research location was searched using the NCES online database to identify the school's official classification and ensure no city, suburb, or town schools are present in the sample.

The NCES rural classification contains three subcategories: fringe, distant, and remote. Fringe rural territories are less than or equal to 5 miles from an urbanized area $(50,000$ or more residents) or 2.5 miles from an urbanized cluster (25,000 to 50,000 residents). Distant rural territories are 5 to 25 miles from an urbanized area or 2.5 to 10 miles from an urbanized cluster. 
Remote rural territories are located at least 25 miles from an urbanized area and at least 10 miles from an urbanized cluster.

The selection of the rural sample was contingent on the schools' proximity to the researcher and teachers' willingness to participate in the study. The researcher attempted to include two "remote rural" schools, but the government teacher from each of these schools did not agree to participate. All five teachers that eventually agreed to participant worked in schools designated as "distant rural." This provides one bureaucratically consistent designation across research settings.

As stated in chapter two, readers should recognize that rurality is a social construction and not just a delineated category based on population size or proximity to urbanized areas. Each rural school and community differed in their values, customs, and sentiments, as well as in their ethnic makeup, socioeconomic levels, and population size. Once sampled by geographic criterion, data collection and analysis focused on the capacity for localized differences in the social constructions of rurality to influence results. For this reason, the study reported participants' perceptions of their unique rural school and community experiences, in addition to demographic and geographic descriptions, ensuring an authenticity of results - something recommended by rural researchers (Donehower et al., 2011).

\section{Data Collection}

Data were drawn from three sources: interviews, classroom observations, and artifacts. The convergence of three data sources helped to triangulate findings. Triangulation is the process of supporting a study's findings by "showing that at least three independent measures" agree or do not contradict (Miles et al., 2014, p. 299), though, contradictions that arise during 
triangulation may help to reveal nuances about a phenomenon that were not yet known (Tracy, 2010). Furthermore, a corroboration of sources enhances the trustworthiness of data analysis.

\section{Interviews}

Interviews acted as the main source of data collection for this study. Multiple interviews occurred throughout the research process, including an initial semi-structured interview, informal post-observation interviews, and a culminating interview. Interviews allowed for the coconstructions of knowledge between the researcher and participants rather than on locating meanings and narratives solely in one or the other. In this way, interviews were "intersubjective and social" (Kvale \& Brinkmann, 2009, p. 18).

First, after agreeing to participate, each teacher sat for an individual interview lasting approximately an hour. This first interview was semi-structured in its design. A protocol, or script, was used loosely by the researcher to guide the interview (see Appendix A). The interview script contained topics and suggested questions that aimed to examine participants' conceptualizations of citizenship education and uncover their perceptions of rural influences on gatekeeping. Interview questions were adapted from past studies of teachers' citizenship conceptualizations (Castro, 2013; Saada, 2013) and on emergent themes from the aggregated body of literature. However, the semi-structured nature of the interview enabled the researcher's "judgement or tact" to be used to decide how strictly to stick to the script and "how much to follow up the interviewee's answers" and new directions that arose (Kvale \& Brinkmann, 2009, p. 130). The semi-structured interview allowed the freedom to pursue topics that came from the participants themselves - a critical component to discover indigenous perspectives. Also, due to the purpose of the initial interview, the researcher implemented a "funnel shaped interview" design (Kvale \& Brinkmann, 2009, p. 130), where indirect questions were posed from the start to 
engage the interviewee in a general discussion of their background, the school and community, and their beliefs on social studies education before directly asking for their perceptions of community values, political sentiments, and citizenship conceptualizations. In this case, the funnel shape method offered a non-combative approach to addressing potentially controversial, value-laden issues.

Informal post-observation interviews occurred during each field visit. The interview script assisted in starting conversations with participants about classroom occurrences; however, field notes were also utilized to generate additional questions for the post-observation interviews. These interviews sought to understand the enacted curriculum and instructional decisions of teachers, specifically focusing on how teachers' citizenship aims were implemented in the observed lessons, how teachers' directed (or redirected) lessons to adhere to lesson objectives, and if teachers made gatekeeping decisions based on perceived external pressures. Postobservation interviews enabled the researcher to examine more deeply conditions and social interactions as they arose within the setting. Post-observation interviews often faced time constraints due to participants' work schedules, but on average lasted 15 minutes.

The final interview acted as a culmination of the data collection phase of research. As prior data were analyzed, the final interview sought to provide more depth and insight into teacher's conceptualizations and perceptions; and investigated discrepancies and nuances from the data. This interview enabled participants to confirm the researchers' developing interpretations before the final write up of findings. This acted as a member check or member reflection (see data analysis section).

All initial and culminating interviews were digitally recorded. Some post-observation interviews were recorded, but most were documented using paper and pencil due to the bustling 
nature of classrooms. The initial and culminating interview data were transcribed verbatim to enable full data analysis. After reviewing field notes, post-observation interviews were selectively transcribed, with sections of the interviews copied in full based on their relevancy to the developing themes of the study - a discerning method of data condensation used by past researchers when dealing with enormous amounts of qualitative data (see Hawley, 2010). To protect the confidentiality of participants, all recorded audio files and interview transcriptions were uploaded and stored on a password protected computer that only the researcher had access.

\section{Classroom Observations}

Classroom observations enabled the examination of the phenomenon within its natural setting “as lived by participants" (Gay, Mills, \& Airasian, 2012, p. 381). It produced understanding of participants' responses to events and circumstances as they arose (Emerson et al, 2011). The researcher acted as a passive or "moderate" participant, meaning that the researcher was present in the research setting but did not actively participate, or only occasionally interacted, with people in it (DeWalt et al., 1998, p. 262). Immersion into the research environment in this capacity allowed the researcher to observe the social conditions of the phenomenon in a way that improved the quality and trustworthiness of data (p. 264).

After the first interview, four of the five participants' classrooms were observed approximately once a week over a three month time period (March - May 2016). One participant was not observed due to her teaching government in the fall term. The observation schedule allowed the researcher to document an average of eight different lessons for each participant and witness a variety of social interactions and participant experiences. Observations of four participants within similar rural contexts enabled substantial data to be gathered the relationships 
between teachers' stated aims and their enacted curricula. Observation metrics are fully reported in chapter four.

Extensive field notes were taken during each observation, totaling over 50 handwritten pages. These notes described the physical setting, behavior of participants, and their social interactions. Also, during notetaking, the researcher used jottings, or initial impressions and reactions to observed events (Emerson et al. 2012). After observations, field notes were written into narratives scenes to detail classroom happenings while they were fresh in the researcher's mind. Scholars suggest that field notes are critical to answer research questions because local meanings are often revealed "indirectly and inferentially by looking for the perspectives and concerns embedded and expressed in naturally occurring interaction," and not through directly asking participants (Emerson et al., 2011, p. 27).

Emerson et al. (2011) suggest there is not one "correct" way to write about what one observes in the field and that a variety of interpretations are possible. In this way, writing field notes is an interpretivist endeavor. In an attempt to portray the world of rural citizenship education in this study, field notes were driven by concrete details and sensory imagery, not abstract or evaluative depictions (Emerson et al., 2011). Special attention was paid to dialogue since it often "conveys character traits, advances action, and provides clues to the speaker's social status, identity, personal style, and interests" and "captures members" terms and expressions" as they are used in specific situations (p. 65). As stated above, these field notes were utilized to generate additional questions during post-observation interviews. Also, they were used to assist in data analysis as they drove initial interpretations and evolving data analysis. Lastly, field notes acted as an important triangulation of data sources to strengthen the credibility of findings. 


\section{Artifacts}

Artifacts are written or visual sources of data that contribute to understandings about what is happening in a classroom or school; hence, they are common source of data in qualitative research (Gay et al., 2012). In this study, artifacts were collected during classroom observations to help uncover connections between conceptualizations and practices, presenting a material record of content selection. Artifacts included curriculum guides, lesson plans, worksheets, project guidelines, tests, and assigned readings. An average of ten artifacts were collected per participant. These sources were scrutinized to substantiate teachers' conceptualizations of citizenship education and curricular decisions; to evaluate if teachers' citizenship aims were present in the materials they selected for student learning; and to judge for the presence of other influences upon the curriculum. In this way, artifacts helped to answer the research questions and triangulate results.

\section{Data Analysis}

Qualitative analysis can help draw valid and trustworthy meanings from data sources, but unlike quantitative data analysis, it is a "continuous, iterative enterprise" (Miles et al., 2014, p. 14). Miles et al. (2014) suggest data analysis contains three concurrent flows of activity: (1) data condensation, (2) data display, and (3) conclusions drawing/verification. Each of these are explained below with descriptions of their practices in this study.

Data condensation is "the process of selecting, focusing, simplifying, abstracting, and/or transforming the data that appear in the full corpus (body) of written-up field notes, interview transcripts, documents, and other empirical materials" (Miles et al, 2014, p. 12). It involves analytical choices about "what data chunks to code..., what category labels best summarize a number of chunks, which evolving story to tell" (p. 12). For this reason, competent data 
condensation can be established by using thorough analytical procedures and adherence to rigorous coding methods, both backed by theoretical rationales.

In this study, data underwent the constant comparative method of coding (Corbin \& Strauss, 1990, 2014). Constant comparison is an inductive approach to data analysis that categorizes particular participant beliefs and actions into more abstractly defined classes (Miles et al., 2014, p. 285). As soon as the first set of data was collected and transcribed, it was loaded into NVivo, an analysis software for text-based data. This software allowed the researcher to electronically code each case, then explore concepts across each case that were relevant to answering the research questions.

At first, open coding was used. Open coding let the researcher freely associate chunks of data within each case, utilizing topics, words, and phrases that arose from the data. This style of open coding enabled the data to "speak for itself" instead of forcing it into pre-defined codes or themes.

After initial codes were made, pattern coding was utilized. Pattern coding is "a way of grouping" initial codes into a smaller number of categories, themes, or constructs (p. 86). Pattern coding made connections across data, from all sources and participants, to reveal emergent answers to the research questions. Open codes, and the clusters of data they represent, were grouped based on similarities. As new patterns emerged, previous data was reexamined and conceptual categories were refined. This process continued until all relevant data fit into the designated conceptual categories. These categories were used to construct a theory that answered the research questions.

It should be noted that jottings and analytical memo writing were used throughout the analysis process. Jottings are "the researcher's fleeting and emergent reflections and commentary 
on issues during fieldwork and especially data analysis" (Miles et al., 2014, p. 94). They can "strengthen coding by pointing to deeper or underlying issues that deserve analytical attention" (p. 94). Similarly, memoing can be utilized to document the researcher's thinking and reflecting on the data (Miles, et al., 2014). Both jottings and memoing were tools used throughout the research project to make sense of the data and develop conceptual ties between clusters and constructs.

To ensure credibility and trustworthiness of analyses, Miles et al. (2014) recommend data displays. A data display is "an organized, compressed assembly of information that allows conclusion drawing and action" (Miles et al., 2014, p. 12). Miles et al, (2014) state that displays should be "focused enough to permit a viewing of a full data set in the same location and are arranged systematically to answer the research questions at hand." (p. 108). In this study, data were used to form of a matrix to reveal the patterns that emerged from coding. A final matrix was included in the write-up of the study (see Appendix C). The data display allows readers to "re-create (the researcher's) intellectual journey with some confidence" (Miles et al., 2014, p. 108). Doing so, reveals the consistency, rigor, and systematic approach the researcher took during data analysis.

The ultimate goal of a grounded theory study is to construct a theoretical statement that is based (or grounded) in substantial data and thorough data analysis. The processes of data condensation and creating data displays helped to draw conclusions from the study's large textual data set. Miles et al. (2014) define drawing conclusions as the process of "interpreting what things mean by noting patterns, explanations, causal flows, and propositions" (p. 13). Drawing conclusions is an interpretive and continuous throughout the analysis process until all data are fully considered. In this study, conclusions were drawn by noting patterns and themes, 
clustering data, and creating the matrix - all tasks that required aggregation and comparisons of data, helping to draw credible conclusions. The final themes that emerged from data analysis constitute the theoretical statement about the phenomenon.

\section{Trustworthiness}

Trustworthiness (also referred to as credibility) in qualitative research, deals with the verisimilitude and plausibility of findings (Tracy, 2010). Whereas in quantitative studies, trustworthiness is supported through ensuring valid measurement devices and reliability through replications; in qualitative studies, the researcher is the measurement tool (Merriam, 2002). To bolster trustworthiness, Tracy (2010) suggests qualitative researchers utilize thick descriptions, triangulation or crystallization, multivocality, and partiality. Each of these components are discussed in this section.

Thick descriptions mean the researcher provides in-depth depictions that explain culturally situated meanings (Geertz, 1973). Because qualitative research examines a phenomenon embedded within a given context, it is imperative that the researcher provide extensive details about the context to show readers the scene and not simply tell them what to think (Tracy, 2010). Also, thick descriptions are more likely to reveal tacit knowledge to help understand interaction and behavior within the setting under investigation (Tracy, 2010). In the current study, use of three data sources enabled thick descriptions to be constructed.

Triangulation, in a traditional sense, is using multiple sources, theoretical viewpoints, or methods of analysis to see if they converge on the same finding, therefore making the results more valid. This study adopted this practice. Yet, some critics argue that triangulation does not fit well within the social constructionist paradigm since the paradigm recognizes multiple realities (Tracy, 2010). Crystallization is offered as an alternative. Instead of focusing on 
corroboration as validity, Tracy (2010) suggests "multiple types of data, researcher viewpoints, theoretical frames, and methods of analysis allow different facets of problems to be explored, increases scope, deepens understanding, and encourages consistent (re)interpretation" (p. 843). Crystallization makes space for uncorroborated findings as a way to expose nuances and multiple truths in a scene. Simply put, conflicting data points do not make a study less valid, but instead reveal variances within and across cases.

Multivocality means that participants' voices are situated prominently in the research. This makes space for differences of opinion, including ones that diverge from other participants as well as the researcher, and is inclusive to cultural differences (race, class, gender, age, or sexuality) within the research setting (Tracy, 2010). Multivocality produces trustworthy findings by remaining true to participants' voices and actions. This study recognizes multivocality by ensuring the distinct voice of each participant was maintained throughout data condensation and differences between participants were noted in the findings.

The final safeguard taken to ensure trustworthiness in qualitative studies is member checking, or what Tracy (2010) calls member reflections. Engaging in member reflections moves beyond checking the accuracy of researchers' interpretations, instead offering a chance to collaborate and elaborate on findings - perhaps producing new data and a richer analysis (Tracy, 2010). The current study engaged in member reflections during the final interview. Through this practice, the study offered co-constructed knowledge stemming from social constructionism and resulted in accurate and honest portrayals of participants.

\section{Ethical Concerns}

Every researcher should consider the ethical issues involved with his or her study (Gay et al., 2012), particularly in cases involving human subjects. This study sought the approval of the 
College of Education and Human Services' Institutional Review Board (IRB) at West Virginia University. The IRB process served as an external check on ethical concerns and the researchers' proactive means of addressing them. Specifically, the IRB process ensures ethical procedures such as doing no harm, avoiding deception, negotiating informed consent, and ensuring privacy and confidentiality (Tracy, 2010).

Gay et al. (2012) state that the most basic and important ethical issues in research are protecting participants from harm and ensuring they freely agree to participate. This study sought and obtained informed consent from participants (see Appendix B) to ensure they understood the nature of the study, any possible risks, and agreed to participate under their own free will. The study contained minimal risks outside of those which occur in the ordinary school environment. The study did not use any form of deception. Participants knew the goals and procedures of the study from the outset and were free to remove themselves at any point without penalty.

Participant confidentiality was another important ethical consideration. Participants were informed of the steps that the researcher took to protect their confidentiality. All participant names, as well as the names of schools and locations, were assigned pseudonyms. All transcribed data was stored on a password protected computer. All hard copy materials (field notebook and teaching artifacts) were stored in a locked file cabinet to which only the researcher had access. No revealing descriptions were used in the written report of the study.

Ethical concerns in qualitative research extend beyond promises to adhere to specific procedural guideposts. Tracy (2010) acknowledges the existence of situational ethics, relational ethics, and exiting ethics in qualitative studies. Situational ethics are concerned with moments that arise in the field. Since these are unpredictable and particular to each research scene, Tracy (2010) recommends researchers "constantly reflect on our methods and the data worth exposing" 
(p. 847). Relational ethics deals with mutual respect and interdependence between the researcher, the participants, and the community (Tracy, 2010). Since rural populations are often viewed as marginalized by society (Theobald \& Wood, 2010), extra precaution was taken in this study to cooperate with participants in mindful, communal ways. For example, the researcher's interpretation of data underwent member reflections to ensure the rural population were not misrepresented. Also, participants were included in the process of defining the rules of the study (i.e. the extent of the researchers' access and involvement), so the researcher did not insult or unintentionally cause distress to participants. Related to this, exiting ethics deals with how the researcher leaves the scene and shares results, meaning the researcher must be aware of how their findings might be interpreted (or exploited) by readers (Tracy, 2010).

\section{Methodological Limitations}

Grounded theory methods provide rich details about a specific phenomenon, leading to the formulation of an inductively-derived theory to describe the phenomenon in similar contexts. This goal is known as transferability (Miles, et al., 2014). However, the theory discussed in this study remains untested in all possible rural environments and findings are not generalizable to all rural populations. Future research should test this theory in both similar and different rural locales. Also, data analysis was undertaken by only one researcher. To ensure data analysis was credible, research-supported analysis techniques were utilized (i.e. constant comparison coding, data displays). The researcher was transparent about data analysis procedures and, as an external check, member reflections were utilized during the research process. It is noteworthy to recognize that researcher subjectivity in qualitative studies may highlight specific aspects of the phenomenon that would otherwise go unmentioned (Kvale \& Brinkmann, 2009). Lastly, the 
exploratory nature of this study means that other researchers should corroborate or refute its findings to better understand the nuances of the phenomenon.

\section{Conclusion}

Despite the increase in research on citizenship education over the last two decades, little prior knowledge exists that is context-specific. Dewey (1916/2008) suggests the act of teaching cannot be separated from the context of the community. The qualitative methods of this study helped to reveal these connections within rural communities, examining closely participants' perceptions of place and their intersection with citizenship education. Ultimately, the methods revealed new knowledge on citizenship education, adding deeper understandings of the influence of rural contexts upon teachers' conceptualizations and gatekeeping. 


\section{CHAPTER IV}

\section{CONTEXTS}

Grounded theory research requires a deep understanding of participants' experiences moving and working within their unique environments (Corbin \& Strauss, 2014). To gain this insight, the researcher examined the particular settings and conditions that influenced participants' decisions. Investigations of the research contexts helped to explain connections between people, places, and the social structures that affected participants' lives, helping to uncover nuances of the phenomenon that go unnoticed in other research designs.

This study utilized a grounded theory research design to examine the relationships between rural contexts, teachers' conceptualizations of citizenship, and the decisions they make as gatekeepers of the curriculum. This chapter provides detailed information on the specific settings of the study that enabled these examinations. It presents descriptions of the four rural schools, their surrounding communities, and introduces the five participants' biographical information. Lastly, the study's observation metrics are reported.

As discussed in the previous chapter, this study was interested in understanding teachers' perceptions of rurality and how their unique perceptions contributed to decisions they made about the curriculum. Since rural is ambiguous, seen as both a term for geographic locales and a socially constructed ideal (Brown \& Schafft, 2011), the credibility of the findings would be lessened if teachers' perceptions were reported without objective descriptions of their rural communities. Following Brown and Schafft's (2011) suggestion to treat the varying conceptions of rurality (geographic and social) as complimentary instead of conflictual, this chapter describes geographical information for each research setting and introduces participants' perceptions of 
their settings. Chapter five more fully reports teachers' perceptions of rurality as they connect to citizenship education.

Geographic information in the current chapter includes each district's population, proximity to urban areas, school enrollment figures, and the district's economic indicators like median income and poverty rate. This chapter utilizes data from the United States Census and from the National Center for Educational Statistics. These concrete figures assist in developing readers' knowledge of rural areas as distinct physical places. Also, these data provide readers greater contextual knowledge of the settings to make sense of teachers' mental constructions of rurality. This use of multiple conceptual frameworks to understand a construct enhances the credibility of the study (Tracy, 2010).

In addition to geographical information on the rural settings, this chapter introduces the participants of the study. Relevant biographical information is provided to help contextualize participants' perceptions and actions. Each participant's biography is positioned as a subsection within their school's section. This sequencing acknowledges that participants' role as rural teachers was inherently linked to the contexts of their rural schools. It provides the logical and inseparable connection between participants' perspectives and their rural contexts. Additionally, observation metrics are reported in this chapter to make clear to the reader the level of frequency and duration of time the researcher spent in each rural setting.

\section{Settings and Participants}

The goal of this section is to provide readers with the knowledge of specific characteristics of each school and community, as well as introduce biographical information about each participant. These environmental and biographical conditions lay bare the conditions 
that impact participants' conceptualizations and decision making and, therefore, contribute to theory-building on rural citizenship education.

In this study, four different research locations were utilized. Several commonalities existed across each location. All research locations were publicly funded schools - three high schools and one combined high school/middle school - and each was categorized as distant rural by the NCES. Distant rural schools are at least 5 to 25 miles from an urbanized area $(50,000$ or more residents) or 2.5 to 10 miles from an urbanized cluster (25,000 to 50,000 residents). The four schools were located within a 70 mile circumference of each other and centrally located within one southeastern state. Schools were situated in different counties and, therefore, ran by different school boards. All four schools contained majority white student populations, had varying levels of minority students enrolled, and had less than $50 \%$ of students on free or reduced lunch. See Table 1 for further descriptions of school characteristics. All schools and participants were given pseudonyms to protect their anonymity.

Table 1

School Demographics

\begin{tabular}{|c|c|c|c|c|c|}
\hline Name & $\begin{array}{l}\text { NCES } \\
\text { classification }\end{array}$ & $\begin{array}{l}\text { Grade } \\
\text { Levels }\end{array}$ & $\begin{array}{l}\text { Students } \\
\text { Enrolled* }\end{array}$ & $\begin{array}{l}\text { Free/ } \\
\text { Reduced } \\
\text { Lunch }\end{array}$ & Racial Composition \\
\hline $\begin{array}{l}\text { Smallwood } \\
\text { High }\end{array}$ & Distant Rural & $9-12$ & 1,000 & $42 \%$ & $\begin{array}{l}92 \% \text { White } \\
5 \% \text { Black } \\
3 \% \text { Hispanic } \\
2 \% \text { Multiracial } \\
<1 \% \text { Asian/ Pacific Islander } \\
<1 \% \text { Amer. Indian/Alaskan }\end{array}$ \\
\hline $\begin{array}{l}\text { Stuart } \\
\text { County } \\
\text { High }\end{array}$ & Distant Rural & $9-12$ & 700 & $40 \%$ & $\begin{array}{l}\text { 64\% White } \\
24 \% \text { Black } \\
10 \% \text { Multiracial } \\
1 \% \text { Hispanic } \\
<1 \% \text { Asian/ Pacific Islander } \\
<1 \% \text { Amer. Indian/Alaskan }\end{array}$ \\
\hline
\end{tabular}




\begin{tabular}{|c|c|c|c|c|c|}
\hline $\begin{array}{l}\text { Central } \\
\text { County } \\
\text { High }\end{array}$ & Distant Rural & $9-12$ & 600 & $42 \%$ & $\begin{array}{l}75 \% \text { White } \\
15 \% \text { Black } \\
6 \% \text { Hispanic } \\
4 \% \text { Multiracial } \\
<1 \% \text { Asian/ Pacific Islander } \\
<1 \% \text { Amer. Indian/Alaskan }\end{array}$ \\
\hline $\begin{array}{l}\text { Henry Lee } \\
\text { Combined }\end{array}$ & Distant Rural & $6-12$ & 500 & $49 \%$ & $\begin{array}{l}\text { 63\% White } \\
35 \% \text { Black } \\
1 \% \text { Multiracial } \\
<1 \% \text { Hispanic } \\
<1 \% \text { Amer. Indian/Alaskan } \\
<1 \% \text { Asian/Pacific Islander }\end{array}$ \\
\hline
\end{tabular}

*All figures are approximations to ensure anonymity

Data Source: National Center for Education Statistics, Common Core of Data (CCD), Public School Data, 2014-2015 School Years, Retrieved from https://nces.ed.gov/ccd/

\section{Smallwood High School}

Smallwood High School consisted of several one story buildings interconnected by covered walkways. It sat along a rural two lane highway surrounded by farm land and sparsely dispersed houses. A separate middle school sat on property adjacent to the high school. Opened in the 1960s, Smallwood High was one of three high schools in the county school district, but the only one that catered to students living in several small communities and thinly populated roadways in the southern half of the county. The closest town laid approximately 12 miles north with a population of 6,000 residents. The school was adjacent to two metropolitan areas that overflowed across the county line in the northeast and southwest. The first metropolitan area (pop. 260,000) was 38 miles away and the other area (pop. 310,000) was 20 miles in the opposite direction. Noteworthy, the school was roughly 10 miles north of a popular recreational lake that led to increased tourism in the region. Also, the lake contributed to a small amount of recent population growth in the county due to people re-locating from outside the area to live at properties around the lake. A participant from Smallwood High reported that in-migration to the region created political tensions between longtime residents and newcomers concerning the 
demand for services. Referring to these tensions, the participants said, "It's changing the face of the county, slowly, and sometimes it is painful, but it's happening."

Among the research sites, Smallwood High had the largest overall student population $(\sim \mathrm{n}=1,000)$ and the largest percentage of white students $(92 \%)$. The median per capita yearly income in the county was $\$ 29,000$ and the estimated poverty rate was $9.4 \%$. These figures placed the county as the least economically deprived of the four school districts; yet, the numbers were influenced by the economic impact of the encroaching wealthy suburbs of the metropolitan areas, as well as recreational tourism and expanding residences near the lake. Economic indicators could not be found that separated the rural section of the county from the more densely populated sections.

Mr. Howard and Ms. Finch. Smallwood High was the only research site where two government teachers, as opposed to one, participated in the study. Mr. Howard and Ms. Finch taught down the hall from each other. They worked cooperatively to construct their government course curriculum. The school ran on an A-B block schedule, where students attended the same classes on Monday, Wednesday, and Friday one week and the following week they attended on Tuesday and Thursdays. Each class period ran 90 minutes in length.

Mr. Howard was a white man in his fifties. He had 32 years of teaching experience (with 28 years at Smallwood High). He taught regular $12^{\text {th }}$ grade government classes, as well as Advanced Placement (AP) United States government and politics, AP psychology, and sociology. Mr. Howard was the department chair. He coached cross country and track and field and served in an assortment of advising roles at the school. He held a bachelor's degree in history from a large university and a master's degree in curriculum and instruction from a small private college, both located in a nearby metropolitan area. For the duration of his work at 
Smallwood High, he lived approximately 15 miles from the school in a suburb of one of the metropolitan areas adjacent to the county.

Mr. Howard said that he moved around a lot as a child because his father worked for the state highway department and moved the family "wherever the roads were being built." During his teenage years, he went to middle school and high school in a heavily-populated metropolitan area located in a different part of the state. Mr. Howard spoke positively of metropolitan areas as places to visit but not live. He said he enjoyed amenities that were not available in rural areas. Mr. Howard and his wife chose their current suburban residence because it split the difference between their two families. Also, he spoke of being close enough to the city to enjoy "everything you would want," which included major athletic events, concerts, and theater productions. Though Mr. Howard lived 15 miles from the school, he identified with the school's rural community because of his length of employment at the school and involvement in the students' and formers students' lives.

Ms. Finch was a white female in her mid-twenties. She had three years of teaching experience, one year at an alternative learning center within the district and two years at Smallwood High. She taught regular $12^{\text {th }}$ grade government classes and worked as the assistant junior varsity softball coach. Ms. Finch held a bachelor's degree in history and a master of arts in teaching from two different small private colleges located in an adjacent metropolitan area. She pursued the degrees consecutively before seeking employment as a teacher. Ms. Finch said that she entered the teaching profession because of her love of history. She noted that the majority of the government curriculum at Smallwood High School was developed by Mr. Howard and she frequently looked to him for advice. 
Ms. Finch was raised in and, at the time of the study, lived approximately 30 miles from Smallwood High in the suburbs of one of the metropolitan areas, commuting to the school each day for work. Ms. Finch was unmarried. She spoke of Smallwood High School's community as being "out there." She believed most of the families and students "don't ever leave" the community to live elsewhere. Ms. Finch attended city schools as a student, and she said the rural community around Smallwood High was a lot different than where she grew up, including its largely conservative political ideology. The following table contains demographical information for all of the participants.

Table 2

Participant Demographics

\begin{tabular}{|l|l|l|l|l|l|}
\hline Name & School & $\begin{array}{l}\text { Years } \\
\text { Teaching }\end{array}$ & $\begin{array}{l}\text { Resides } \\
\text { within } \\
\text { School's } \\
\text { District }\end{array}$ & Courses Taught & College Degrees \\
\hline $\begin{array}{l}\text { Mr. } \\
\text { Howard }\end{array}$ & $\begin{array}{l}\text { Smallwood } \\
\text { High }\end{array}$ & 32 & No & $\begin{array}{l}\text { AP US } \\
\text { government and } \\
\text { politics, state } \\
\text { and national } \\
\text { government, } \\
\text { AP psychology, } \\
\text { sociology }\end{array}$ & $\begin{array}{l}\text { B.A. in History } \\
\text { Instruction }\end{array}$ \\
\hline Ms. Finch & $\begin{array}{l}\text { Smallwood } \\
\text { High }\end{array}$ & 3 & No & $\begin{array}{l}\text { state and } \\
\text { national } \\
\text { government }\end{array}$ & $\begin{array}{l}\text { B.A. in History } \\
\text { M.A.T (Masters of Arts } \\
\text { in Teaching) }\end{array}$ \\
\hline $\begin{array}{l}\text { Ms. } \\
\text { Thompson }\end{array}$ & $\begin{array}{l}\text { Stuart } \\
\text { County } \\
\text { High }\end{array}$ & 6 & Yes & $\begin{array}{l}\text { AP government } \\
\text { and politics, } \\
\text { US history }\end{array}$ & $\begin{array}{l}\text { B.A. in Political Science } \\
\text { M.A.T. }\end{array}$ \\
\hline Ms. Kelly & $\begin{array}{l}\text { Central } \\
\text { County } \\
\text { High }\end{array}$ & 25 & $\begin{array}{l}\text { Yes } \\
\text { state and } \\
\text { national } \\
\text { government }\end{array}$ & $\begin{array}{l}\text { B.A. in History } \\
\text { M.Ed. in Curriculum and } \\
\text { Instruction }\end{array}$ \\
\hline Mr. Nixon & Henry Lee & 3 & $\begin{array}{l}\text { state and } \\
\text { national } \\
\text { government, } \\
\text { world history }\end{array}$ & $\begin{array}{l}\text { B.A. in History } \\
\text { M.A.T. }\end{array}$ & No \\
\hline
\end{tabular}




\section{Stuart County High School}

Stuart County High School sat within a town of approximately 1700 people. The town was the largest in Stuart County and acted at the county seat. The school was the only county high school and, therefore, catered to students from across a large rural district that held roughly 15,000 people. The county contained only one public elementary school and middle school, so in the words of Ms. Thompson (a study participant), "[students] are with each other from the time they start school until the time they graduate... it's a sense of community that you don't necessarily have at a larger school." Farming and forestry were the dominant economic activities in Stuart County. Also, historical tourism accounted for some economic activity within the county. Stuart County High School was roughly 20 miles from a major metropolitan area of 260,000 people. The school contained the second largest minority enrollment $(\sim 36 \%)$ of the four high schools in the study. Interestingly, while the county contained a lower than average median per capita income $(\$ 23,000)$ and an estimated poverty rate of $15.1 \%$, the school contained the lowest percentage of students on free and reduced lunch (40\%).

Ms. Thompson. Ms. Thompson was a white female in her late twenties. She had taught at Stuart High School for 6 years. She taught US history, US and state government, and AP US government and politics. At the time of the study, Ms. Thompson was not teaching any sections of government. She was department chair and senior class advisor. Ms. Thompson was unique in that she held an undergraduate degree in political science, as opposed to a degree in history that each of the other participants possessed. She received this degree from a large public university over an hour drive from Stuart County. Also, she held a masters of arts in teaching and was pursuing a second master's degree in political science from a large private Christian university. Ms. Thompson was the only participant that was raised in the community where she worked and 
lived. She graduated from Stuart High School. She said that "everybody knows my family and step-family" and that this level of familiarity created a "trust" between herself and her community.

\section{Central County High School}

Central County High School sat along a stretch of four lane highway that connected two large metropolitan areas. It was approximately 37 miles from one metro area (pop. 207,000) and 32 miles from the other (pop. 267,000). Central County High was the lone high school in the county school district. Immediately beside the high school, and independently run, was the county's lone middle school. The county had a total population of just under 15,000 and was unique in that no incorporated towns or cities existed within the county. The high school was located 3 miles outside of a small community of 500 people that also acted as the county seat. The county possessed a yearly median per capita income of $\$ 28,000$ and an estimated poverty level of $13.4 \%$ of the population. While agricultural pursuits speckled the county's landscape, particularly apple orchards, it was also home to a burgeoning alcohol industry (i.e. wineries, breweries, and distilleries) and outdoor recreational areas that made tourism a major sector of the county's economy. Noteworthy, at the time of the study, the county was the focus of a political controversy concerning the construction of a large natural gas pipeline. While the governor stated that pipeline construction would increase job growth in the areas, the sentiment of many county residents was that the pipeline would disrupt the pristine mountains and valleys that contributed to recreational tourism and that it would not create long-term employment for county residents.

Ms. Kelly. Ms. Kelly was a white woman in her fifties. She had taught for 25 years. She came to teaching as a second career having first spent ten years as a manager within the food and 
beverage industry. She grew up on the outskirts of a large metropolitan area in a different part of the state. After high school, she attended a large public university near her hometown majoring in history. Upon graduating, she moved to Central County for a restaurant management position in a local resort. More than a decade later, she quit her restaurant job and became a substitute teacher. She concurrently pursued teacher licensure and her master's degree in curriculum and instruction from another large public university in a nearby metropolitan area. In her first year of substitute teaching, she filled a vacant position teaching government at Central County High School. She remained teaching that course at the school throughout her entire career. Over the past 20 years, Ms. Kelly resided on a plot of land in a "picturesque" valley on the opposite end of the county. Ms. Kelly and her deceased husband where originally outsiders to the area; however, after many years of renting they purchased their property. Other residents in the community said, "We are glad to see locals got it." Ms. Kelly said that she was honored to be considered a local.

Ms. Kelly was the only participant who had extensive professional development for citizenship education. In the early 2000s, she attended a two-week workshop in the nation's capital with teachers from several states, followed by periodic meetings with a regional team of teachers. The workshop was sponsored by the Annenberg Foundation. It focused on helping teachers incorporate yearlong citizen action projects into their courses. These projects required students to work together to determine a local public problem and then plan and execute the necessary steps to resolve the problem. Ms. Kelly said she carried out the project with her students one year, but afterward discontinued the project due to time constraints.

\section{Henry Lee Combined School}

The last research site was Henry Lee Combined School. It was the smallest rural school in the study, though it was composed of grades 6-12. The school's student enrollment was 500 of 
which only 300 students comprised grades 9-12. The middle school and high school shared one building (hence the school's "combined" name); however, the middle school and high school had their own administrators, faculties, and office systems. The school sat across train tracks about a mile from a two lane road. The closest town was six miles away with a population of just over 1000 residents. The school was approximately 27 miles from a metropolitan area of 267,000. This metropolitan sprawl leaked into the opposite end of the county; therefore, the county contained four other high schools that held NCES classifications as fringe rural, distant town, and midsize suburban. The county's median per capita income was approximately $\$ 23,000$ with an estimated $15.1 \%$ poverty rate. These statistics placed the district as the most economically deprived of the four research settings. Henry Lee Combined contained the highest minority student population $(\sim 37 \%)$ and the highest amount of students on free and reduced lunch (49\%). Henry Lee's administrator stated that the school is under threat of closure due to its small size and running costs.

Mr. Nixon. Mr. Nixon was a white male in his mid-thirties. He had three years of teaching experience, all at Henry Lee Combined. He taught government and world history, and he served as the school's head softball coach. As a child, Mr. Nixon grew up in a metropolitan coastal area of the Deep South and, as a teenager, moved with his family to a mountainous western state where he attended and graduated from a very small rural high school. He said that his positive experiences in a rural high school were the reason he wanted to work at a small rural school as a teacher. After high school, Mr. Nixon went back to his birthplace to attend a large public university, but he dropped out without receiving a degree. He got married and started his own car and boat detailing business. Mr. Nixon shared that after nearly ten years of working at his small business, where he "made $\$ 150,000$ a year," he got a divorce from his wife and moved 
with his daughter to the farm where he currently lives. Once moved, Mr. Nixon attended a local private college and received his bachelor's degree in American History and subsequently received a master's of arts in teaching from another small private college within the same city. His farm was located in a rural area approximately 25 miles from Henry Lee Combined in an adjacent county that was home to Stuart High. Mr. Nixon commuted on average 45 minutes a day.

\section{Observation Metrics}

The researcher visited all but one participant's classroom multiple times throughout the research project. The exception was Ms. Thompson who was not teaching a government course during the semester that observations occurred. Ms. Thompson's town was visited once during the research project to observe its historical significance and to see the position of the school within the town.

The table below depicts the frequency and duration of participant observations. Site visits included anytime the researcher stepped foot onto the school's campus for observations and/or interviews. This was included because some visits occurred when lessons were not observed due to teacher absences and school assemblies; yet, on these days field notes were taken that focused on social interactions outside of the classroom. These non-instructional visits included two times when the researcher was given tours of the schools by either the participant or an administrator. The number of lessons observed was dictated by the number of individual class periods that the researcher observed. Mr. Nixon's school, Henry Lee Combined, was the only institution to utilize a seven period school day with approximately 50 minutes allotted per class, therefore the researcher observed more individual lessons at this location than any other. All other participants' schools utilized varying block schedules where classes were 
approximately 1 hour and 30 minutes. The average observation time for each participant was figured by totaling the hours of classroom observations and dividing it by the number of observation visits. Observations included varying amounts of pre- and post-class times where students were still interacting with the teacher or the teacher was preparing instructional materials for the next class or handling routine teacher duties such as hallway monitoring and club advising. Time spent conducting post-observation interviews was not included in the averaging of observation times as these were done at lunch or after the school day had ended. It should be noted, Ms. Kelly's classroom was visited the least amount due to a time-consuming district-level approval process. This delayed entry was offset by averaging longer observations per visit at the site once entry was gained.

Table 3

Observation Metrics

\begin{tabular}{|l|l|l|l|l|}
\hline Participant & $\begin{array}{l}\text { Number } \\
\text { of Site } \\
\text { Visits }\end{array}$ & $\begin{array}{l}\text { Number of } \\
\text { Lessons } \\
\text { Observed }\end{array}$ & $\begin{array}{l}\text { Average } \\
\text { Observation Time } \\
\text { per Visit }\end{array}$ & $\begin{array}{l}\text { Total Classroom } \\
\text { Hours Observed }\end{array}$ \\
\hline Mr. Nixon & 6 & 10 & 1 hr. 50 mins. & 11 hrs. \\
\hline Ms. Finch & 6 & 5 & 1 hr. 45 mins. & 8 hrs. 45 mins. \\
\hline Mr. Howard & 5 & 5 & 1 hr. 45 mins. & 8 hrs. 45 mins. \\
\hline Ms. Kelly & 4 & 6 & 2 hrs. 45 mins. & 8 hrs. 15 mins. \\
\hline Ms. Thompson & N/A & N/A & N/A & N/A \\
\hline
\end{tabular}

\section{Conclusion}

This chapter described the characteristics of each research setting, introduced each participant in the study, and conveyed observation metrics. This information contributed the contexts used to frame the study's findings. Details from this chapter were synthesized with findings from interviews, observations, and documents to make connections about relationship between structures in rural contexts. Chapter five reports on the major themes that emerged from 
data analysis and chapter six offers a discussion of these relationships to develop a theoretical statement about rural citizenship education. 


\section{CHAPTER V}

\section{FINDINGS}

This chapter reports the study's findings through three interconnected themes. The themes emerged from a systematic analysis of the data. Data sources included interviews, observations, and artifacts. Each theme is supported here with examples from the data. The themes converge to provide a nascent theory on the impact of rural contexts on citizenship education. This theory is based on experiences of the five participating government teachers across four rural school districts. Specifically, findings provide new understandings about rural teachers' conceptualizations of citizenship education, the relationship between place and citizenship education, and curricular-instructional gatekeeping. Findings from this chapter expand upon context-specific knowledge in the field of citizenship education thereby promoting more accurate representations of rural teachers' perceptions and practices.

This study sought to answer three research questions:

1. How do government teachers in rural schools conceptualize citizenship education?

2. How do teachers' perceptions of place impact citizenship education in rural contexts?

3. How is curricular-instructional gatekeeping in citizenship education impacted by rural contexts?

The first theme, citizenship education as practical knowledge, presents participants' conceptualizations of citizenship education. This theme directly answers question one and concurrently introduces several contextual factors that are developed further by the other themes. Participants' conceptualizations emerged through examining their definitions of good 
citizenship, their curricular aims, and their reasons for choosing such aims. Participants focused largely on teaching basic civic knowledge in hopes that it would transfer to traditional citizenship actions outside of schools.

The second theme, place-based learning for future (dis)placements, builds upon the first theme by examining the impact of participant's perceptions of place on their citizenship curricula. The theme contains the purposeful parenthetical use of "dis" before the term placements to suggest that students' future lives as citizens within their rural community are uncertain. Participants demonstrated the use of local funds of knowledge to prepare students for citizenship; yet, they simultaneously promoted that students should leave rural areas in search of college and career success. This produced a deficit message to students about place. This theme exposes the unfulfilled potential of teaching place-conscious citizenship to rural students.

The final theme is the gatekeeping triad. This theme deals extensively with the convergence of other factors that influence teachers' curricular-instructional decision making in rural schools. The three constructs of the gatekeeping triad (self, others, and authority) emerged during successive rounds of data coding. The first construct, self, represents the influence of teachers' personal life histories, dispositions, and early teaching experiences on their curricular aims and instructional strategies. The second construct, others, represents the curricular interests and influences of students, parents, community members, colleagues, and administrators. This construct distinguishes social interactions within rural contexts as a relevant, ambient influence on teachers' decision making. The final construct, authority, represents the influence of statemandated standards, high-stakes tests, and district-level pacing guides on teachers' citizenship lessons. Participants' perceptions of these influences are examined to produce knowledge on how rural teachers navigate authoritative determinants of their citizenship curriculum. This 
theme, taken as a whole, reports how rural conditions, such as familiarity and trust, enabled participants to use, blend, and reject various curricular inputs.

In this chapter, the three themes are dealt with individually, each revealing a specific aspect of citizenship education in rural contexts. Yet, they also converge to highlight relationships between conceptualizations, perceptions of place, and social structures. In this way, the themes offer a new theoretical understanding of the impact of rural contexts on citizenship education. Furthermore, the themes directly stem from constructs and patterns in the data and raw data are used to support the claims of each theme. This type of reporting gives purpose and position to rural teachers' perspectives that have been largely silent in educational research.

To strengthen the credibility of the study, a data display was created to help the reader recreate the intellectual journey of the researcher (Miles et al., 2014). Readers can visualize the data analysis process that produced the three themes. Table 3 presents an excerpt of the data display, or construct matrix, created during this study's data analysis. The column on the far right contains concepts that emerged directly from the raw data. Moving to the left, sets of concepts were grouped into categories that best explained their commonalities, then grouped again into larger, more abstract main categories. This was a continual and fluid process throughout data collection, refined with each step as more data came into the picture. Subsequent rounds of data condensation fostered a clearer image of the final constructs and how various categories and constructs related to one another. The final themes encapsulate the major narratives of the data set, rooted across ascending levels of refinement, to ensure they best represent the raw data. In addition to this matrix, the researcher's constant memo writing during data collection and analysis helped to make sense of participant behaviors and question emerging interpretations of the phenomenon. See Appendix $\mathrm{C}$ for the full construct matrix. 
Table 4

Excerpt of Construct Matrix

\begin{tabular}{|c|c|c|c|c|}
\hline Theme & Construct & Main Category & Category & Concepts \\
\hline 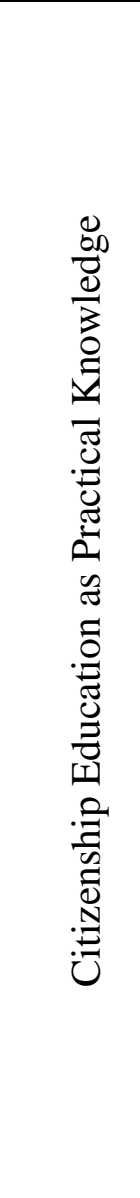 & $\begin{array}{l}\text { Citizenship } \\
\text { Education }\end{array}$ & Conceptualizations & Stated Goals & $\begin{array}{l}\text { - participate } \\
\text { - life skills (i.e. work } \\
\text { together, use a computer, } \\
\text { public speaking, critical } \\
\text { thinking, professional } \\
\text { dress, interview skills) } \\
\text { - understand our nation } \\
\text { - pick a candidate to } \\
\text { support } \\
\text { - be attentive to local } \\
\text { politics } \\
\text { - not be fooled by news } \\
\text { - be tolerant and accept } \\
\text { plurality } \\
\text { - know rules and how to } \\
\text { redress grievances } \\
\text { - think for themselves and } \\
\text { get personally involved } \\
\text { - be informed decision } \\
\text { makers } \\
\text { - read the news } \\
\text { - get the basics of } \\
\text { government } \\
\text { - register to vote } \\
\text { - defend an argument }\end{array}$ \\
\hline
\end{tabular}




\begin{tabular}{|c|c|c|c|c|}
\hline 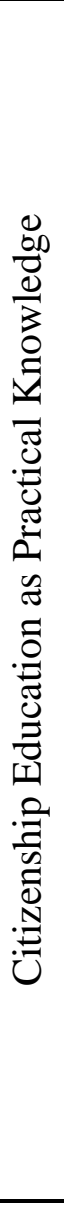 & $\begin{array}{l}\text { Citizenship } \\
\text { Education }\end{array}$ & Conceptualizations & $\begin{array}{l}\text { Motivations for } \\
\text { Goals }\end{array}$ & $\begin{array}{l}\text { - connect politics to real } \\
\text { life } \\
\text { - knowledge of how to } \\
\text { deal with bureaucracy that } \\
\text { affects life } \\
\text { - "hard knocks" life } \\
\text { lessons } \\
\text { - to know and work with } \\
\text { government } \\
\text { - to work towards } \\
\text { consensus and } \\
\text { compromise } \\
\text { - regardless of future, } \\
\text { same basic skills needed } \\
\text { - get ready for college } \\
\text { discussions } \\
\text { - "government's messy } \\
\text { because its life" } \\
\text { - teach personal } \\
\text { independence } \\
\text { - connect to local events } \\
\text { and people } \\
\text { - not to blindly adopt } \\
\text { others' views (parents, } \\
\text { teachers, communities) }\end{array}$ \\
\hline 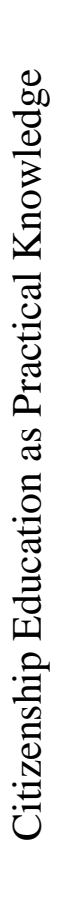 & $\begin{array}{l}\text { Citizenship } \\
\text { Education }\end{array}$ & Conceptualizations & $\begin{array}{l}\text { Definitions of a } \\
\text { Good Citizen }\end{array}$ & $\begin{array}{l}\text { - pays attention to news } \\
\text { - pays taxes } \\
\text { - participates in jury duty } \\
\text { - votes } \\
\text { - upholds the law } \\
\text { - willing to work on } \\
\text { elections } \\
\text { - campaign for candidates } \\
\text { - be part of a political } \\
\text { party } \\
\text { - volunteer with } \\
\text { organizations they think } \\
\text { are important } \\
\text { - works within established } \\
\text { structures } \\
\text { - willing to talk about } \\
\text { issues } \\
\text { - get involved } \\
\text { - take care of other people }\end{array}$ \\
\hline
\end{tabular}




\section{Theme 1: Citizenship Education as Practical Knowledge}

The first theme emerged during early interviews with participants and was developed through additional classroom observations, interviews, and examinations of teaching artifacts. While participants displayed slight variations in the way they talked about citizenship and in their lesson activities, data converged around conceptualizations of citizenship education as practical knowledge. The phrase practical knowledge represents teachers' desires to transmit disciplinary knowledge to rural students with the intention that it transfers into practical, or useful, citizenship actions as adults. Data showed participants emphasized teaching their students basic governmental facts, such as its structures and political processes, so they would be knowledgeable and, therefore, capable of fulfilling traditional citizenship duties like voting, volunteering, and following laws and regulations. Furthermore, participants incorporated workforce skills into their government courses and spoke of economic productivity as an expectation of good citizenship.

Mr. Howard and Ms. Finch, who co-planned their government courses at Smallwood High School, implemented a lesson that epitomized citizenship education as practical knowledge. In the lesson, students worked with a partner to select and research a state-level bureaucratic agency and present their findings to the class. The essential question for the project was "How does the agency work for us?" After the lesson, Mr. Howard was asked about its citizenship aim. He responded, "I try to connect students to real-life practical citizenship skills... I want them to know what to do if their grandmother isn't getting her social security check, which government agency to contact."

Similarly, his colleague Ms. Finch emphasized practical citizenship knowledge with her students. She said that she gives a knowledge-based citizenship test at the beginning of the 
school year to evaluate students' "understanding of citizenship" and throughout the year she covers all of the material on the test. This test consisted of questions that focused on the structures and purposes of government. She expressed that citizens needed specific knowledge of government and skills for personal life to carrying out their responsibilities and duties. She said that good citizens vote, pay taxes, uphold the law, serve on juries, and campaign for candidates.

Typifying her conceptual focus, Ms. Finch assisted students in "filling out tax forms" to prepare them for "life skills." She emphasized the importance of voting with students. She said, "We ask students to sign up to work at the election polls that are in this area. I had about 20 kids work at the polls last election day. They got to see other people come and cast their votes." Similarly, volunteering at local polls was something Ms. Kelly encouraged with her students at Central County High School. Both participants said that working polls on Election Day was intended to help students understand the voting process and inspire them to become involved in local and national political campaigns.

Another of Mr. Howard's lessons aimed at teaching students civic knowledge so they could carry out traditional political behaviors. Mr. Howard facilitated an impromptu class discussion on a controversial parking issue at the school. The issue consisted of students wanting to drive their vehicles after school from the designated student lot to a separate lot closer to the school's athletic fields for evening practices and games. This is something students were barred from doing at Smallwood High. During the discussion, Mr. Howard stressed the importance of knowing how to redress grievances through established procedures. He directed classroom talk on the issue, lecturing on ways to get the school policy changed, including lobbying administration and garnering parental support. After the lesson, Mr. Howard commented on its application to the bigger picture of citizenship: 
[Students need] a working knowledge of the government and how to use it, how to understand it as much as they can. And then how to be able to work with it. We all understand that there are rules that we have to follow and sometimes we don't like it but we get to redress those grievances and it is a wonderful thing about a democracy. Let them know that they can do that. That's important.

Both Mr. Howard and Ms. Kelly, the two oldest and longest serving teachers, said that students had to "get the basics down" to be successful citizens. To Ms. Kelly, possessing basic civic knowledge and staying informed of current events were critical to involvement in political life. She had students read the newspaper every day for the first five minutes of class and offered them a chance to discuss current events with their classmates. It was observed that students often remained reticent and Ms. Kelly continued with her pre-planned lesson. During one lecture, a student asked if the class could share their opinions on the topic of immigration. Ms. Kelly responded, "Yeah, now that you are informed on the basics." However, no students engaged in political talk as Ms. Kelly was starting a "Crash Course" youtube.com video segment that was followed immediately by more teacher-centered instruction and a vocabulary quiz.

As Ms. Kelly displayed, all participants emphasized the importance of students "being" or "staying informed" of contemporary political events so they could competently participate in their presumed roles as citizens. Mr. Nixon from Henry Lee Combined School incorporated a weekly current event presentation activity into his instruction. His reasoning was that "good citizens take the wheel and steer every once in a while." Mr. Nixon asked students to find and read an online news article using a set of classroom notebook computers, summarize the article, briefly report the summary in front of the class, and then field their classmates' questions. Mr. Nixon believed this activity taught critical thinking by helping students "sift through what the 
media is feeding [citizens]." He also said that it helped students "work on public speaking skills." Yet, observations of this activity showed students struggled with comprehension of political events and the activity failed to produce the type of engagement between classmates and the presenter that Mr. Nixon desired. Presenters were unable to answer questions posed by classmates because, when not reticent, classmates sought information that was not located in the article and presenters did not possess the requisite knowledge to answer these types of questions. Likewise, students sometimes misunderstood the meaning of current events due to a lack of prior knowledge on the terminology and groups involved. At these points, Mr. Nixon spent time lecturing and editorializing about the events to "get students to think critically." Other studentcentered lessons and projects observed in Mr. Nixon's room resulted in similar occurrences.

Participants emphasized preparing students for "real life" or "life outside the classroom." The notion of teaching for real life emerged in the data as a complex assortment of curricular aims in preparation for personal, civic, and work life after high school. For Mr. Nixon, teaching for real life included his desire for students to "be involved in local politics," form their own political ideologies, and have awareness of the electoral and judicial systems. Mr. Nixon viewed government and politics as "messy." He was the only participant who aimed at helping students become more "tolerant of other cultures and other people." Yet, few of his observed lessons incorporated this aim; and some lessons communicated stereotypes and offensive insinuations concerning marginalized groups, such as when Mr. Nixon teased a male student for having a "boyfriend" though the student appeared to identify as a heterosexual.

Another component of this "real life" or practical knowledge aim was that every participant highlighted workforce skills as part of their citizenship curricula. Mr. Nixon, who taught at the smallest rural school in the poorest county, required students to practice interview 
skills, public speaking, and writing cover letters, resumes, and informational reports. For him, this workforce aim stemmed from his own first career as a business owner. Exemplifying this aim, Mr. Nixon planned, though did not implement due to time limitations, a "shark tank" activity that replicated the structure of a popular television show. In this activity, students were to act as entrepreneurs seeking financial backing to start their own business. Students were asked to write a business plan, create a commercial, and deliver a presentation to the class. Emphasis was placed on practical ways to make money and be economically productive.

Career-related notions of citizenship permeated Mr. Howard's and Ms. Finch's curriculum as well. They provided lessons on job interviewing, expected professional dress, and emphasized computer skills. At one point, Mr. Nixon used a capitalistic analogy when discussing his teaching philosophy. He said, "I have a product I am trying to sell students which is their education and you need to almost go Machiavellian on them - whatever means necessary."

When Ms. Thompson was asked about the skills she hoped her students learned for life outside the classroom, she offered a response that highlighted college preparation. She wanted her students to be able to communicate in college learning environments and be open to divergent views on issues. She said:

When you go to college and you try to use [unsupported claims] in a discussion section of a course, they are going to look at you and laugh. You are not going to get credit and then you are never going to want to speak again. So you need to learn really quickly how to frame your argument in a way that not only makes you look intelligent but also means that you are not attacking somebody. Also, you need to know how to behave when you are getting attacked. Those are really important lessons, life lessons, from me that they learn. They need to learn that not everyone thinks the same way, not everybody is from 
Stuart County High School, and not everybody is from a small town and has the same opinions because a lot of them do have very similar opinions.

Ms. Thompsons's emphasis on communication reveals an additional dimension to the theme of citizenship education as practical knowledge that was present in each rural setting social consciousness. While participants emphasized students' individual development in mastering civic knowledge objectives, they also acknowledged that citizenship is a social endeavor. Teachers stressed the importance of working with other citizens, often as part of groups or organizations, and volunteering or helping one's neighbors. These social aims were best summarized by Mr. Howard who said, “A good citizen is someone who understands that we are all in this together. It's not a 'me' thing, it's everyone." When asked to elaborate on this point, Mr. Howard said, “... to work for consensus and compromise which is the original intention of everything that we've done as opposed to conflictual.” Likewise, recognizing productive social components in citizenship, Ms. Kelly said:

Another component [of citizenship] would be, not just involved in politics, but involved in your community wherever you are. And know how to go about doing things and being active. To take care of other people and groups whether it's through the government or community service or that kind of thing

Ms. Thompson stressed the importance of joining church or civic organizations and "trying to make a difference in the community." Mr. Nixon was unique in saying that he emphasized "plurality" with his students, believing it to be a "foreign concept" to most of them.

Participants' attentiveness to social consciousness provides a nuanced understanding of citizenship education in rural contexts; however, their sentiments remain within the framework of practical knowledge as participants continued to emphasize traditional pathways of civic 
togetherness - such as volunteering and joining civic-minded organizations. Furthermore, teachers' attempts to highlight social consciousness within their lessons sometimes fell short. For example, teachers spoke of using cooperative groups to teach students to work together; yet, group projects occupied a minimal amount of in-class time. Also, when student-to-student discussions of controversial issues were observed, students often made disjointed points, spread false information, and produced anger and resentment. These forms of negative political talk often went uncorrected by teachers. For example, during one student-centered discussion on abortion rights, a male student in Ms. Finch's class suggested pregnant teenage women were "whores." His comment went unacknowledged by the instructor.

On the point of controversial issues, most participants talked positively about incorporating them as a form of practical knowledge. As Mr. Nixon said, controversial issues "prepare students for the real world of politics." Only one participant was hesitant to incorporate controversial issues into her lessons, saying that they are "something the students sometimes bring up... I only bring them up if it has something to do with what we are talking about that day." During observations, this participant redirected or avoided controversial issues when students voiced them in class.

To illustrate, a controversial issue arose that directly impacted the Smallwood High. At the start of school one day, over 25 vehicles driven by students and community members circled the school three times flying Confederate battle flags from their windows or truck-beds. Some vehicles also flew the "Don't Tread on Me" flag, the POW-MIA flag, the United States of America flag, and the Christian flag. This flag parade was in response to an event the previous day where a student was reprimanded by administrators for displaying the Confederate battle flag from his truck in the school parking lot. The student said that he was honoring the recent 
death of musician Merle Haggard; yet, all banner and flag displays were against school policy for student drivers.

On the morning of this flag parade, students entered the participant's first period government class and were abuzz with talk of the event. Several students tried to engage the teacher in discussion by asking questions about its meaning and stating their opinions on the controversy. The teacher, however, quieted the class and redirected them to the pre-planned lesson on state-level bureaucratic agencies. In a sidebar to the researcher the teacher asked, "Did you enjoy the redneck parade?" The teacher later stated that she did not think the controversy was relevant to the planned lesson and did not want things to get out of control in her classroom. Ms. Thompson appeared most committed to the notion of controversial issues, saying in her first interview, "Yeah! That's the most fun!" She reasoned that students "need to know how to defend their own arguments.” Elaborating on her motives for including controversial issues, she said:

They need to know the background of the issue, they need to know just because they have an opinion of something doesn't mean their opinion is right and doesn't mean that other people don't have a different opinion. Just because it's a different opinion doesn't mean it's necessarily wrong and it doesn't necessarily make their own opinion wrong. It is just someone coming at it with a different perspective... I want them to understand that you can't necessarily argue something "because my parents said so!" because that's not an argument, or “because I read it." That's not an argument either.

While Mr. Nixon did not implement any planned debates or discussions, he often brought up controversial issues during his lectures. He said that his students were from rural areas that were "insulated and protected" and that they sometimes talked about other groups or political 
ideologies in derogatory ways. He said during these times, he encouraged students to question their assumptions about other ideologies, other groups of people, and the language they use to describe them. Also, he perceived that their insularity kept them from having firsthand experiences with urban plights like homelessness and gang-related crimes. Additionally, when issues arose in his class that were controversial, he used it to show the differences between liberals, moderates, and conservatives so students could learn to think independently about issues. Yet, the differences he highlighted between ideologies were often simple and onedimensional, such as saying conservativism was the position for "religious people."

At Smallwood High, Mr. Howard and Ms. Finch implemented student-centered debates on controversial political issues as a culminating activity at the end of the school year, though they differed in their inclusion of controversial issues up to this point. In the activity students voluntarily picked a viewpoint on an issue, then researched and prepared a statement of their position and engaged in a two-on-two debate with timed segments for opening statements, rebuttals, and questions from classmates. As stated previously, student-to-student conversation on controversial issues sometimes promoted false information and resentment between students. The researcher observed some students using terminology and viewpoints that appeared influenced by presidential candidate Donald Trump (e.g. calling Mexicans rapists). Other specific groups, such as transgendered people and women, were referred to in ways that could be perceived as offensive. Teachers did not intervene at these moments and discussions were ended without further reflection on the issues. The researcher asked teachers what students were to learn from the debate. One teacher said, "Now they know there are two sides to each issue." With desperation the other teacher joked, "They didn't learn much." 
As data suggested, rural teachers of government emphasized civic knowledge for students so they could carry out traditional citizenship roles and responsibilities as adults, such as paying taxes, voting, and volunteering. Also, data revealed nuances on rural citizenship education, including a strong emphasis on workforce preparation and some attentiveness to traditional civic views on social involvement. While participants were committed to teaching "real world" issues in their government courses, observations suggested current event lessons and discussions of controversial issues often led to the sharing of incorrect information by students and, occasionally, disparaging rhetoric.

\section{Theme 2: Place-based Learning for Future (Dis)placements}

The second theme illuminates the ways that perceptions of place impacted citizenship education in rural contexts. It highlights teachers' purposeful use of place-based learning and their concurrent endorsement of the narrative that students must leave rural areas after high school to find better college and career options. Also, this theme explores the ways teachers' tacit assumptions of rurality factored into their citizenship instruction.

Data demonstrate participants implemented place-based learning. They utilized community resources to assist in the development of students' citizenship knowledge. Resources included field trips to local historical and political sites, hosting local political leaders as guest speakers, and promoting student involvement in local elections and political campaigns. Also, participants used many references to local events, people, and occupations to connect course content with students' prior knowledge. When participants were prodded to expound on the aims and purposes of utilizing local resources, they stated the importance of students being knowledgeable about local government and "things that affect their lives." 
Commonalities in teachers' perceptions of rural places illuminated their place-based curricula. Participants discussed rural communities in terms of similar geography, economic activities, and cultural ideals. Participants used the words "remote," "spread out," and "beautiful" when discussing the geography of their regions. Mr. Nixon and Ms. Thompson, teaching in adjacent albeit similar rural districts, spoke of the dominance of farmland and dispersed houses in their regions. Mr. Nixon said that each year he has students who miss several days of school to help their families harvest tobacco. Also, related to rural economics, Mr. Nixon discussed the importance of a large timber manufacturing plant that provided a high portion of local jobs. He said, "Someone in every student's family works for the plant." Yet, he and Ms. Thompson were aware that recent closings of other factories in their respective counties meant that more rural people were seeking work elsewhere. This was a distressing, but matter-of-fact point. Mr. Nixon said, rural people are a "proud people" and have deep roots with the land and community, but he conceded that the "community dynamic is getting smaller and smaller" due to a dwindling population as people move to the city.

Despite perceptions of waning economies, participants discussed their schools as institutions that produced a sense of community as they pulled together dispersed rural people. The perceived social vitality of rural regions was connected with the familiarity and heritage that the local school provided. A majority of the participants referred to their school's community as "tight-knit." Ms. Kelly said, "People really know their neighbors" and "have friends of all age groups.” Ms. Kelly had taught most of her current students' parents and frequently saw them outside of school. Likewise, Ms. Finch said "student's parents and grandparents went to Smallwood High," which provided a common link between generations of rural families. Ms. 
Thompson said, "Everyone knows everyone and you are related to half the people," and in her community "people really help out their neighbors."

For Ms. Thompson, the concept of community held increased importance as the area around Stuart County High had recently experienced a natural disaster that left many farms and structures damaged, but saw people unite to assist in rebuilding efforts. Also, the school and community had experienced several student suicides and a homicide. Ms. Thompson said a successful high school football season helped the community heal its wounds and "bring everyone back together." Both Mr. Nixon and Mr. Howard also mentioned the importance of school athletic events in bringing together a dispersed rural population, providing a common sense of pride, and connecting community leaders with school happenings.

Despite elements of familiarity and pride, communities were often spoken of in desperation by teachers due to varying changes that were occurring across the regions. Some areas, such as Mr. Nixon's and Ms. Thompson's locales, experienced “stagnant population growth" or out-migration of people to cities. Other areas dealt with problems of in-migration of "people from out of state" due to increased recreational tourism. Mr. Howard felt that increased tourism and outsiders moving to the local lake meant that his school's community was no longer the same community of yesteryear. He believed the change was "sometimes painful" as it brought long-term residents head-to-head with newcomers over demands for public services and the "luxuries" of city life. All of the participants, even those in high tourism areas, talked about the increasing number of rural people who work in the city due to a lack of "white collar jobs" in rural areas. Mr. Howard said that he passes " 14 or 15 cars heading into town each morning for every 1 or 2 cars heading out here." 
These multifaceted perceptions of rurality and place influenced teachers' decisions about the curriculum and often produced a deficit message to students about rural places. Participants valued place-based learning; yet, their promotion of the idea that students should leave rural areas did not display a critical consciousness of place. For example, Mr. Nixon took his students on a field trip to tour the local court house to connect students' knowledge of the judicial system with its practice in local life. He also carried out field trips to local historic sites to teach students about the nation's foundational ideals. Likewise, Ms. Kelly invited a local politician to address county-level government with students, giving students insight into the citizenship responsibility of paying taxes and getting returns through public services. Yet, the guest speaker suggested students would have to leave their rural communities to find good jobs. While using local resources, Mr. Nixon and Ms. Kelly place-based learning failed to produce critical thinking about rural places, their relationship to broader, more complex political issues, or the reciprocal relationship between students' lives and place. When teachers coupled local civic lessons with narrative of leaving the community for academic and career success, they endorsed messages that their community is not worth civic investments. This presents a failure to engage students in place-conscious civic life. The one project that may have helped students think more critically about place in civic life, Ms. Kelly’s year-long citizenship action project, was stopped after one year due to time constraints.

When asked to expound on students' (dis)placement after high school, Ms. Thompson and Ms. Kelly estimated that nearly half of their students go away to college. Though they acknowledged some return after college to work as teachers or in management in local industries (Ms. Thompson's own life mirrored this first pathway). Ms. Thompson said that many of the college-educated students and those educated in trade schools would end up living in their 
hometown but commute to work in the metropolitan area that is 20 miles away. Ms. Kelly said that a few students would go into rural family businesses (i.e. logging or farming) and a few would work in the local tourism industry, but many would leave for college and careers elsewhere. Mr. Nixon suggested that because of waning industrial life in the communities around Henry Lee Combined that "people are leaving in search of jobs" and that a rural teacher has to prepare students for life outside of their local community.

When asked whether teachers altered their instruction based on the recognition that some students would leave the area for college or jobs, participants emphasized that their approach to citizenship education, which focused on practical knowledge, was transferable to any future locales. However, further illumination of this point showed that participants assumed students would remain close by or live within the state. Ms. Kelly and Ms. Thompson stressed that students leave to live in the adjacent metro areas. Mr. Howard said he believed that students who left their rural community after high school would continue to live within the state and that much of their local civic knowledge would be transferable similar locales. Mr. Howard's own life history, living in a variety of places within the state, influenced his beliefs on this matter. He said:

I've got that information that I can share with them. There are going to be differences in each place. It is life and choices, but the core is still the same. If they know the basic knowledge, they can make the jump to whatever are their specific needs.

Ms. Finch concurred when asked about students leaving the area after high school. She said, "Every student needs to have the same basic knowledge when they leave me." However, Ms. Finch was unique amongst participants that she believed, based on her short tenure at 
Smallwood High, that a vast majority of students stay in the area upon graduation, speculating that only "10 or so students left the area from last year's graduating class (of 200+)."

Connections between teachers' perceptions of rurality and citizenship education was refined further when participants were observed in their classrooms. In addition to endorsing narratives of leaving, they displayed tacit views on rurality that countered their convictions to withhold negative assumptions about rural students. Participants tended to assume local “conservative" "blue-collar" values dominated students' mindsets. Political issues were discussed through teachers' presumptions of students' values. For example, when teaching about different political perspectives on the issue of gay marriage, Mr. Nixon reminded students that "liberal is not a bad word." He also said that "religious people are conservative" and "against gay marriage." These excerpts display his assumption that students identified with the evangelical Christian belief system. He made no mentions of the complexity that religion plays in gay marriage. Ms. Finch made comments in front of her class about "all you Trump supporters" which received cheers and the pumping of fists in the air from a few students.

Narratives of leaving after high school appeared tied to perceptions of the local economy. Ms. Kelly and her guest speaker both made remarks about the local area having "no jobs for young people." Students made comments about their preference to "leave" or "get out of" their rural community upon graduation. At no time did the researcher observe teachers instructing students to think about the sustainability of rural areas or ideas to address the challenges of their local economies. Mr. Nixon promoted moving to suburban and urban areas. He said, "They (suburban areas) have money, but not this area. There are no doctors or lawyers out here." When introducing his shark tank activity, Mr. Nixon told students to create businesses that target 
metropolitan areas, not rural areas because "rural people do things on their own." He said at this time, "Small businesses make jobs, not the government."

The data paint the picture that teachers' perceptions of rurality and place influence their citizenship objectives and instructional choices. Participants perceived their communities as undergoing change. These perceptions fed the narrative that rural young people should relocate or commute to work in cities. Participants utilized place-based learning, but did not stimulate critical examinations of place thereby obfuscating place-conscious civic involvement. Teachers' perceptions of place complimented their traditional conceptualizations of citizenship education. Teachers' believed that successful citizenship was rooted in basic knowledge of government and the execution of routine political behaviors, regardless of place. This displayed a deficit in placeconscious citizenship instruction.

\section{Theme 3: The Gatekeeping Triad}

The final theme that emerged from the data focuses directly on curricular-instructional gatekeeping. This theme builds upon the previous theme by examining other factors common in rural areas that materialized in the data as curriculum determinants. The theme consists of three interrelated constructs (self, other, and authority) which work to influence rural teachers' decision-making on citizenship curricula. Findings illuminate the ways rural teachers navigated a myriad of factors within their unique environments. Specific rural conditions, such as familiarity and remoteness, enabled teachers to use, blend, or reject various curricular inputs in their government courses. The conditions under which these element interact are examined in this section.

\section{Self}


The first construct in this theme is self. The term self is used to reflect the impact of teachers' life histories, dispositions, and teaching experiences - all categories that emerged from the raw data (see Appendix C). Gatekeeping assumes teachers have the ultimate control over their curriculum and that they use their frames of reference to make decisions (Thornton, 1989). Findings in this theme suggest the motives for their decisions lie within their formative experiences.

Participants' life histories acted as reservoirs of experience that assisted in the formation of their conceptualizations of citizenship education and, therefore, their curriculum. For example, Mr. Howard believed that moving around the state as a child provided him with a broad perspective on the variety of human experiences that exist in society. He used this personal experience as an asset during his instruction for citizenship, often discussing events from his own life to highlight the ways specific citizenship expectations played out in the real world. Mr. Howard stated his conceptualization of good citizenship stems from "environmental" factors such as the values his parents instilled in him and his memories of the close relationships his grandparents had with their neighbors. When Mr. Howard discussed these elements, he spoke of his own "socialization" that helped him to be "receptive to different ideas." In his classroom, he attempted to encourage the same receptiveness in his students through sharing multiple perspectives on issues. Mr. Howard's description of one learning activity illuminates this goal: At the beginning of the year, I have students take out a piece of paper, draw a line down the middle of it, and write liberal on the left and conservative on the right. If there is a topic we talk about like abortion, they can put down pro-choice or pro-life. At the end of the year, I want them to circle which one they are. Then I want them to go down and count and see if they are $100 \%$ conservative or $100 \%$ liberal or if they are in the middle 
like the bulk of the population... Sometimes they are surprised because they will come in spouting whatever political ideology they are and then turn around and say, "I didn't realize I thought that way." Welcome to growing up. It's cool.

Working in tangent with past life experiences, participants discussed their own teaching philosophies and personal dispositions. These self-beliefs influenced curriculum decisions as teachers emphasized certain content and learning objectives over others. Mr. Howard held an educational philosophy that all teachers should "morph and modify" their instruction because the world constantly changes. This belief made him more receptive to curricular input from younger colleagues and produced his desire for students to stay up-to-date on contemporary political issues. Both Ms. Kelly and Mr. Nixon held a teaching philosophy that "getting to know students" was a prerequisite to successful learning. They encouraged open classroom environments and attempted to build trust between themselves and their students.

Across multiple interviews, Mr. Nixon stated his commitment to prepare students to rebound when "life knocks them down." This aim was rooted in overcoming his own life adversities such as owning a small business, experiencing a divorce, and raising a daughter as a single dad. He said, "Life is about adapting and overcoming... and solving problems.” For Mr. Nixon, this meant instructing students for a type of citizenship that was resilient and practical. As discussed in the first theme, his dispositions influenced him to develop capitalistic-orientated assignments and analogies.

Similarly, past educational experiences, both as students and as teachers, influenced participants' approaches to citizenship education. For example, Mr. Nixon moved with his family as a teenager to a western state and experienced rural education for the first time. He said this was "revolutionary" for him because the rural teachers acted as "more than just teachers." 
They were mentors. He said that he experienced a "family dynamic" in his rural high school and it motivated him to want teach in a rural school. For Mr. Nixon, this experience fostered a sense of trusted friendship between students and teachers that only existed in rural schools. His personable interactions with students inside and outside of his own classroom revealed this disposition in action.

As a new teacher, Mr. Nixon said that the school principal took the first-year faculty to tour the surrounding areas by school bus, saying "this is where your students live." Mr. Nixon said that this event had a big impact on him, to see the economic destitution and poverty of his district. Ms. Thompson grew up in the town where she currently teaches. She said that her knowledge of and familiarity with community is one of her greatest assets as a government teacher. Her experiences as a college student also motivated her to prepare students with the skills they would need for next academic level.

All of the participants, except for Ms. Thompson, spent time growing up in metropolitan areas. These participants often used urban-centric language when talking about rural places. For example, Ms. Kelly said that she thinks of rural as "not in the city." She believed city life is not as socially blended as in rural areas. She said that city life is "focused around specific neighborhoods or streets" and that people in the city "probably don't know anybody else that lives on any of the other streets." She believed it was opposite in rural areas, saying life is "more blended" and "you know everyone." These personal beliefs, based on her own life experiences, corresponded with her desires to get to students to "care about their neighbors" as citizens and be involved in community service.

Seen here, life histories and personal dispositions emerged to form the construct of self. Self acted as a stimulus for teachers' curricular aims and conceptions of good citizenship. 
Teachers interpreted their role as citizenship educators through personal experiences as they acted within their rural places. Self provided the underpinnings from which other components of this theme interact. The gatekeeping process was fluid for rural teachers as they tended to possess a good sense of themselves and their desires; yet, the self was not autonomous. Participants considered the desires of additional people when making decisions about the curriculum, hence the emergence of the next theme - others.

\section{Others}

Others, or people outside of oneself, emerged as a factor which influenced participants' gatekeeping in citizenship education. Others, as used here, represents students, parents, community members, colleagues, and administrators. This construct recognizes the impact of social interactions, often amiable and productive, that teachers navigated within rural contexts to produce a curriculum that satisfied various parties vested in rural education. Data from this study revealed similar social interactions and participant responses across each specific rural setting.

First, students attempted to influence lessons on citizenship in each rural classroom through direct and indirect means. Through direct means, such as voicing questions and comments during instruction, students held some influence on the curriculum; though this was truer in classrooms where teachers relinquished some of their power to students. On most occasions, students were observed trying, often unsuccessfully, to steer lessons toward their personal interests and understandings of content. While teachers gave varying amounts of attention and space to students' voices and talking points, student input was often halted short as teachers redirected students to the preplanned lesson.

Represented of this action, Ms. Kelly and Ms. Finch redirected student initiated discussions of controversial issues when other activities were preplanned. In these situations, 
students' contributions held little influence on changing teachers' decisions about the curriculum or planned methods of instruction. Student input appeared to be unwarranted and, therefore, rejected by teachers. Students thereafter displayed signs of boredom and detachment from the lesson at hand. However, during cooperative group activities students held more influence over the direction of their learning experience, through both interactions with other students and with the teacher. Cooperative groups altered the power dynamic in ways that allowed students more freedom to pursue aspects of the curriculum they found engaging. Teachers varied in their ability to facilitate desired learner outcomes during group activities as students sometimes vocalized topics well outside the scope of the government courses.

Participants stated their consideration of students' interests and abilities during the planning phases of lessons. In this way, students indirectly impacted the curriculum. Ms. Thompson's goal of helping students to become caring and conscientious adults was tied to her intimate concern for students and for the community. As a former graduate of the school, Ms. Thompson felt personally responsible for mentoring students, often referring to them as "my kids." She was motivated to take on a wide variety of advising roles at the school. Similarly, for other participants, intimate interactions with rural students expanded well beyond the classroom walls. Teachers who coached sports placed value on healthy personal connections with students. These relationships were utilized in class to forge bounds through which citizenship instruction was perceived to hold more meaning and utility. Exemplifying this point, Mr. Nixon said that rural teaching was about building "trusted friendships." He kept in touch with many former students, offering them support as a mentor and friend.

Similar to indirect student influence, parents and community members played a tacit role in affecting teachers' curricular-instructional decisions. Mr. Nixon, explaining the lack of direct 
parent involvement, said parents work "two or three jobs" or "have younger kids at home." Familiarity between teachers and parents established parents influence on the curriculum while also providing teachers the means to navigate their influence. Ms. Thompson said people in her community "know me" and "the community and the parents know that I'm not trying to persuade their kid one way or the other (concerning political ideologies)." Familiarity was displayed in Ms. Kelly's discussion of parents and community. She said that she is Facebook friends with many of the students' relatives, sees them at the grocery store, and dines with them at monthly Rutarian club meetings (Rutarian clubs are rurally located community service organizations). Furthermore, Ms. Kelly invited her acquaintance, a county-level politician, to speak to her students.

The close relationships between rural teachers and their communities offered trust and like-mindedness concerning curricular aims. Teachers reported that they had never received complaints or faced criticism from the community due to their curriculum or instruction. Also, though teachers perceived mostly conservative political leanings in their communities, they professed a commitment to political impartiality in the classroom and declared parental support for their lessons as the reason their gatekeeping choices were never criticized.

Interactions with faculty within the school (e.g. colleagues and administrators) appeared to have a greater influence on teachers' gatekeeping than students, parents, or community members. Mr. Howard's and Ms. Finch's joint-planning of their government course exemplified this action. When asked to explain the cooperative planning, Ms. Finch, the less experienced teacher, gave credit to Mr. Howard, the department chair, for his great lesson ideas. In this aspect, their association acted as a mentorship for the younger teacher. When asked about his department-level collaborations, Mr. Howard said: 
The young people in this department don't realize what an impact they have on me. When they come in, they are fresh. They are rookies. They don't really know what's going on or what we are teaching. I can say, "Well here is what we've done, he's how we worked through this," and one will say, "I wonder what if we did this to it?" and I say, “Good idea, Let's go!"

Despite identical plans, lesson implementation differed between the co-workers. In one observed lesson, procedures were similarly stated by both Mr. Howard and Ms. Finch; yet, each teachers' demeanor altered the learning experiences for students. Mr. Howard's classes were teacher-directed and Ms. Finch's classes allowed for more student-to-student interactions. For Ms. Finch, this was guided by her personal desire to get students to "work with someone they might not normally work with because that's part of life," while Mr. Howard placed value in sharing his expertise and engaging students in short interchanges. Despite these instructional differences, mutual planning efforts provided the framework and objectives for the lesson.

Ms. Thompson also discussed her interactions with colleagues about the curriculum, though she perceived these relationships as being mostly one directional due to her role as department chair. She said:

I'm kind of the expert on government at my school because that was my major in college and I'm getting my masters in politics and political communication. So, no one really questions me about what I want to do or how I want to teach. They kind of just leave it up to me. I give the other teachers who teach government my curriculum materials. I tell them, "Here is everything that I use and here is everything that I did. Follow it. Don't follow it - whatever you want to do. If you have any questions, come see me." I am kind of the government go-to person around here. I get away with what I want. I don't care if 
other teachers do the exact same thing or not. I know the school is really pushing for us to all be alike, but I tell them this is what I know. I'm not going to not do something because the other teachers don't want to do it.

In addition to navigating relationships with colleagues, administrator approval played a role in participants' gatekeeping. All participants said that they had a good personal relationship with their administrators and that this produced a satisfactory amount of autonomy in their curriculum development. Mr. Nixon said that his school's head principal and assistant principal were very supportive of his curricular-instructional decisions. The assistant principal often observed his classroom during student presentations and voiced support for his goals to develop students' public speaking skills. The head principal was a former social studies teacher who provided Mr. Nixon advice to improve his instruction - something Mr. Nixon found valuable in his pursuit to become a better teacher. None of the participants voiced concerns that their curricular-instructional decisions would ever be viewed negatively by administrators.

Taken as a whole, the desires of "others" on teachers' curricular-instructional gatekeeping was omnipresent, though their effects on directing teachers' actions remained variable. Students' influences upon the curriculum were both direct and non-direct; yet, direct actions were mostly controlled through teacher redirections to preplanned lessons. Teachers' close relationships with students in rural schools tacitly influenced instruction more than students' impromptu voices in the classroom. Similarly, familiarity via teachers' relationships with parents and community members created an environment of trust that enabled gatekeeping autonomy. Albeit, this autonomy was contingent on parents and teachers having likeminded goals. Goals included impartiality when teaching political perspectives and focusing on civic knowledge objectives. Positive relationships with colleagues and administrators led to the 
sharing and support of curriculum and instructional ideas and, likewise, resulted in teachers perceiving a high level of autonomy within their classrooms.

\section{Authority}

Authority emerged as the final construct in the gatekeeping triad. Authority, as used here, represents all of the bureaucratic structures that lie outside of the rural school and community which influence the curriculum. These structures include state-level legislation and district-level policies. All participants mentioned state standards in response to the question: How do you decide what to teach your students regarding citizenship? This suggests the pervasiveness of external sources of authority in rural classrooms. Participants acknowledged state standards influenced the scope of their curriculum and they reported adhering to state standards and district-level pacing guides. However, participants felt they had autonomous decision-making power regarding instructional activities and, therefore, the freedom to pursue their own personal aims for their students' citizenship development. In this way, participants spoke of implementing the standards using their preferred methods of instruction, not of subverting or rejecting the state standards. Noteworthy, however, participants perceived state-mandated testing as a much greater influence on their curricular-instructional decisions.

Exemplifying participants' attitudes about the relationship between state standards and instruction, Mr. Nixon said:

In the government class, I have a lot of flexibility in what I can do and what I can't do. The class has 19 state standards that go with it, but there is no real "you got to teach this, then teach this, then teach this." No, you can hop, skip, and jump around depending on what's going on (current events) and I love that about that class. 
All participants mentioned similar sentiments regarding state standards and autonomous classroom instruction. Ms. Kelly called the state standards "essential knowledge" that her students needed to learn in the government course. She perceived the standards as the guide which establishes the major aims of her course. Demonstrating this point, Ms. Kelly constructed a large three-ring binder for her course that listed the state standards in correspondence to each of the textbook's units and chapters. Each section of the binder contained relevant standards, key vocabulary terms, main ideas, lecture notes, worksheets, and activities. Ms. Kelly said, "You have a little more freedom [in the government course] but there are still things that the students are supposed to learn."

Ideas of freedom, flexibility, and autonomy were related to teachers' personal perceptions regarding state-mandated testing. The $12^{\text {th }}$ grade government course, which all five participants' instructed, did not require state-mandated end-of-the-year tests. Because of the absence of standardized tests, teachers felt they had more freedom and time to plan and carry out their preferred projects. Ms. Finch said:

We had a unit where the students did a project where they had to create a political campaign. Someone had to be the political candidate and they had to run the campaign. So I have the flexibility to do things like that, where if I had a test at the end of the year then I would not be able to do that.

Mr. Howard had been involved in developing the district-level pacing guide for the government course with a team of teachers from around the county. He said that standards and curriculum pacing guides were "a thing that are necessary," though he too believed they did not infringe on his autonomy as a teacher. He said: 
You can teach those items in the standards and be specific about those things, but you don't have to dwell on them. I give examples of things all around and we go different directions depending on the flavor of the day, the politics of what is going on. We are able to get all the points necessary, but I can still get that done and add in things that are interesting.

Similar to Ms. Kelly, Mr. Howard viewed state standards positively, saying that the guidelines provide "a base knowledge everyone should know." However, Mr. Howard shared the most critical views on high-stakes testing, saying:

I don't believe in testing students one way. One test, one way, one time. That is not a measurement of how much a child knows. I've had some brilliant kids come through here that flunk every test.

When asked to elaborate, Mr. Howard suggested that testing should be used as a learning tool to improve student understanding of content and show their application of ideas to other situations. In his class, he said students frequently performed poorly on their first test, but improved through retests as they learned from their mistakes. He said retesting students meant they "have an understanding of how to take the information and move forward with it, which is what we should be doing anyway."

In addition to standards and high-stakes testing, participants relied on textbooks for guidance regarding the purposes, scope, and sequence of their government course, and consequently, their aims for citizenship education. Because textbooks were adopted at the district-level, they fit under the authority construct. Textbooks were rarely mentioned in interviews with participants; yet, classroom observations and artifact analysis revealed their presence and use in the classroom. In this way, they had a direct influence on the enacted 
citizenship curriculum. As a caveat to this point, all participants utilized supplemental readings, most often in the form of news articles and other associated research, as well as lecture points that expanded upon or interpreted textbook content through teachers' perspectives and opinions. Teachers' ultimately made decisions that guided their students' learning experiences, but these decisions were, in part, framed by external sources.

Sources of authority were perceived by rural teachers as largely positive or "necessary" and they felt the need to "cover" state standards and curriculum guidelines. Teachers did not feel restricted by authoritative structures. They worked within the structures to pursue their own intuitions and curricular desires. In this way, their gatekeeping aligned with the standards. Participants' feelings of autonomy in the face of authority were linked to their conceptualization of citizenship education as practical knowledge. Citizenship education was conceptualized in ways that did not contradict or challenge the expectations of authoritative structures, and were either allied with them or in harmonious supplementation of them.

\section{Conclusion}

This chapter presented the study's findings through three interconnected themes. The first theme, citizenship education as practical knowledge, conveyed participant's conceptualizations, aims, and motives for their citizenship curriculum. Rural teachers conceptualized citizenship education as teaching students basic knowledge that could be applied in traditional citizenship roles. Emphasis was also placed on preparing students with skills for the workforce or college.

The second theme, place-based learning for future (dis)placements, was built on participants' use of local resources and rural funds of knowledge for their citizenship instruction. This theme examined how place-based learning converged with teachers' beliefs that rural places held largely inadequate job opportunities, thereby forcing students to leave the area after high 
school for better college and career options. In this way, rural citizenship education was uncritical of place. This theme was complicated by teachers' assumptions about rural life, such as the dominance of conservativism and poverty, which resulted in narratives that students themselves seemed poised to embrace.

The last theme was the gatekeeping triad. Three major constructs - self, others, and authority - emerged from data to represent a variety of influences on teachers' curricularinstructional decisions. The theme examined the interaction of the three constructs and teachers' navigation of them within rural educational contexts. The factors that influence the curriculum were filtered through the lens of self. The self represents participants' dispositions, motives, and teaching philosophies rooted in formative life experiences. Data showed that participants' were influenced by their own life experiences and drew upon them as anecdotes to highlight course content and motivations for specific curricular aims. Others represent the desires of students, parents, community members, colleagues, and administrators. Data suggest that teachers' perceived a high level of agreement between varying groups of others, utilizing trust and familiarity in their social interaction thus enabling confident gatekeeping. Authority represents the bureaucratic structures that influenced the curriculum, such as state-mandated standards and high-stakes tests, as well as pacing guides and textbooks adopted at the district level. Participants made decisions that worked within or in compliment to the authoritative frameworks, and felt freedom to implement their curriculum without external interference, especially because of the absence of high-stakes testing for the course.

The next chapter offers a discussion of these findings to explain the theoretical significance and to describe how this new knowledge fits into the fields of citizenship education 
and rural education. Applications of the findings are discussed for the improvement of rural teaching and rural teacher education. Lastly, recommendations for future research are offered. 


\section{CHAPTER VI}

\section{DISCUSSION}

Researchers recognize that curricular-instructional gatekeeping is influenced by teachers' conceptualizations (Cornett, 1990; Evans, 1990; Fickel, 2000) and environmental factors, such as the authority structures of schools (Fry \& O'Brien, 2015; Sondel, 2015) and the sentiments of local communities (Romanowski, 1996; Saada, 2013). Yet, a myriad of schooling contexts are unexamined by citizenship education researchers (Vinson, 1996). Particularly, a dearth of knowledge exists on the impact of rural contexts upon citizenship education (Martin \& Chiodo, 2007). Ignoring this gap enables the continued marginalization and devaluing of rural communities (Theobald, 1997). This lack of knowledge facilitates misunderstandings of rural education by disregarding rural teacher perspectives, and it potentially exacerbates divestments in rural communities by encouraging only urban-centric answers to citizenship education issues.

This study helped to fill the knowledge gap in rural citizenship education by using a qualitative approach that purposely elevated rural teacher voices and their context-specific knowledge. It utilized a grounded theory design and a social constructionist lens to capture these authentic perspectives. Specifically, this study examined the experiences of five rural teachers of government to uncover their conceptions of citizenship education, place, and the factors that they perceive as influences upon their citizenship curriculum. The results of this examination produced a picture of rural citizenship education that is new in the field of educational research.

The previous chapter described and provided evidence for three themes that emerged from the data. These themes helped to answer the research questions; and when taken as a whole, function as a descriptive statement of rural citizenship education. The present chapter further develops this nascent picture by scrutinizing the meaning of the themes. Prior bodies of literature are reexamined to position the study's findings about rural citizenship education within the 
broader fields of rural education and citizenship education. Implications of the study's findings are presented for scholars, practitioners, and teacher educators. Lastly, this chapter offers directions for future research on citizenship education in rural contexts.

\section{Connecting the Themes}

Theory building through grounded research requires examining the unique conditions and relationships between social structures that give rise to a specific phenomenon (Corbin \& Strauss, 2014). The current section builds upon the presentation of themes from chapter five by offering a concise, interconnected statement on the phenomenon of rural citizenship education. To make clear the presentation of this nascent theory, identifiers were selected for each theme that encapsulate its major emphasis. These identifiers make lucid for readers the distinct aspects of rural citizenship education encompassed by each theme and offers a chance to succinctly relate the themes and, therefore, produce an easily comprehendible model for readers.

The themes in chapter five included: (a) citizenship education as practical knowledge; (b) place-based learning for future (dis)placements; and (c) the gatekeeping triad. While the three themes appear somewhat disconnected and varied, each offers insight into a certain component of rural-specific citizenship education. These components are identified as conceptualizations, place, and influences.

Revisiting the research questions and highlighting the study's major findings helps to assemble the picture of rural citizenship education. The study sought to understand rural teachers' conceptualizations of citizenship education (question 1); perceptions of place (question 2); and gatekeeping in rural contexts (question 3). The themes provided answers to the three questions through developing an interlocking explanation of rural citizenship education. The first theme, citizenship education as practical knowledge, focused upon describing teachers' 
conceptualizations. For this reasons, the theme was condensed to the identifier:

Conceptualizations. These conceptualizations were complementary to findings in themes two and three. Teachers made decisions about citizenship education that honored their "practical knowledge" conceptualizations, that aligned with their perceptions of place (theme two), and that were agreeable with other influences (theme three). Moreover, the relationship between teachers' gatekeeping decisions and conceptualizations was bidirectional. Perceptions of place and other influences impacted participants' aims for citizenship education.

The second theme, place-based learning for future (dis)placements, offered deeper and more refined context-specific understandings of the conceptualizations presented in the first theme, particularly as they were put into practice by teachers. This theme relied on an examination of teachers' perceptions of place and rurality and their use of local resources for citizenship instruction. For this reason, this theme was given the identifier: Place. Perceptions of place forged pathways through which teachers' conceptualizations (theme one) became realized as context-specific. Exemplifying this point, teachers' place-based perceptions offered the everpresent expectation that students should leave rural areas for future college and career success. This point was reconciled with conceptualizations of citizenship as "practical knowledge" as teachers displayed confidence that their curriculum and instruction would be sufficient for competent citizenship regardless of students' future locales (i.e. displacements). Also, perceptions of place were connected to the third theme - the gatekeeping triad. Teachers perceived that their gatekeeping represented the desires of the local community. They found support for their decisions in the social and bureaucratic structures of their rural schooling situations. Moreover, gatekeeping was navigated through the familiarity with rural places and people. Data revealed the concept of place to be a separate, ever-present context that influenced 
teachers' actions and thoughts; hence, its position as a standalone theme in the findings. Self, others, and authority impact gatekeeping within the realm of place, not in addition to it.

The final multi-faceted theme, the gatekeeping triad, presented three constructs that emerged from the data detailing major factors which influenced rural teachers' decision making about their curriculum. For this reason, this theme was rebranded with the identifier: Influences. This theme depicted various curricular inputs (self, others, and authority) within rural settings. These influences helped to understand the building blocks of teachers' conceptualizations of citizenship education (theme one) through how they developed their aims and motivations. Also, the influences revealed how teachers navigated the curriculum within their rural place (theme two).

Taken as a whole, the three themes describe citizenship education in rural contexts. They display the relational aspects of rural people, places, and structures. Thinking of the themes as three separate, but interconnected components helps to assemble an image of rural citizenship education that establishes the range and relationships of this emergent theory. The figure below offers a visual depiction of these interconnected components. The triangle model represents the harmonious alignment and salient relationships of the three components. The arrows and corresponding boxes express the specific bidirectional connections between each component. 


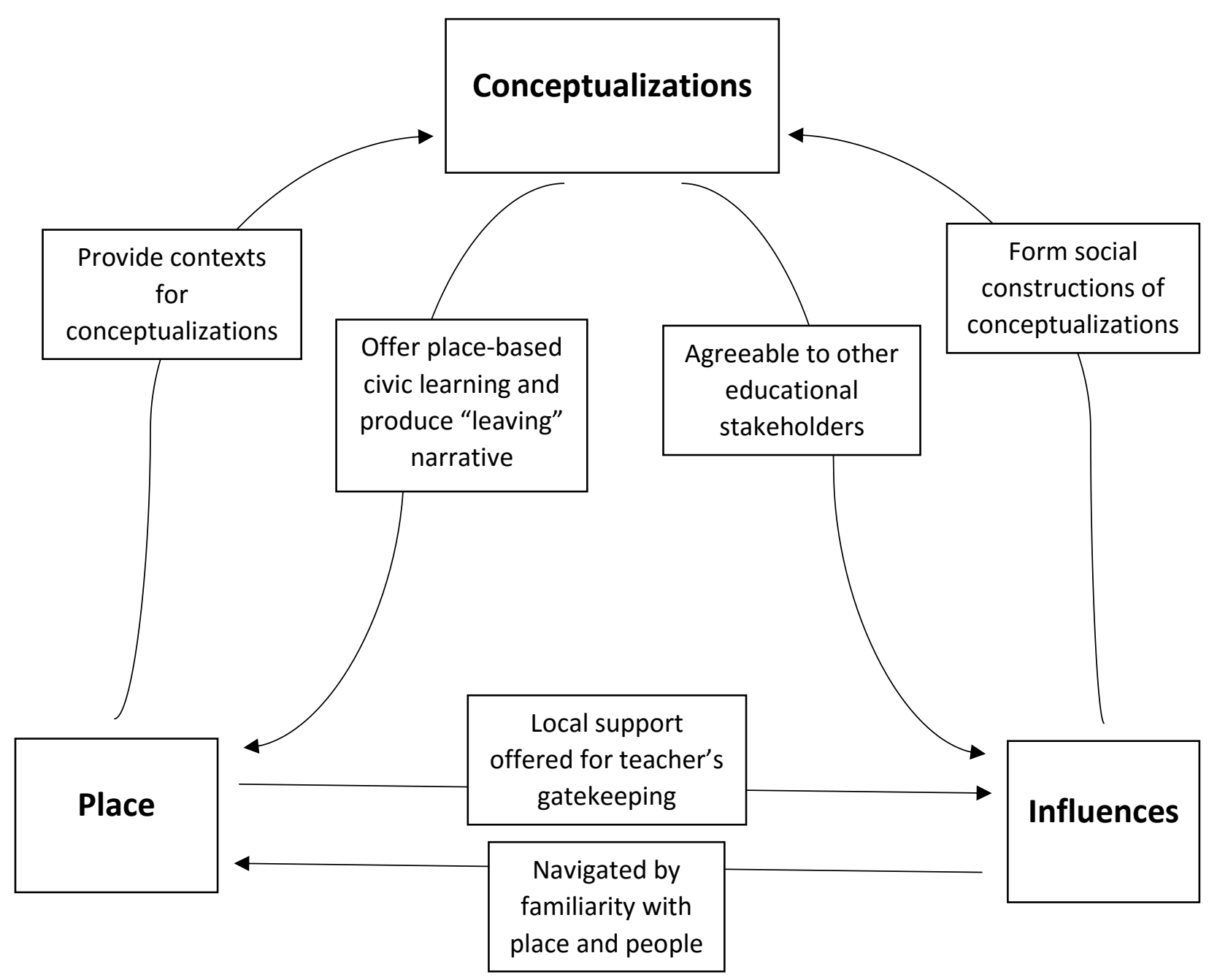

Figure 1: Intersections within Rural Citizenship Education

\section{Interpreting the Findings}

This section reexamines the existing literature relevant to the study's findings.

Reexamining existing literature helps to make sense of the findings and produce a more meaningful understanding of rural citizenship education. Through this act of reexamination, it becomes apparent how the findings extend upon existing knowledge and how prior knowledge helps to interpret the emergent picture of rural citizenship education.

\section{Conceptualizations}


The first theme revealed rural teachers' conceptualizations of citizenship education as practical knowledge. Participants believed that students should be prepared for citizenship by possessing knowledge of basic governmental structures and political processes. They hoped that this knowledge would transfer to engagement in traditional citizenship roles and expectations, including voting, obeying laws, and paying taxes. Instruction in rural classrooms, therefore, focused largely on transmitting a body of established civic knowledge to students and helping make connections to the "real world," or what teachers' perceived as necessary. These aims included work-related skills, being informed voters, and knowing how to participate in established political processes.

Some prior research suggests that transmitting basic civic knowledge and teaching expectations for traditional citizenship roles is common place in America's social studies classrooms (Kahne et al., 2000; Patterson et al., 2012; Torney-Purta, 2002). Yet, scholars warn that such instruction presents a narrow conceptualization of citizenship (Arbowitz \& Harnish, 2006; Parker, 1994; Westheimer \& Kahne, 2004). Arbowitz and Harnish (2006) said that traditionalist conceptualizations of citizenship align with the ideals of civic republicanism (i.e. virtuosity and patriotism); however, these ideals discount the real world existence of conflicting values, diversity, and transnationalism. Westheimer and Kahne (2004) call traditionalist approaches to citizenship education personally responsible citizenship because they emphasize individual involvement in civic life and they focus on obedience to law and loyalty to the state. They suggest that personally responsible citizenship is not inherently democratic and would even be valued in totalitarian states because of its emphasis on compliancy and allegiance. Others suggest democracy requires direct participation and the recognition of multiculturalism (Parker, 
1994), value conflicts (Hartoonian \& Van Scotter, 2012), and thoughtful decision making (Engle, 1960/1996).

In this light, rural teachers of government presented a personally responsible approach and, therefore, a largely traditional rendering of citizenship to their students. This approach may not be wholly adequate preparation for democratic life. While teachers perceived their approaches as "essential" and "adequate" for students' citizenship development, their conceptualizations offered a democratic deficit. Issues of pluralism, social injustices, and value conflicts where either nonexistent or addressed in peripheral fashion. Participants spoke of critical thinking, teaching multiple viewpoints, and teaching students to "think for themselves," but these aims appeared in lessons as choosing between simple left versus right policy choices, not examining the underpinning values or complexity of political ideologies. Additionally, teachers allowed stereotypical perspectives of marginalized groups and misinformation on political issues to go unchallenged when offered by students.

Additional caveats to teachers' conceptualizations, such as focusing on social consciousness, added complexity and depth to their conceptualizations, though remained fully within traditional notions of citizenship. Social consciousness was discussed in terms of volunteering, serving ones' community, joining civic or religious clubs, and caring for neighbors - actions that are largely individualistic, confined, and consensus driven. Teachers' conceptions of social consciousness did not focus on overcoming societal inequalities or advocating for oppressed groups. Socially conscious citizenship was contrived as being personally responsible. It failed to address systemic problems in society; therefore, it did little to promote the necessary democratic ideal of political equality (Westheimer \& Kahne, 2004) or social justice (Rawls, 1971) 
Secondly, participants' displayed a willingness to incorporate controversial issues into their lessons. Controversial issues can teach students the democratic skills of group deliberation, critical thinking, and tolerance (Hess, 2009); yet, observations depicted that controversial issues were raised in ways that led to tension between students, the sharing of misinformation, and little focus on improving deliberation skills. Findings could be indicative of research that suggests many teachers are unprepared to facilitate controversial issue discussions (Hess, 2009). Hess (2009) said that teachers often conflate controversial issues discussions with current events and do not possess the pedagogical expertise to facilitate discussions. It appears rural teachers are no different.

Pattison-Meek (2012) posits that rural students' political opinions are like-minded and recommends that teachers challenge students' prior held opinions with opposing views. Findings here demonstrate this to be mostly true. Participants acknowledged that their classes leaned toward one political ideology, often conservative. The vitriol rhetoric of presidential candidate Donald Trump was present in observed classrooms, though so too were student opinions that challenged these views - albeit quieter and less prevalent. Teachers said they attempted to show "both sides" of issues to students. It was observed that teachers treated views on political issues superficially and often avoided them altogether.

Parker (1994) suggests multiculturalism should be infused into citizenship education. All of the rural classrooms in this study contained ethnically diverse students, but racial and cultural issues were seldom discussed and students' ethnicities did not appear to predict their sentiment towards politics. As one participant said, "We have black students that fly the confederate flag here. It's just part of the culture." Another participant said, "You see a kid walking down the hall between classes wearing the confederate flag with his best friend who is African-American and 
it's not a big deal." Teachers did not appear strongly committed to teaching about racial justice apart from textbook-based lessons on civil rights. Teachers perceived racial issues as largely absent from their schools and communities, despite the presence of racially-charged events such as the confederate flag parade at Smallwood High School. This disconnect between perceptions and reality appeared to support their continued focus on knowledge-based instruction. Current events that dealt with race as a controversy (i.e. police brutality and \#blacklivesmatter) were largely absent from rural classrooms.

Teachers' emphasis on college and career preparation in government classes acted as a final caveat to their conceptualizations of citizenship. Prior research notes that students come to understand society and their place in it through what is emphasized in schools as "official knowledge" (Apple, 1996). Government teachers' efforts to teach students job-related skills and expectations for employment meant that teachers emphasized a "citizen-as-worker" ideal. This conception presents a compliant, non-creative citizenship role, thereby fitting traditional notions of personally responsible citizenship. Furthermore, this emphasis may be indicative of the neoliberal trend in education towards competitive, individualistic notions of life - something some scholars criticize as undemocratic (Giroux, 2002).

In light of existing scholarship, rural teachers' conceptualizations of citizenship education likely leave students unprepared for the full range of citizenship skills needed in a democracy. Particularly, students instructed with only traditional notions of citizenship may fail to possess the requisite critical thinking skills and empathetic dispositions that democracy requires for competent decision making (Engle, 1960). Further implications specific to rural students are discussed later in this chapter. The next component positions teachers' perspectives on "place" within the present literature. 


\section{Place}

Rural citizenship educators demonstrated an awareness of place that continuously influenced curriculum and instructional choices. They acknowledged their rural places to be distinct from urban areas in regards to population size and geographic remoteness, as well as in ideals and culture. They demonstrated a purposeful use of local resources to connect the course content to things that were familiar to students. Teachers acknowledged that their specific rural locales were changing and that these changes produced within-community tensions over the redefinitions of rural ways of life. Teachers' perceptions of rurality led them to make assumptions about rural students and places. Teachers were often unaware of their own assumption and the impact they had on lessons. Classroom observations revealed actions that countered their statements to withhold judgements of students and the rural community. Teachers assumed students and parents were largely conservative and that rural areas were generally poor and lacking in professional occupations. Likewise, participants, both community insiders and outsiders, posited a strong narrative to students to leave their rural area for college and careers after high school; yet, this emphasis on future displacements did not alter the way teachers instructed for citizenship, leaving citizenship devoid of place-consciousness.

These results display a rather complex intersection of place and citizenship education. Place-based learning, something participants' displayed, made the citizenship curriculum more relevant to students; however, Azano (2011) warns that without a critical lens place-based learning can hinder rural students' capacity to identify and interpret the challenges affecting their communities. Since participants conceptualized citizenship as transmission of basic civic knowledge, their use of place-based learning came up short of teaching more critical notions of both citizenship and place. Teachers did not move students toward increasingly complex and 
sophisticated notions of citizenship or more critical inquiries into place. Azano (2011) suggests this type of place-based learning produces a deficit to understanding place by failing to connect the familiar to larger issues that seem more remote.

Failures to think critically about place may take on greater importance when teachers endorse the narrative of "leaving" rural communities for economic advancement. Petrin, Schafft, and Meece (2014) suggests students' perceptions of economic pressures factor into their decisions to leave more than the advice of teachers; however, findings here point to teachers' persistent shaping of students' perceptions through their discussion of economic pressures in their government curriculum. In this way, rural teachers' complicity in rural brain drain is actually facilitated through explicit statements to all students and not just the attention and resources they invest in high achieving students as prior research suggests (Petrin et al., 2014).

Woodrum's (2004) analysis of class discrepancies in rural perceptions could illuminate these curricular messages. Woodrum (2004) suggests that rural teachers (often coming from the middle class) "endorse the gesellschaft necessity of competition and social mobility," whereas the families of poor students place greater value on "community, allegiance to place, and interrelationships (gemeinschaft)" (p. 9). When present, class discrepancies between teachers and students could complicate the treatment of place within the government curriculum. Middle class teachers may posit conceptions of good citizenship tied to economic progress out of the community, thereby contributing to the deterioration of some rural places. Woodrum (2004) said that middle-class residents regret the loss of community when rural-based schools and businesses close, yet ultimately they think of them as signs of economic "progress" that could benefit children (p. 9). This sentiment aligns to the notions of place and rurality that participants advanced in this study. 
Participants also believed their emphasis on traditional civic knowledge would be adequate for students regardless of their future habitations - a curricular aim devoid of place consciousness. Past citizenship education research suggests this type of aim is limiting to future citizens. Journell (2013) showed that government teachers instructed students for their presumed roles in society, restraining students' conceptions of citizenship and, therefore, leaving them under-prepared for democratic life. Findings here confirm that rural teachers of government instructed for limited notions of citizenship that focused on practical knowledge and economic productivity. Participants did not often extend their instructional aims to more critical notions of citizenship (i.e. multiculturalism, internationalism, or critiques of structure or places). Since teachers encouraged students to leave rural areas to work or study in urban areas, their citizenship instruction produced a particularly incongruent knowledge deficit, presenting a missed opportunity to engage in critical interrogations of place.

Theobald (1997) says the concept of rural community could restore democratic life in America, but place-conscious instruction is needed. The "leaving" narrative posited by rural teachers of government implies that rural communities were not necessarily worth students' civic investments. This narrative positions urban life over rural life, facilitating the depreciation of the rural-based community that Theobald advances. A more thoughtful and critical inclusion of place into citizenship education would enable rural students to possess better understandings of community, its connection with larger political and economic life, and students' proactive citizenship roles both within and beyond it. As of now, it appears rural teachers of government contribute messages that thwart fulfillment of this democratic potential.

\section{Influences}


The final component concerned the myriad of influences upon participants' curricularinstructional gatekeeping. These influences were categorized as self, others, and authority. Self encompassed teachers' curricular aims rooted in their past experiences and their personal dispositions. Others encompassed the direct and indirect influences of other people within the rural school and community, such as students, parents, colleagues, and administers. Authority represented the impact of state and district-level standards, curriculum guides, and textbooks. Each of these influences occurred within the context of rural places that enabled perceptions of trust, familiarity, and like-mindedness to be used as tools of curriculum navigation.

Past research suggests these categories of influences on curricular-instructional gatekeeping are experienced by many teachers regardless of locales. For example, gatekeeping is influenced by teachers' belief systems (Parajes, 1992), personal histories (Fickel, 2000), college coursework (Cornett, 1990), school culture (Sondel, 2015), state standards (Romanowski, 1996), and community beliefs (Shaver et al., 1980; Romanowski, 1996). Findings in this study display similar factors, but also produced new knowledge on the conditions that enabled rural teachers to navigate these influences in specific ways.

Trust and familiarity frequently appeared in the data as the reasons that participants felt enabled to carry out their gatekeeping of the curriculum with autonomy. However, participants noted their citizenship education aims and others' wishes were largely aligned. This is an important stipulation uncovered in this study because past research showed tensions between community desires and teachers' decisions (Rapoport, 2009) or tensions between administrators' desires and teachers' decisions (Sondel, 2015) that resulted in teachers feeling pressured to alter their curriculum. Findings here show no such pressures. Rural teachers with largely traditional citizenship aims felt autonomy because of their familiarity and like-mindedness with the 
community and colleagues. However, questions are raised about the social groups within rural areas in which teachers found this support. Teachers' social interactions tended be with school, business, community leaders, and parents of athletes and students involved in various school activities. While some teacher-community member interactions occurred in common spaces (e.g. grocery stores), these were largely incidental. Marginalized groups within rural communities did not appear to have sustained interactions with teachers.

Questions remain about rural teachers who may emphasize more non-traditional citizenship aims. Since scholars emphasize teaching progressive citizenship to students to fulfill the aims of democracy (Arbowitz \& Harnish, 2006; Westheimer \& Kahne, 2004), findings here present a possible apprehension for the acceptance of such approaches in close-knit rural locales. Future research should work to uncover this specific phenomenon and understand the conditions that give it rise. Are teachers reluctant to seek progressive citizenship aims because of the perceived closeness of their school communities? If it remains true that most rural teachers aim for traditionalist orientations of citizenship, the need is heightened for teacher educators to address more critical examinations of citizenship and place with their pre-service teachers and their navigation within rural communities.

Lastly, state standards and the absence of state-mandated testing acted as important influences upon teachers' gatekeeping. Each participant spoke of having freedom to pursue contemporary political events or work-related objectives because their class time was not influenced by test preparation. This finding complements past research which showed the inverse, that high-stake testing restrained teachers' curricular-instructional choices (Au, 2007). Had rural teachers been required to prepare students for end-of-the-year testing in government, their instruction would likely have focused more on test preparation and memorization of 
disciplinary knowledge. This was something at least one participant lamented as an awful educational practice.

Corbett (2007) suggests that curriculum standards tend to be placeless in nature. In this study, teachers' decision making was constrained by the state's predefined scope and sequence of the course. The state standards for the $12^{\text {th }}$ grade government course, and its sequencing in the overall high school curriculum, set guidelines and expectations for the content and objectives of the course that were largely devoid of place. Archbald and Porter (1994) found social studies teachers can still feel high levels of autonomy when centralized standards exist. In this study, participants reported feeling autonomy in their curriculum decision making; yet, their perceptions of autonomy were tied to content selection that agreed with or complemented predefined standards.

\section{Implications}

As stated above, findings suggested that rural teachers of government conceptualized citizenship education as teaching basic civic knowledge to engender traditional involvement in political, social, and economic life. While preparing students for some aspects of citizenship, these conceptualizations stopped short of recognizing the full range and expectations of democratic citizenship. In this way, they fit personally responsible notions of citizenship rather than participatory or justice-oriented notions (Westheimer \& Khane, 2004). To improve rural citizenship education, teacher educators should better prepare future rural teachers with critical conceptualizations of citizenship, rationales for such conceptualizations, and methods for teaching students these conceptualizations. This point coincides with past research which suggest pre-service teachers need to develop commitments to and pedagogical knowledge for teaching conceptualizations that represent democratic ideals like multiculturalism (Castro, 2013) and 
social justice (Fry \& O’Brien, 2015). Failing to do so risks leaving future rural citizens unprepared for the realities of democratic life. Furthermore, teacher educators should lead preservice teachers in critical examinations of place to help them better understand their own roles in promoting rural sustainability versus narratives of "leaving."

This study revealed that rural teachers recognized the bidirectional (though uneven) relationship of urban and rural life. It also revealed the existence of racial blindness within rural schools because "everyone gets along." Yet, complex race-related controversies existed (e.g. confederate flag parade) that demand acknowledgement of race-based discrimination and inequalities. This incongruence speaks to the need for rural teachers to think critically about issues of race, pluralism, and inequalities in American life. As of now, these topics remain underemphasized in the rural government classrooms of this study. The need for including critical discussions of pluralism and inequalities are pressing as these issues received heightened attention in the national political climate. This is particularly true as students were observed borrowing Trumpesque rhetoric (misleading and offensive language) when referencing specific minority groups during political conversations in rural classrooms.

To their credit, rural teachers recognized the need for citizens to understand multiple viewpoints or "both sides of an issue," yet, when they sought pedagogical approaches that emphasized students' use of critical thinking or evaluation, it often resulted in perfunctory treatment of controversies or negative student-to-student interactions. Hess (2009) suggested teachers need pedagogical expertise when teaching controversial issues. Findings here suggest that rural teachers possess a willingness, but not a know-how. This calls for rural teacher education or professional development that could enhance such practices. 
The intersection of place and citizenship education provides further implications for rural students' citizenship development. Rural citizenship educators demonstrated an intimate connection with their communities through place-based learning, but these experiences failed to critically engage students in conceptions of place and their relationship to larger political and economic issues. Rural citizenship educators must be asked to think critically about connections between rural places and education for citizenship. Past scholarship offers suggestions for teachers to use rural community resources to enhance global citizenship education (Waterson \& Moffa, 2015) and liberal democratic skills and dispositions (Waterson \& Moffa, 2016). Rural teachers of government can utilize a place-based curriculum to make relevant progressively more advanced and interconnected studies in citizenship.

Similarly, teachers should be asked to think critically about their assumptions of rurality and their role in perpetuating narratives that may damage rural communities. Findings in this study depicted teachers who cared deeply for rural students and rural communities, but held expectations that students should leave rural areas in search of educational and economic success. When paired with government teachers' emphasis of college and career readiness, the effects of this expectation send a strong message that supports rural divestments. Rural teachers of government must become reflective about their role in fostering community sustainability and the power it holds to teach students about investing in community and, therefore, democratic life (see Theobald, 1997). Furthermore, rural students, regardless of future locales, should understand the reciprocal nature of one's involvement with rural places and engage in political actions that honor rural life.

Finally, this study provides knowledge on connections between the rural citizenship curriculum and the factors that influence it. This knowledge informs curriculum theorists and 
teacher educators with understandings of the relational aspects of the curriculum, revealing that familiarity, trust, and like-mindedness foster an agreeable citizenship curriculum in rural places. Rural teachers made decisions that adhered to their personal conceptualizations, while working under the auspice of state and local standards and peaceably navigating the desires of others. Since teachers taught traditionalist notions of citizenship - ones aligned with other influences, questions remain about the effects of a more broadly conceived progressive citizenship education in rural areas. This is particularly pressing as liberal citizenship education holds the power to develop the critical citizenship skills and dispositions that could benefit rural democratic life (Waterson \& Moffa, 2016).

\section{Limitations and Future Research}

This section discusses the limitations of the study and offers directions for future research. While the study's findings developed an initial picture of rural citizenship education, future research is needed to further examine each individual themes, their relationships, and test these initial findings in other similar (and dissimilar) rural environments. This study stimulated many new questions that researchers should address if they desire to understand rural contexts and, therefore, better prepare future rural teachers for their role as citizenship educators.

As a qualitative study, the findings were context-bound. The study examined the perceptions of five teachers in four distinct rural schools in relatively close proximity with one another in one southeastern state. Through its grounded theory design (Corbin \& Strauss, 2014), the study detailed specific conditions that influenced participants' perspectives and decisionmaking. These results should be transferable to rural contexts with similar conditions. Results, however, are not generalizable to all rural places and, therefore, act as a preliminary, not conclusive, block of knowledge. 
Related to the study's transferability, it is important to recognize that despite popular mythology, many rural communities and rural schools are dissimilar across the United States and world. As other rural places offer differences in local settings, teacher backgrounds and dispositions, students' lives, and administrative support (etc.), results will likely differ as well. Other researchers should replicate or extend upon this study to understand the specific conditions in other rural areas that give rise to differences in rural teachers' conceptualizations of citizenship education and the factors that influence their curricular-instructional gatekeeping. This future research enables inter-rural diversity to be better understood and, therefore, refines the emergent descriptions offered by this study. Furthermore, efforts should be made to compare citizenship education in rural locales with citizenship education in urban and suburban locales. Currently, these comparisons do not exist. This study can be utilized by researchers as a base of knowledge for the rural components of such studies.

Also, on par with grounded theory design, this study purposely casted a broad net into the rural settings to reveal unknown perspectives and conditions that might answer the research questions. Understandably, the results depicted a multi-faceted picture of rural citizenship education, where teacher conceptualizations and place intersected in numerous ways. Since this study was limited by its duration, geographic range, and manpower (i.e. one researcher), not all pathways were followed to their conclusions. Future studies should delve deeper into the individual themes presented here to produce nuanced understandings of the specific facets of rural citizenship education.

For example, this study found that workforce skills were part of each teacher's conceptualizations of citizenship education. They valued workforce preparation due to their own real world experiences and their perceptions of what was important in life after high school. Yet, 
questions remain as to the full range of reasons for these aims and their effects on rural students. Are these curricular choices the result of teachers' interpretations of state standards/the common core? Are they indicative of American society's emphasis on economic competition? If teachers emphasize skills for work instead of skills for political life, what might the outcomes be? Does emphasizing workforce skills cater to the needs of the rural community or the expectation of an urban-centered business world?

This study was teacher-centered. It focused on their thoughts and actions, and apart from observed interactions with students and colleagues, it recognized "others" through the perceptions of teachers. The focus on teachers' perceptions aligned with the social constructionist philosophical perspective of the study and the theoretical framework of gatekeeping which presents teachers as the ultimate curriculum decision-maker. However, this focal point limited the scope of understanding about rural life to teachers' perceptions. Geographical data on communities and schools (see chapter four) supplemented teachers' perceptions of rurality. Future studies should engage in research that examines rural conditions from the perspectives of students, administrators, or community members. These future findings might illuminate the ways rural teachers' perceptions correspond to others' perceptions in their environment. This knowledge would help to understand a broader range of socially constructed rural life, perceptions of place, and connections between teachers' curricular choices and outside influences. Similarly, this study focused on curricular inputs, but not its effects. Future studies should examine student outcomes to understand the impact of rural-specific citizenship education upon learners.

Overall, the findings of this study present a salient, though nascent theory to describe the impact of rural context on citizenship education. This study is important because it was the first 
to purposely examine rural teachers' conceptualizations of citizenship education and their perceptions of conditions that impacted their decision-making. The study found rural teachers conceptualized citizenship as "practical knowledge" and that their decisions remained largely aligned with state standards and traditional expectations. Perceptions of place were omnipresent and impacted teachers' language, lessons, and goals. Most notably, teachers encouraged students to leave rural places due to economic pressures, displaying uncritical (and potentially damaging) ideas of place and citizenship. Lastly, teachers held a sense of trust and familiarity, perceived to be specific to rural life, which fostered feelings of autonomy in curricular decision making, though no decisions challenged traditionalist notions of citizenship. As a grounded study, the findings here offer an initial descriptive theory build upon organic data - a theory that helps to fill the long existing research gap of rural-specific citizenship education. 


\section{REFERENCES}

Abowitz, K. K., \& Harnish, J. (2006). Contemporary discourses of citizenship. Review of Educational Research, 76, 653-690.

Apple, M. W. (1996). Cultural politics and education. New York, NY: Teachers College Press. Apple, M. (2002). Patriotism, pedagogy, and freedom: On the educational meanings of September 11. The Teachers College Record, 104, 1760-1772.

Anderson, C., Avery, P. G., Pederson, P. V., Smith, E. S., \& Sullivan, J. L. (1997). Divergent perspectives on citizenship education: A q-method study and survey of social studies teachers. American Educational Research Journal, 34, 333-364.

Andrews, T. (2012). What is social constructionism?. Grounded Theory Review, 1. Retrieved online at http:/groundedtheoryreview.com/2012/06/01/what-is-social-constructionism/

Archbald, D. A., \& Porter, A. C. (1994). Curriculum control and teachers' perceptions of autonomy and satisfaction. Educational Evaluation and Policy Analysis, 16(1), 21-39.

Au, W. (2007). High-stakes testing and curricular control: A qualitative metasynthesis. Educational Researcher, 36, 258-267.

Avery, P. G. (2004). Social studies teacher education in an era of globalization. Critical issues in social studies teacher education, 375.

Avery, P. G. (2007). Civic education in the United States: Increased challenges. Citizenship Teaching and Learning, 3(2), 22-39.

Azano, A. (2011). The possibility of place: One teacher's use of place-based instruction for English students in a rural high school. Journal of Research in Rural Education, 26(10), $1-12$. 
Banks, J. A. (2008). Diversity, group identity, and citizenship education in a global age. Educational Researcher, 37, 129-139.

Barr, R. D., Barth, J. L., \& Shermis, S. S. (1978). The nature of the social studies. Palm Springs, CA: Etc Publications.

Beard, C. A. (1934). The nature of the social sciences in relation to objectives of instruction. New York, NY: Charles Scribner's Sons.

Beinart, P. (2015, December 9). It's not just Trump. The Atlantic. Retrieved from http://www.theatlantic.com/politics/archive/2015/12/before-donald-trump-there-was-anncoulter/419517/

Berger, P., \& Luckmann, T. (1966). The social construction of knowledge: A treatise in the sociology of knowledge. Soho, NY: Open Road Media

Bishop, B. (2008). The big sort: Why the clustering of like-minded America is tearing us apart. New York, NY: Houghton Mifflin.

Bishop, B. (2015, January 27). GOP wins house vote in $82 \%$ of rural counties. The Daily Yonder. Retrieved from http://www.dailyyonder.com/gop-wins-house-vote-82counties/2015/01/27/7697/

Bishop, B., \& Gallardo, R. (2012, November 11). Rural voter turnout drops $18 \%$ in 2012. The Daily Yonder. Retrieved from http://www.dailyyonder.com/rural-voter-turnout-drops-18$2012 / 2012 / 11 / 28 / 5514$

Bouck, E. C. (2004). How size and setting impact education in rural schools. Rural Educator, 25(3), 38-42.

Bourke, B. (2014). Positionality: Reflecting on the research process. The Qualitative Report, 19, 1-9. 
Brown, D. L. (2008). The future of rural America through a social-demographic lens. In J. Wu, P. W. Barkley, \& B. A. Weber, Frontiers in Resource and Rural Economics: Humannature, Rural-urban Interdependencies, (pp. 229-247).Washington, DC: Earthscan.

Brown, D. L., \& Schafft, K. A. (2011). Rural people and communities in the 21st century: Resilience and transformation. Cambridge, UK: Polity.

Brubaker, D. L. (1977). A conceptual framework for social studies curriculum and instruction. Social Education, 41, 201-5.

Burton, M., Brown, K, \& Johnson, A. (2013). Storylines about rural teachers in the United States: A narrative analysis of the literature. Journal of Research in Rural Education, 28(12), 1-18.

Butts, R. F. (1980). The revival of civic learning: A rationale for citizenship education in American schools. Bloomington, IN: Phi Delta Kappa Educational Foundation.

Carr, P. J., \& Kefalas, M. J. (2009). Hollowing out the middle: The rural brain drain and what it means for America. Boston, MA: Beacon Press.

Castro, J. (2013) What makes a citizen? Critical and multicultural citizenship and preservice teachers' understanding of citizenship skills. Theory \& Research in Social Education, 41, 219-246.

Cloke, P., \& Milbourne, P. (1992). Deprivation and lifestyles in rural Wales.-II. Rurality and the cultural dimension. Journal of Rural Studies, 8, 359-371.

Conover, P. J., \& Searing, D. D. (2000). A political socialization perspective. In L. M. McDonnell, P. M. Timpane, \& R. Benjamin (Eds.), Rediscovering the democratic purposes of education (pp. 91- 124). Lawrence, KS: University of Kansas Press. 
Corbett, M. J. (2007). Learning to leave: The irony of schooling in a coastal community. Nova Scotia: Fernwood Publishing.

Corbin, J. M., \& Strauss, A. (1990). Grounded theory research: Procedures, canons, and evaluative criteria. Qualitative Sociology, 13, 418-427.

Corbin, J., \& Strauss, A. (2014). Basics of qualitative research: Techniques and procedures for developing grounded theory. Thousand Oaks, CA: Sage publications.

Cornett, J. W. (1990). Teacher thinking about curriculum and instruction: A case study of a secondary social studies teacher. Theory \& Research in Social Education, 18, 248-273.

Crotty, M. (2003). The foundations of social research: Meaning and perspective in the research process. Thousand Oaks, CA: Sage.

Darling-Hammond, L. (2006). Constructing 21st-century teacher education. Journal of Teacher Education, 57, 300-314.

Dewey, J. (2008). Democracy and education. New York, NY: The MacMillan Company. (Original work published in 1916)

Dewalt, K., DeWalt, B., \& Wayland, C. (1998). Participant observation. In J. Fernandez, M. Herzfeld, \& H. R. Bernard (Eds.) Handbook of methods in cultural anthropology (pp. 259-300) Lanham, MA: AltaMira Press.

DeYoung, A. J. (1987). The status of American rural education research: An integrated review and commentary. Review of Educational Research, 57, 123-148.

Donehower, K., Hogg, C., \& Schell, E. E. (2007). Rural literacies. Carbondale, IL: SIU Press.

Dudley, K. M. (1996). The problem of community in rural America. Culture \& Agriculture, 18(2), 47-57. 
Easton, S. E. (1985, October). Social studies and citizenship education in rural America: Process and product. Paper presented at the National Conference on Rural Teacher Education. Bellingham, Washington. Retrieved from ERIC database. (ED261847)

Emerson, R. M., Fretz, R. I., \& Shaw, L. L. (2011). Writing ethnographic fieldnotes. Chicago, IL: University of Chicago Press.

Engle, S. H. (1996) Decision making. In W.C. Parker (Ed.). Educating the democratic mind (pp. 117-126). Albany, NY: State University of New York Press. (Original work published 1960).

Evans, R. W. (1990). Teacher conceptions of history revisited: Ideology, curriculum, and student belief. Theory \& Research in Social Education, 18, 101-138.

Evans, R.W. (2004). The social studies wars: What should we teach the children?. New York, NY: Teachers College Press.

Fickel, L. H. (2000). Democracy is messy: Exploring the personal theories of a high school social studies teacher. Theory \& Research in Social Education, 28, 359-389.

Frank, K. A. (1998). Quantitative methods for studying social context in multilevels and through interpersonal relations. In P. D. Pearson \& A. Iran-Nejad (Eds.), Review of research in education (Vol. 23, pp. 171-216). Washington, DC: American Educational Research Association.

Fry, S. W. and O'Brien, J. (2015). Cultivating a justice orientation toward citizenship in preservice elementary teachers. Theory \& Research in Social Education, 43, 405-434.

Garcia, R. L. (1991). Teaching in a pluralistic society: Concepts, models and strategies. New York, NY: Harper Collins. 
Gaudelli, W., \& Heilman, E. (2009). Reconceptualizing geography as democratic global citizenship education. Teachers College Record, 111, 2647-2677.

Gay, L. R., Mills, G. E., \& Airasian, P. W. (2012). Educational research: Competencies for analysis and applications. Upper Saddle River, NJ: Pearson Higher Ed.

Geertz, C. (1973). Thick description: Toward an interpretive theory of culture. The interpretation of cultures: Selected essays (Vol. 5019). Basic books.

Gilbert, A., \& Yerrick, R. (2001). Same school, separate worlds: A sociocultural study of identity, resistance, and negotiation in a rural, lower track science classroom. Journal of Research in Science Teaching, 38, 574-598.

Gimpel, J.G., \& Karnes, K.A. (2006). The rural side of the urban-rural gap. PS: Political Science \& Politics, 467-472. Retrieved from http://www.apsanet.org/imgtest/PSJuly06GimpelKarnes.pdf

Giroux, H. (2002). Neoliberalism, corporate culture, and the promise of higher education: The university as a democratic public sphere. Harvard Educational Review, 72, 425-464.

Glaser, B. G., \& Strauss, A. L. (2009). The discovery of grounded theory: Strategies for qualitative research. Piscataway, NJ: Transaction Publishers.

Halfacree, K. (2004). Rethinking 'rurality'. In T. Champion \& G. Hugo (Eds.), New forms of urbanization: Beyond the urban-rural dichotomy. Surrey, UK: Ashgate (pp. 285-304)

Halfacree, K. (2006). Rural space: constructing a three-fold architecture. Handbook of rural studies, 44-62.

Hawley, T. S. (2010). Purpose into practice: The problems and possibilities of rationale-based practice in social studies. Theory \& Research in Social Education, 38, 131-162. 
Hektner, J. (1994). When moving up implies moving out: rural adolescent conflict in the transition to adulthood. Retrieved from ERIC database (ED 374 949)

Hertz, T., Kusmin, L., Marré, A., \& Parker, T. (2014). Rural Employment Trends in Recession and Recovery. USDA-ERS Economic Research Report, (172). Retrieved from http://www.ers.usda.gov/media/1551844/err172.pdf

Herzog, M., \& Pittman, R. B. (1995). Home, family, and community: Ingredients in the rural education equation. Retrieved from ERIC database. (ED388463).

Hess, D., \& Ganzler, L. (2007) Patriotism and ideological diversity in the classroom. In J. Westheimer (Ed.) Pledging allegiance: The politics of patriotism in America's schools (pp. 131-138). New York: Teachers College Press.

Hogg, M. A. (2006). Social identity theory. Contemporary Social Psychological Theories, 13, $111-136$.

Howley, M., Howley, A., \& Eppley, K. (2013). How agricultural science trumps rural community in the discourse of selected U.S. history textbooks. Theory and Research in Social Education, 41, 187-218.

Hoyle, J. R., \& Slater, R. O. (2001). Love, happiness, and America's schools. Phi Delta Kappan, 82, 790-794.

Johnson, J., Showalter, D., Klein, R., \& Lester, C. (2014). Why rural matters 2013-2014: The condition of rural education in the 50 states. Washington, DC: Rural School and Community Trust.

Journell, W. (2011). Teaching the 2008 Presidential Election at three demographically diverse schools: An exercise in neoliberal governmentality. Educational Studies: A Journal of the American Educational Studies Association, 47, 133-159. 
Kahne, J., \& Middaugh, E. (2006). Is patriotism good for democracy? A study of high school seniors' patriotic commitments. Phi Delta Kappan, 87(8), 600-607.

Kahne, J., Rodriguez, M., Smith, B., \& Thiede, K. (2000). Developing citizens for democracy? Assessing opportunities to learn in Chicago's social studies classrooms. Theory \& Research in Social Education, 28, 311-338.

Kane, T. (2005, November 7). Who bears the burden? Demographic characteristics of U.S. military before and after 9/11. Report \#05-08 on National Security and Defense. The Heritage Foundation. Retrieved from http://www.heritage.org/research/reports/2005/11/who-bears-the-burden-demographiccharacteristics-of-us-military-recruits-before-and-after-9-11

Kleykamp, M. A. (2006). College, jobs, or the military? Enlistment during a time of war. Social Science Quarterly, 87, 272-290.

Kusmin, L. (2012). Rural America at a glance. USDA-ERS Economic Brief, (21). Retrieved from http://papers.ssrn.com/sol3/papers.cfm?abstract_id=2202862

Kvale, S., \& Brinkmann, S. (2009). Interviews: Learning the craft of qualitative research interviewing. Thousand Oaks, CA: Sage Publications.

Kymlicka, W., \& Norman, W. (1994). Return of the citizen: A survey of recent work on citizenship theory. Ethics, 104, 352-381

Lay, J.C. (2006). Learning about politics in low-income communities: Poverty and political knowledge. American Politics Research, 34, 319-340.

Lee, M. (2006). "Going global": Conceptualization of the "other" and interpretation of crosscultural experience in an all-white, rural learning environment. Ethnography and Education, 1, 197-213. 
Leydet, D. (2014). Citizenship. In The Stanford Encyclopedia of Philosophy, E. N. Zalta (Ed.). Retrieved from http://plato.stanford.edu/archives/spr2014/entries/citizenship

Lichter, D. T., \& Brown, D. L. (2011). Rural America in an urban society: Changing spatial and social boundaries. Annual Review of Sociology, 37, 565-592.

Mann, B. (2006). Welcome to the Homeland: A Journey to the Rural Heart of America's Conservative Revolution. Hanover, NH: Steerforth Press.

Martin, L. A., \& Chiodo, J. J. (2007). Good citizenship: What students in rural schools have to say about it. Theory \& Research in Social Education, 35, 112-134.

Martorella, P. H. (1996). Teaching social studies in middle and secondary schools (2nd ed). New York: Merrill.

McHenry-Sorber, E. (2014). The power of competing narratives: A new interpretation of rural school-community relations. Peabody Journal of Education, 89, 580-592.

McIntosh, P. (2005). Gender perspectives on educating for global citizenship. In Nodding, N. (Ed.). Educating citizens for global awareness (pp. 22-39). New York, NY: Teachers College Press.

McKee, S. C. (2008). Rural voters and the polarization of American presidential elections. PS: Political Science \& Politics, 41, 101-108.

McNeil, L. M. (2013). Contradictions of control: School structure and school knowledge. New York, NY: Routledge.

Merriam, S. B. (2002). Qualitative research in practice: Examples for discussion and analysis. San Francisco, CA: Jossey-Bass.

Miles, M. B., Huberman, A. M., \& Saldaña, J. (2014). Qualitative data analysis: A methods sourcebook. Thousand Oaks, CA: Sage Publications. 
Mitchell, C. J. (2005). Population change and external commuting in Canada's rural and small town municipalities: 1996-2001. Canadian Journal of Regional Science, 28, 461-486.

National Center for Educational Statistics. (2007). Status of Education in Rural America. Washington, DC: NCES. Retrieved from ERIC Database. (ED497509).

National Council for the Social Studies. (1994), Expectations of excellence: Curriculum standards for social studies. Silver Spring, MD: NCSS.

National Council for the Social Studies. (2001). Creating Effective Citizens. Silver Spring, MD: NCSS. Retrieved from http://www.socialstudies.org/system/files/publications/se/ 6505/650511.html

National Council for the Social Studies. (2013). The College, Career, and Civic Life (C3 Framework for Social Studies State Standards: Guidance for enhancing the rigor of K-12 civics, economics, geography, and history. Silver Spring, MD: NCSS.

Noddings, N. (Ed.). (2005). Educating citizens for global awareness. New York, NY: Teachers College Press.

Pajares, M. F. (1992). Teachers' beliefs and educational research: Cleaning up a messy construct. Review of educational research, 62, 307-332.

Parker, W. C. (1994). "Advanced" ideas about democracy: Toward a pluralist conception of citizenship education. Retrieved from ERIC database (ED383599)

Parker, W., \& Jarolimek, J. (1984). Citizenship and the Critical Role of the Social Studies. NCSS Bulletin No. 72. Boulder, CO: SSEC Publications

Partridge, M. D., Ali, K., \& Olfert, M. (2010). Rural-to-urban commuting: Three degrees of integration. Growth and Change, 41, 303-335. 
Pattison-Meek, J. (2012) 'Rurality matters: Revealing the challenges of educating for social justice in rural schools'. In P. Cunningham \& N. Fretwell (Eds.) Creating communities: Local, national and global (pp. 606-622). London: CiCe.

Patterson, N., Doppen, F., \& Misco, T. (2012). Beyond personally responsible: A study of teacher conceptualizations of citizenship education. Education, Citizenship, and Social Justice 7, 191-206.

Petrin, R. A., Schafft, K. A., \& Meece, J. L. (2014). Educational Sorting and Residential Aspirations Among Rural High School Students What Are the Contributions of Schools and Educators to Rural Brain Drain?. American Educational Research Journal, 51, 294326.

Purcel, D., \& Shackelford, R. (2005, January). An evaluation of the impact of rural school consolidation: What challenge may a new round of school consolidations have on the safety, educational performance, and social environments of rural communities? Paper presented to the National Rural Association Executive Committee. Retrieved from ERIC database. (ED497051)

Rapoport, A. (2009). A forgotten concept: Global citizenship education and state social studies standards. Journal of Social Studies Research, 33, 91-112.

Rapoport, A. (2010). We cannot teach what we don't know: Indiana teachers talk about global citizenship education. Education, Citizenship and Social Justice, 5, 179-190.

Rawls, J. (1971). A theory of justice. Cambridge, MA: Harvard University Press.

Richardson, W. (2006) Combining cognitive interviews and social science surveys: Strengthening interpretation and design. In Barton, K. (ed.) Research methods in social 
studies education: Contemporary issues and perspectives (pp. 159-181). Greenwich: Information Age Publishing.

Roberts, P., \& Green, B. (2013). Researching rural places on social justice and rural education. Qualitative Inquiry, 19, 765-774.

Romanowski, M. H. (1996). Issues and influences that shape the teaching of US history. Advances in Research on Teaching, 6, 291-312.

Ross, E. W. (2001). The struggle for the social studies curriculum. In E.W. Ross (Ed.), The social studies curriculum: Purposes, problems, and possibilities (pp. 19-41). Albany: State University of New York.

Saada, N. L. (2013). Teachers' perspectives on citizenship education in Islamic schools in Michigan. Theory \& Research in Social Education, 41, 247-273.

Saxe, D. W. (1992). Framing a theory for social studies foundations. Review of Educational Research, 62, 259-277.

Seifert, E., \& Simone, P. (1980). Personnel practices or recruiting and keeping effective teachers in smaller schools. The Small School Forum, 2(2), 12-14.

Schafft, K. A., \& Jackson, A. Y. (2010). Rural education for the twenty-first century: Identity, place, and community in a globalizing world. College Park, PA: Penn State Press.

Shaver, J. P., Davis, O. L., Jr., \& Helburn, S. W. (1980). An interpretive report on the status of precollege social studies education based on three NSF-funded studies. In What are the needs in precollege science, mathematics, and social science education? Views from the field (pp. 3-18) (Publication SE-90). Washington, DC: National Science Foundation.

Sherwood, T. (2001). Where have all the "rural" gone? Rural educational research and current federal reform. Rural School Community Trust, Washington, DC. 
Sondel, B. (2015) Raising citizens or raising test scores? Teach for America, "no excuses" charters, and the development of the neoliberal citizen. Theory \& Research in Social Education, 43, 289-313.

Starr, P. (2014, November 3). Red state, blue state: Polarization and the American situation. The American Prospect. Retrieved from http://prospect.org/article/red-state-blue-statepolarization-and-american-situation

Theobald, P. (1997). Teaching the commons: Place, pride, and the renewal of community. Boulder, CO: Westview Press.

Theobald, P., \& Wood, K. (2010). Learning to be rural: Identity lessons from history, schooling, and the US corporate media. In K. A. Schafft and A. Youngblood Jackson (Eds.), Rural education for the twenty-first century: Identity, place, and community in a globalizing world (pp. 17-33). University Park, PA: Penn State Press.

Thornton, S. J. (1989). Aspiration and practice: Teacher as curricular-instructional gatekeeper in social studies. Paper presented at the American Educational Research Association, San Francisco, CA.

Thornton, S. J. (2005). Teaching social studies that matters: Curriculum for active learning. New York, NY: Teachers College Press.

Torney-Purta, J. (2002). The school's role in developing civic engagement: A study of adolescents in twenty-eight countries. Applied Developmental Science, 6, 203-212.

Tracy, S. J. (2010). Qualitative quality: Eight "big-tent" criteria for excellent qualitative research. Qualitative inquiry, 16, 837-851.

Turner, C. (2015, December 10). President Obama signs education law, leaving 'no child' behind. National Public Radio. Retrieved from http://www.npr.org/sections/thetwo- 
way/2015/12/10/459219774/president-obama-signs-education-law-leaving-no-childbehind

U. S. Census Bureau (1995). Urban and rural population: 1900-1990. Retrieved from https://www.census.gov/population/www/censusdata/files/urpop0090.txt

U. S. Census Bureau (2015) 2010 census urban and rural classification and urban area criteria. Retrieved from https://www.census.gov/geo/reference/ua/urban-rural-2010.html

U. S. Department of Agriculture. (2012). Remarks by USDA secretary Tom Vilsack at 2012 farm journal forum. (Release No. 0357.12). Retrieved from http://www.usda.gov/wps/portal/usda/usdahome?contentidonly=true\&contentid=2012/12 /0357.xml

Vinson, K. D. (1998). The "traditions" revisited: Instructional approach and high school social studies teachers. Theory \& Research in Social Education, 26, 50-82.

Walsh, K. C. (2012). Putting inequality in its place: rural consciousness and the power of perspective. American Political Science Review, 106, 517-532.

Washington, E. Y. \& Humphries, E. K. (2011). A social studies teacher's sense making of controversial issues discussions of race in a predominantly white, rural high school classroom. Theory and Research in Social Education, 39, 92-114.

Waterson, R. A., \& Moffa, E. D. (2015). Applying Deweyan principles to global citizenship education in a rural context. Journal of International Social Studies, 5(1), 129-139.

Waterson, R. A., \& Moffa, E. D. (2016). Citizenship education for proactive democratic life in rural communities. Education, Citizenship, and Social Justice. Advance online publication. DOI: 10.1177/1746197916648286 
Westheimer, J., \& Kahne, J. (2004). What kind of citizen? The politics of educating for democracy. American Educational Research Journal, 41, 237-269.

White, S., \& Kline, J. (2012). Developing a rural teacher education curriculum package. Rural Educator, 33(2), 36-43.

Wilkinson, K. P. (1991). The community in rural America. Westport, CT: Greenwood Publishing Press.

Williams, M. S. (2003). Citizenship as identity, citizenship as shared fate, and the functions of multicultural education. In K. McDonough \& W. Feinberg (Eds.). Citizenship and education in liberal-democratic societies: Teaching for cosmopolitan values and collective identities (pp. 208-247). Oxford: Oxford University Press.

Woods, M. (2009) Rural geography: Blurring boundaries and making connections. Progress in Human Geography 33, 849-58.

Woodrum, A. (2004). State-mandated testing and cultural resistance in Appalachian schools: Competing values and expectations. Journal of Research in Rural Education, 19(1), 1-10. 


\section{APPENDIX A}

\section{INTERVIEW PROTOCOL}

\section{Teachers' conceptualizations of citizenship education}

1. What do you think is the purpose of your government course?

2. What specifically do you hope students will gain from your teaching of government?

3. Many scholars equate teaching social studies with preparing effective citizens. How would you characterize an ideal citizen?

4. In what ways do you teach towards this ideal in this course?

\section{Factors influencing decision-making about the curriculum}

1. What experiences helped to shape your sense of teaching citizenship?

2. How do you decide what content to teach students?

3. How much personal control do you believe you have over the content of your courses?

4. What are the barriers present to teaching for the goals you want to teach towards?

5. In what ways do you consider the desires of others when teaching social studies? (i.e. fellow teachers, department heads, administrators, parents, religious institutions, community members, district supervisors, state/national standards, the local/national political climate)

\section{Teachers' perception of rural community life and its influence on their curriculum}

1. Can you describe the local community to me?

2. What do you think the community believes is the purpose of teaching social studies?

3. What political or social ideologies do you believe are common in the community?

4. How does your awareness of the community's sentiments impact your instruction?

5. Are you a new or long-time resident? How does that impact your instruction?

6. What decisions do you make about the curriculum to teach your unique student population?

7. Are there any topics or issues you avoid because of local sentiments? 


\section{APPENDIX B}

\section{PARTICIPANT CONSENT LETTER}

\section{WestVirginiaUniversity.}

Dear Participant,

This letter is a request for you to take part in a research study that explores citizenship education in rural schools. This is the dissertation project of Eric Moffa, a doctoral student in the College of Education and Human Services at West Virginia University. This project will help to understand the impact of rural school and community life on teachers' decisions about the social studies curriculum. This knowledge can help to better prepare future social studies teachers for work in rural schools.

As a participant, you are asked to sit for two formal interviews with the researcher and agree to be observed in your classroom approximately 8-10 times during the spring semester. Your participation in this project is greatly appreciated.

Your involvement in this project will be kept confidential. Information learned during the interviews or classroom observations will be reported with your identity concealed. Your participation is completely voluntary. You may choose not to answer any question that you do not wish to answer and you may discontinue at any time. Your participation in this project will not affect your current employment. The study offers no greater risks than what would be encountered in the normal carrying out of your teaching duties. The Institutional Review Board of West Virginia University has approved this project.

I hope that you will participate in this study as it could contribute better knowledge of citizenship education in rural schools. Should you have any questions about this letter or the research project, please feel free to contact Eric Moffa at 304-290-8815 or by e-mail at emoffa@mix.wvu.edu.

Thank you for your time and help with this project.

Sincerely,

Eric Moffa

Phone: 304-293-7073 Fax: 304-293-3098

Chestnut Ridge Research Building

886 Chestnut Ridge Road

PO Box 6845

Morgantown, WV 26506-6845 
APPENDIX C

CONSTRUCT MATRIX

\begin{tabular}{|c|c|c|c|c|}
\hline Theme & Constructs & Main Categories & Categories & Concepts \\
\hline \multirow[t]{2}{*}{ 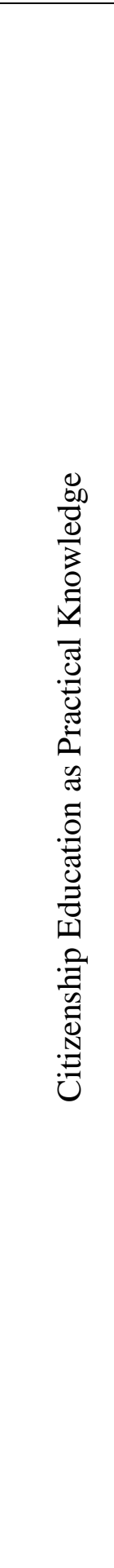 } & $\begin{array}{l}\text { Citizenship } \\
\text { Education }\end{array}$ & Conceptualizations & Stated Goals & $\begin{array}{l}\text { - participate } \\
\text { - life skills (i.e. work } \\
\text { together, use a computer, } \\
\text { public speaking, critical } \\
\text { thinking, professional } \\
\text { dress, interview skills) } \\
\text { - understand our nation } \\
\text { - pick a candidate to } \\
\text { support } \\
\text { - be attentive to local } \\
\text { politics } \\
\text { - media literacy } \\
\text { - be tolerant and accept } \\
\text { plurality } \\
\text { - know rules and how to } \\
\text { redress grievances } \\
\text { - to think for themselves } \\
\text { and get personally } \\
\text { involved } \\
\text { - be informed decision } \\
\text { makers } \\
\text { - read the news } \\
\text { - get the basics of } \\
\text { government } \\
\text { - register to vote } \\
\text { - defend an argument }\end{array}$ \\
\hline & $\begin{array}{l}\text { Citizenship } \\
\text { Education }\end{array}$ & Conceptualizations & $\begin{array}{l}\text { Motivations for } \\
\text { Goals }\end{array}$ & $\begin{array}{l}\text { - connect politics to real } \\
\text { life } \\
\text { - knowledge of how to } \\
\text { deal with bureaucracy } \\
\text { that affects life } \\
\text { - "hard knocks" life } \\
\text { lessons } \\
\text { - to know and work with } \\
\text { government } \\
\text { - to work towards } \\
\text { consensus and } \\
\text { compromise } \\
\text { - regardless of future, } \\
\text { same basic skills needed }\end{array}$ \\
\hline
\end{tabular}




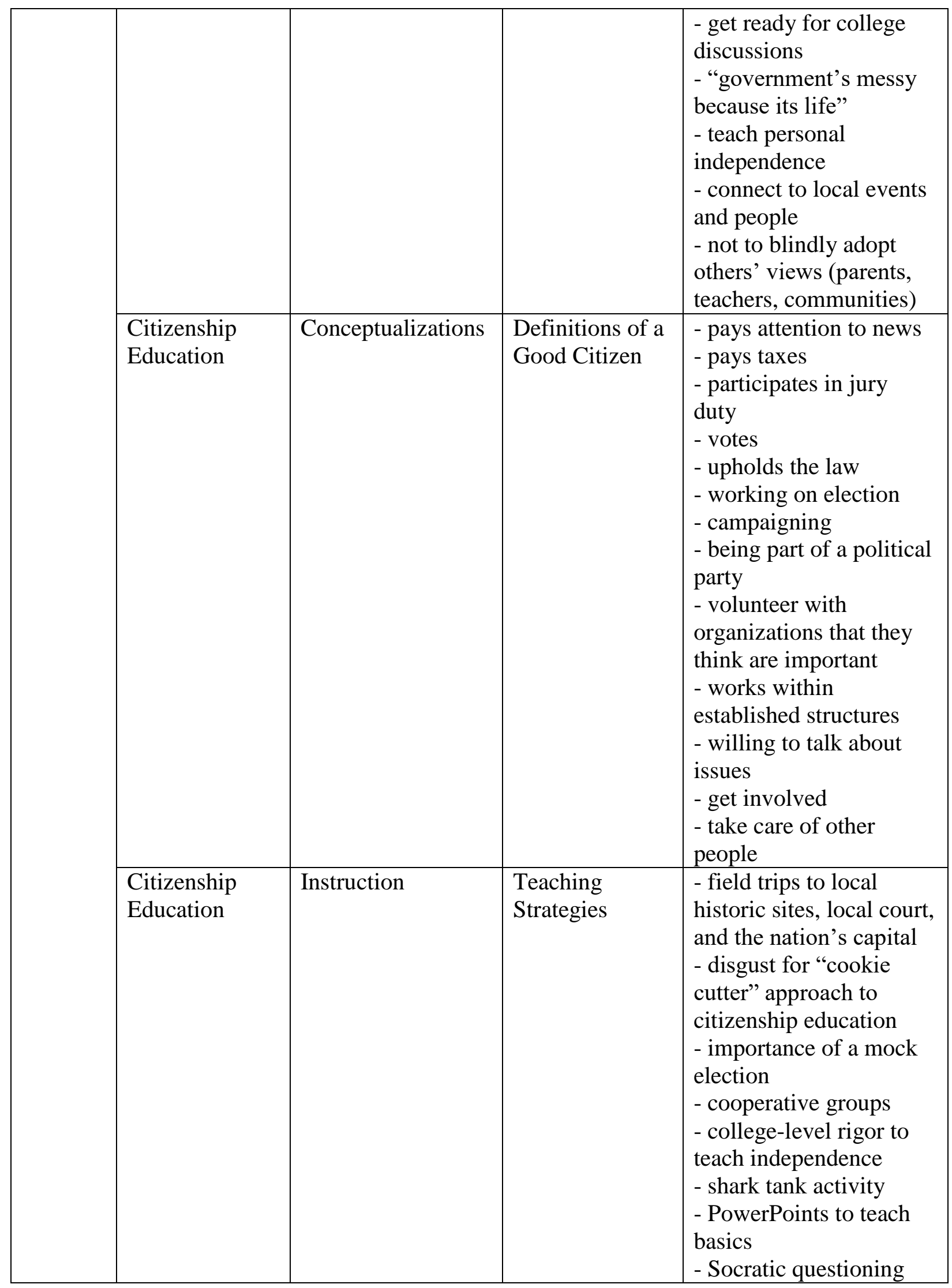




\begin{tabular}{|c|c|c|c|}
\hline & & & $\begin{array}{l}\text { - differentiate because of } \\
\text { inclusive government } \\
\text { classes } \\
\text { - student-ran political } \\
\text { campaigns } \\
\text { - assign written reports } \\
\text { to ensure basic } \\
\text { information is covered } \\
\text { - internet research } \\
\text { instead of spoon fed } \\
\text { information } \\
\text { - current event } \\
\text { presentations } \\
\text { - campaign artifacts and } \\
\text { candidate research } \\
\text { - political ideological } \\
\text { survey } \\
\text { - ethical situations } \\
\text { - working the polls } \\
\text { - citizenship tests } \\
\text { - structured academic } \\
\text { controversies }\end{array}$ \\
\hline $\begin{array}{l}\text { Citizenship } \\
\text { Education }\end{array}$ & Instruction & $\begin{array}{l}\text { Political Self- } \\
\text { disclosure }\end{array}$ & $\begin{array}{l}\text { - committed to } \\
\text { impartiality } \\
\text { - always have balanced } \\
\text { presentation of ideas } \\
\text { - AP students know } \\
\text { teacher's ideology more } \\
\text { than regular students } \\
\text { - don't try to persuade a } \\
\text { student one way or the } \\
\text { other }\end{array}$ \\
\hline $\begin{array}{l}\text { Citizenship } \\
\text { Education }\end{array}$ & Instruction & $\begin{array}{l}\text { Controversial } \\
\text { Issues }\end{array}$ & $\begin{array}{l}\text { - teachers hold positive } \\
\text { and negative attitudes } \\
\text { towards controversial } \\
\text { issues } \\
\text { - playing devil's } \\
\text { advocate to challenge } \\
\text { students } \\
\text { - "both sides are right" } \\
\text { - students bring up the } \\
\text { topics } \\
\text { - real world happenings } \\
\text { - not teachers' truth, just } \\
\text { opinions }\end{array}$ \\
\hline
\end{tabular}




\begin{tabular}{|c|c|c|c|}
\hline & & & $\begin{array}{l}\text { - community trusts } \\
\text { teachers because they } \\
\text { know them } \\
\text { - bring in older students } \\
\text { that are ideologically } \\
\text { strong } \\
\text { - students have similar } \\
\text { opinions } \\
\text { - use of Socratic method } \\
\text { - "agree to disagree" } \\
\text { mentality } \\
\text { - things get "heated" } \\
\text { - avoid politics and } \\
\text { religion socially } \\
\text { - no topic off limits } \\
\text { - avoid personal } \\
\text { sensitivities } \\
\text { - lead rational } \\
\text { discussions } \\
\text { - chart creation to teach } \\
\text { ideological differences } \\
\text { - adapted debate team } \\
\text { format } \\
\text { - try to control it so kids } \\
\text { aren't screaming at each } \\
\text { other }\end{array}$ \\
\hline $\begin{array}{l}\text { Citizenship } \\
\text { Education }\end{array}$ & Autonomy & $\begin{array}{l}\text { Influences on } \\
\text { Curriculum }\end{array}$ & $\begin{array}{l}\text { - no standardized test to } \\
\text { worry about } \\
\text { - principal checks county } \\
\text { pacing guide } \\
\text { - department plans } \\
\text { together } \\
\text { - department chair } \\
\text { influences others } \\
\text { - use AP guidelines } \\
\text { - use state standards } \\
\text { because its required } \\
\text { - course scope } \\
\text { predetermined by } \\
\text { standards } \\
\text { - very flexible because } \\
\text { no standardized test for } \\
\text { government courses } \\
\text { - no one question me } \\
\text { because I have }\end{array}$ \\
\hline
\end{tabular}




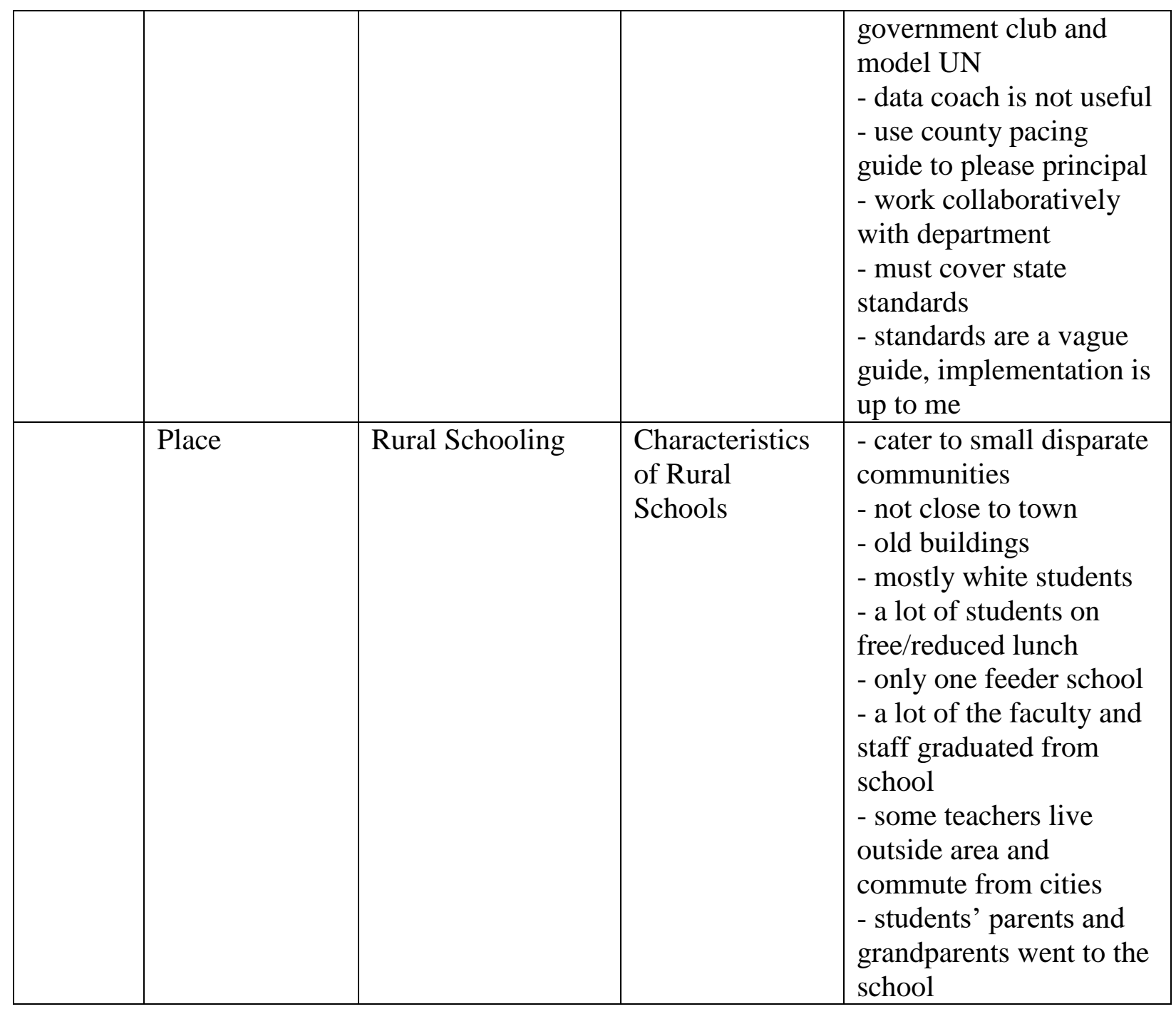




\begin{tabular}{|c|c|c|c|c|}
\hline \multirow[t]{2}{*}{ 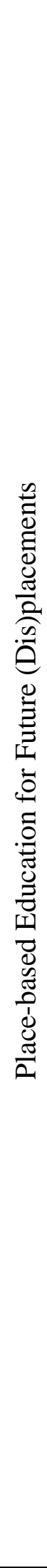 } & Place & Rural Schooling & $\begin{array}{l}\text { Characteristics } \\
\text { of Rural } \\
\text { Students }\end{array}$ & $\begin{array}{l}\text { - diverse learning } \\
\text { abilities } \\
\text { - diverse socio-economic } \\
\text { statuses } \\
\text { - mostly farmers' kids } \\
\text { - come from small } \\
\text { communities spread } \\
\text { throughout county } \\
\text { - not much ethnic } \\
\text { diversity versus a lot of } \\
\text { ethnic diversity } \\
\text { - very few English } \\
\text { Language Learners } \\
\text { - desire to move to city } \\
\text { - desire to go to small } \\
\text { colleges } \\
\text { - desire to keep in touch } \\
\text { with teachers after high } \\
\text { school for mentoring and } \\
\text { friendship } \\
\text { - know each other from } \\
\text { childhood, creating a } \\
\text { sense of community } \\
\text { - very little racial } \\
\text { tensions due to } \\
\text { familiarity } \\
\text { - no bullying (or teacher } \\
\text { are unaware) } \\
\text { - students know one } \\
\text { another and get along } \\
\text { - insulation leads to false } \\
\text { assumptions of other } \\
\text { cultures (even urban life) } \\
\text { - most will stay in area } \\
\text { after graduating } \\
\text { - share mostly } \\
\text { conservative political } \\
\text { opinions in class because } \\
\text { of their } \\
\text { families/upbringing } \\
\end{array}$ \\
\hline & Place & Rural Schooling & $\begin{array}{l}\text { Characteristics } \\
\text { of School } \\
\text { Culture }\end{array}$ & $\begin{array}{l}\text { - extremely personable } \\
\text { - friendliness between } \\
\text { races } \\
\text { - trusting } \\
\text { - a "family dynamic" is } \\
\text { present }\end{array}$ \\
\hline
\end{tabular}




\begin{tabular}{|c|c|c|c|}
\hline & & & $\begin{array}{l}\text { - one strong community } \\
\text { despite large geographic } \\
\text { area served by school } \\
\text { - acts as unifying force } \\
\text { in community } \\
\text { - diverse versus similar }\end{array}$ \\
\hline Place & Rural Schooling & $\begin{array}{l}\text { Experiences as } \\
\text { a Rural Teacher }\end{array}$ & $\begin{array}{l}\text { - long commutes to work } \\
\text { - everyone knows } \\
\text { teachers' personal life } \\
\text { - take on many roles } \\
\text { outside classroom } \\
\text { instruction } \\
\text { - avoid directly asking } \\
\text { about poverty and family } \\
\text { hardships } \\
\text { - requires teachers be } \\
\text { more professional } \\
\text { - being in social } \\
\text { organizations with } \\
\text { students' parents gives } \\
\text { an edge in discipline } \\
\text { - having parents of your } \\
\text { kids in class } \\
\text { - don't make } \\
\text { assumptions about } \\
\text { students or parents }\end{array}$ \\
\hline Place & Rural Community & $\begin{array}{l}\text { Characteristics } \\
\text { of Community }\end{array}$ & $\begin{array}{l}\text { - "not city, not urban" } \\
\text { - stagnant population } \\
\text { growth } \\
\text { - remote farming } \\
\text { community } \\
\text { - most people do not } \\
\text { leave area } \\
\text { - very tight knit } \\
\text { community though large } \\
\text { and spread out (school } \\
\text { provides common bond) } \\
\text { - changing due to influx } \\
\text { of outsiders } \\
\text { - a lot of people } \\
\text { commute to work } \\
\text { outside the area } \\
\text { - diminishing } \\
\text { community dynamic }\end{array}$ \\
\hline
\end{tabular}




\begin{tabular}{|c|c|c|c|}
\hline & & & $\begin{array}{l}\text { - blue collar workers in } \\
\text { rural jobs; white collar } \\
\text { workers commute to } \\
\text { cities } \\
\text { - recreational leagues } \\
\text { connect adults across } \\
\text { wide geographic area } \\
\text { - strong political } \\
\text { opinions on both sides } \\
\text { - mostly conservative } \\
\text { versus a mix (or voting } \\
\text { democrat) } \\
\text { - everyone is related to } \\
\text { everyone } \\
\text { - good citizens, high } \\
\text { voting rates } \\
\text { - every rural area is } \\
\text { different }\end{array}$ \\
\hline Place & Rural Community & $\begin{array}{l}\text { Perceptions of } \\
\text { Rural Culture }\end{array}$ & $\begin{array}{l}\text { - a sense of community } \\
\text { - close family ties } \\
\text { - small, insulated, and } \\
\text { "being protected" } \\
\text { - don't see and hear the } \\
\text { diversity } \\
\text { - will help out their } \\
\text { neighbors } \\
\text { - people really know } \\
\text { their neighbors here } \\
\text { - friends in all age } \\
\text { groups } \\
\text { - get to know other } \\
\text { families } \\
\text { - a "proud people" } \\
\text { - conduct life differently } \\
\text { than in city... more } \\
\text { trusting of others } \\
\text { - a great place to raise a } \\
\text { family }\end{array}$ \\
\hline Place & Rural Community & $\begin{array}{l}\text { Characteristics } \\
\text { of Local } \\
\text { Economy }\end{array}$ & $\begin{array}{l}\text { - poorer than other } \\
\text { schools in county } \\
\text { - one of the lowest paid } \\
\text { counties in state (teacher } \\
\text { salaries) } \\
\text { - people leaving area } \\
\text { because factory closure }\end{array}$ \\
\hline
\end{tabular}




\begin{tabular}{|c|c|c|c|}
\hline & & & $\begin{array}{l}\text { - cheap land and outdoor } \\
\text { recreation attracts people } \\
\text { from outside area } \\
\text { - everyone has at least } \\
\text { one family member that } \\
\text { works for the only big } \\
\text { industry in the area } \\
\text { (logging) } \\
\text { - tobacco farms } \\
\text { - farming dominates } \\
\text { - tourism and resort } \\
\text { areas are thriving } \\
\text { - Airbnb provides } \\
\text { economic option related } \\
\text { to tourism } \\
\text { - people commute to } \\
\text { cities for better jobs/pay }\end{array}$ \\
\hline Place & Rural Community & $\begin{array}{l}\text { Descriptions of } \\
\text { Physical and } \\
\text { Human } \\
\text { Geography }\end{array}$ & $\begin{array}{l}\text { - curvy, country } \\
\text { backroads } \\
\text { - not sitting in traffic } \\
\text { - mountains and valleys } \\
\text { - property that never } \\
\text { comes up for sale } \\
\text { - lots of small } \\
\text { communities strung } \\
\text { around the area } \\
\text { - long travel time for } \\
\text { students }\end{array}$ \\
\hline Place & Rural Community & $\begin{array}{l}\text { Attraction to } \\
\text { Living and/or } \\
\text { Teaching in } \\
\text { Rural Area }\end{array}$ & $\begin{array}{l}\text { - close enough to cities } \\
\text { for entertainment } \\
\text { - beautiful landscapes } \\
\text { - less traffic } \\
\text { - closeness of rural } \\
\text { community } \\
\text { - prior held familiarity } \\
\text { with school, staff, and } \\
\text { community } \\
\text { - more "elbow room" }\end{array}$ \\
\hline Place & Rural Community & $\begin{array}{l}\text { Perceptions of } \\
\text { Urban Life }\end{array}$ & $\begin{array}{l}\text { - where the jobs are } \\
\text { - black population } \\
\text { migrated from rural to } \\
\text { urban for jobs } \\
\text { - contains homelessness } \\
\text { that isn't present in rural } \\
\text { area }\end{array}$ \\
\hline
\end{tabular}




\begin{tabular}{|c|c|c|c|c|}
\hline & & & & $\begin{array}{l}\text { - street criminals, con } \\
\text { artists, and gang life } \\
\text { exist } \\
\text { - a lack of community } \\
\text { other than the people on } \\
\text { your block } \\
\text { - more things to do in } \\
\text { the city } \\
\text { - congested, people on } \\
\text { top of each other }\end{array}$ \\
\hline & Self & $\begin{array}{l}\text { Teaching } \\
\text { Experiences }\end{array}$ & $\begin{array}{l}\text { Motivations for } \\
\text { Entering } \\
\text { Profession }\end{array}$ & $\begin{array}{l}\text { - to support child } \\
\text { - wanting to teach } \\
\text { daughter to "finish what } \\
\text { you start" } \\
\text { - love of history } \\
\text { - to spread knowledge } \\
\text { - love of kids } \\
\text { - not the money } \\
\text { - always wanting to be a } \\
\text { teacher } \\
\text { - a job to keep me in the } \\
\text { area }\end{array}$ \\
\hline 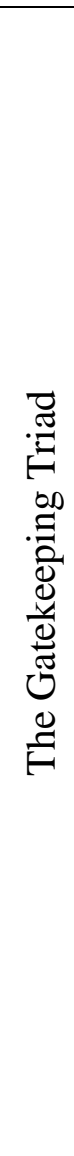 & Self & $\begin{array}{l}\text { Teaching } \\
\text { Experiences }\end{array}$ & $\begin{array}{l}\text { Unique Teacher } \\
\text { Narratives }\end{array}$ & $\begin{array}{l}\text { - being a career changer } \\
\text { - staying in same } \\
\text { position for } 25+\text { years } \\
\text { - moving from urban to } \\
\text { rural teaching } \\
\text { - multiple interviews } \\
\text { before finding current } \\
\text { position } \\
\text { - substitute teaching } \\
\text { experience and covering } \\
\text { wherever administrators } \\
\text { need } \\
\text { - non-traditional } \\
\text { licensure } \\
\text { - starting in an } \\
\text { alternative school } \\
\text { - student teaching in a } \\
\text { rural school } \\
\text { - experiencing rural } \\
\text { community orientation } \\
\text { via bus ride with } \\
\text { principal } \\
\text { - experience "cookie } \\
\text { cutter" approach to }\end{array}$ \\
\hline
\end{tabular}




\begin{tabular}{|c|c|c|c|}
\hline & & & $\begin{array}{l}\text { citizenship education } \\
\text { through professional } \\
\text { development }\end{array}$ \\
\hline Self & $\begin{array}{l}\text { Teaching } \\
\text { Experiences }\end{array}$ & $\begin{array}{l}\text { Relevancy of } \\
\text { Professional } \\
\text { Development }\end{array}$ & $\begin{array}{l}\text { - attendance at seminar } \\
\text { in DC for civic-action } \\
\text { projects } \\
\text { - rejecting projects as } \\
\text { not rurally-relevant }\end{array}$ \\
\hline Self & $\begin{array}{l}\text { Teaching } \\
\text { Experiences }\end{array}$ & $\begin{array}{l}\text { Dealing with } \\
\text { Crises }\end{array}$ & $\begin{array}{l}\text { - natural disaster } \\
\text { - student suicides } \\
\text { - homicide perpetrated } \\
\text { by former student }\end{array}$ \\
\hline Self & $\begin{array}{l}\text { Personal Life } \\
\text { Experiences }\end{array}$ & $\begin{array}{l}\text { Living in other } \\
\text { Places }\end{array}$ & $\begin{array}{l}\text { - growing up in urban } \\
\text { areas } \\
\text { - growing up in rural } \\
\text { community } \\
\text { - moving frequently in } \\
\text { childhood } \\
\text { - moving to rural area } \\
\text { - moving to be near } \\
\text { family at various stages } \\
\text { of life } \\
\text { - roaming streets as } \\
\text { youth }\end{array}$ \\
\hline Self & $\begin{array}{l}\text { Personal Life } \\
\text { Experiences }\end{array}$ & $\begin{array}{l}\text { Family Life as } \\
\text { Child }\end{array}$ & $\begin{array}{l}\text { - lessons of tolerance } \\
\text { from parents } \\
\text { - political socialization }\end{array}$ \\
\hline Self & $\begin{array}{l}\text { Personal Life } \\
\text { Experiences }\end{array}$ & $\begin{array}{l}\text { Family Life as } \\
\text { Adult }\end{array}$ & $\begin{array}{l}\text { - moving to be close to } \\
\text { parents/in-laws } \\
\text { - leaving college to get } \\
\text { married } \\
\text { - impact of having } \\
\text { children } \\
\text { - being a single dad, } \\
\text { rural community } \\
\text { knowing daughter } \\
\text { - using family } \\
\text { connections to find non- } \\
\text { teacher related work } \\
\text { - renting in rural area } \\
\text { - buying home in rural } \\
\text { area and "becoming a } \\
\text { local" } \\
\text { - losing a spouse }\end{array}$ \\
\hline
\end{tabular}




\begin{tabular}{|c|c|c|c|}
\hline Self & $\begin{array}{l}\text { Personal Life } \\
\text { Experiences }\end{array}$ & $\begin{array}{l}\text { Impact of Past } \\
\text { Jobs }\end{array}$ & $\begin{array}{l}\text { - experienced "real } \\
\text { world" of paying taxes, } \\
\text { dealing with bosses, etc. } \\
\text { - working in food and } \\
\text { beverage management } \\
\text { - time spent as bartender } \\
\text { - owning own business } \\
\text { - making financial } \\
\text { decisions }\end{array}$ \\
\hline Self & $\begin{array}{l}\text { Experiences as a } \\
\text { Student }\end{array}$ & $\begin{array}{l}\text { Experiences in } \\
\text { Early Schooling }\end{array}$ & $\begin{array}{l}\text { - graduating from small } \\
\text { rural high school that } \\
\text { acted as a "family } \\
\text { dynamic" } \\
\text { - teachers were trusted } \\
\text { friends } \\
\text { - familiarity with school } \\
\end{array}$ \\
\hline Self & $\begin{array}{l}\text { Experience as a } \\
\text { Student }\end{array}$ & $\begin{array}{l}\text { College } \\
\text { Experiences }\end{array}$ & $\begin{array}{l}\text { - closeness with } \\
\text { professors in small } \\
\text { college adjacent to rural } \\
\text { district } \\
\text { - bachelors in history } \\
\text { and political science } \\
\text { - extreme rigor of one } \\
\text { year MAT program } \\
\text { - currently pursuing } \\
\text { masters in political } \\
\text { communication } \\
\text { - masters in curriculum } \\
\text { and instruction while } \\
\text { teaching full time } \\
\text { - leaving college early } \\
\text { for family } \\
\text { responsibilities, but } \\
\text { having desire to go back } \\
\text { to become teacher }\end{array}$ \\
\hline Self & $\begin{array}{l}\text { Teacher } \\
\text { Dispositions }\end{array}$ & $\begin{array}{l}\text { Attitudes } \\
\text { towards } \\
\text { Teaching and } \\
\text { Learning }\end{array}$ & $\begin{array}{l}\text { - teachers must "morph } \\
\text { and modify" their } \\
\text { practices because the } \\
\text { world changes } \\
\text { - teaching is more than } \\
\text { feeding facts and giving } \\
\text { tests, it's about trust and } \\
\text { counseling } \\
\text { - treating teaching like a } \\
\text { business and students as } \\
\text { clients }\end{array}$ \\
\hline
\end{tabular}




\begin{tabular}{|c|c|c|c|}
\hline & & & $\begin{array}{l}\text { - being professional at } \\
\text { all times } \\
\text { - students need problem } \\
\text { solving skills for life } \\
\text { - getting to know student } \\
\text { is a perquisite to } \\
\text { learning } \\
\text { - student needs to be } \\
\text { comfortable expressing } \\
\text { opinions }\end{array}$ \\
\hline Self & $\begin{array}{l}\text { Personal } \\
\text { Disposition }\end{array}$ & $\begin{array}{l}\text { Life } \\
\text { Philosophies }\end{array}$ & $\begin{array}{l}\text { - always be receptive to } \\
\text { new ideas } \\
\text { - if life knocks you } \\
\text { down, you get back up } \\
\text { and learn from it } \\
\text { - life is adapting and } \\
\text { overcoming }\end{array}$ \\
\hline Others & $\begin{array}{l}\text { Community } \\
\text { Relationships }\end{array}$ & $\begin{array}{l}\text { Interactions } \\
\text { with } \\
\text { Community } \\
\text { Members }\end{array}$ & $\begin{array}{l}\text { - students stole } \\
\text { campaign sign from } \\
\text { man's front yard } \\
\text { - whole community } \\
\text { knows you }\end{array}$ \\
\hline Others & $\begin{array}{l}\text { Community } \\
\text { Relationships }\end{array}$ & $\begin{array}{l}\text { Interactions } \\
\text { with Parents }\end{array}$ & $\begin{array}{l}\text { - lack of parent } \\
\text { involvement due to } \\
\text { multiple jobs or child } \\
\text { care of younger siblings } \\
\text { - help students complete } \\
\text { candidate research and } \\
\text { find campaign artifact } \\
\text { - don't teach students } \\
\text { tact } \\
\text { - No parents has ever } \\
\text { complained about } \\
\text { curriculum or instruction }\end{array}$ \\
\hline Others & $\begin{array}{l}\text { Professional } \\
\text { Relationships }\end{array}$ & $\begin{array}{l}\text { Rapport with } \\
\text { Students }\end{array}$ & $\begin{array}{l}\text { - view students as "my } \\
\text { kids" } \\
\text { - keep in contact after } \\
\text { they graduate } \\
\text { - not scared to be mean, } \\
\text { but fair to students } \\
\text { - must know students' } \\
\text { lives and interests to } \\
\text { teach effectively }\end{array}$ \\
\hline Others & $\begin{array}{l}\text { Professional } \\
\text { Relationships }\end{array}$ & $\begin{array}{l}\text { Administrative } \\
\text { Support }\end{array}$ & $\begin{array}{l}\text { - principals share same } \\
\text { goals for lessons (public }\end{array}$ \\
\hline
\end{tabular}




\begin{tabular}{|c|c|c|c|}
\hline & & & $\begin{array}{l}\text { speaking) and stop in a } \\
\text { lot to observe }\end{array}$ \\
\hline Others & $\begin{array}{l}\text { Professional } \\
\text { Relationships }\end{array}$ & $\begin{array}{l}\text { Teamwork with } \\
\text { Colleagues }\end{array}$ & $\begin{array}{l}\text { - influence of young } \\
\text { teachers on department } \\
\text { - small department } \\
\text { means working closely } \\
\text { together } \\
\text { - share curriculum and } \\
\text { instructional ideas with } \\
\text { colleagues }\end{array}$ \\
\hline Authority & Standardized Texts & $\begin{array}{l}\text { Relevancy and } \\
\text { Opinions of } \\
\text { Standardized } \\
\text { Tests }\end{array}$ & $\begin{array}{l}\text { - no end-of-year test for } \\
12^{\text {th }} \text { grade government } \\
\text { - no tests contributes to } \\
\text { increased feeling of } \\
\text { teacher autonomy } \\
\text { - despise one high stakes } \\
\text { test approach to } \\
\text { citizenship knowledge } \\
\text { - tests should be } \\
\text { application of ideas, not } \\
\text { recall questions }\end{array}$ \\
\hline Authority & $\begin{array}{l}\text { National/Local } \\
\text { Political Climate }\end{array}$ & $\begin{array}{l}\text { Impact of } \\
\text { Negative } \\
\text { Political } \\
\text { Climates }\end{array}$ & $\begin{array}{l}\text { - bitterness and } \\
\text { polarization/ how to } \\
\text { change it } \\
\text { - candidates' rhetoric } \\
\text { and popular issues } \\
\text { become student talking } \\
\text { points } \\
\text { - local politician } \\
\text { scandals create negative } \\
\text { energy }\end{array}$ \\
\hline Authority & $\begin{array}{l}\text { Mandated } \\
\text { Curriculum }\end{array}$ & $\begin{array}{l}\text { Navigating } \\
\text { Standards, } \\
\text { Guides, and } \\
\text { Textbooks }\end{array}$ & $\begin{array}{l}\text { - Must be covered } \\
\text { - teachers can skip } \\
\text { around standards (no } \\
\text { sequencing) } \\
\text { - use state standards and } \\
\text { build up from there } \\
\text { - not bound to textbook }\end{array}$ \\
\hline
\end{tabular}

